UNIVERSIDADE DE BRASÍLIA

INSTITUTO DE BIOLOGIA

CURSO DE PÓS-GRADUAÇÃO EM BIOLOGIA MICROBIANA

FLAVIANE BEATRIZ MARCELINO LARA

Genótipos e filogenia de cepas de Escherichia coli uropatogênicas: detecção de padrões epidemiológicos 


\title{
Genótipos e filogenia de cepas de Escherichia coli uropatogênicas: detecção de padrões epidemiológicos
}

\begin{abstract}
Dissertação apresentada como requisito para conclusão do curso de Mestrado do Programa de Pós-graduação em Biologia Microbiana da Universidade de Brasília.
\end{abstract}

Orientador: Prof. Dr. Alex Leite Pereira

BRASÍLIA, DF 


\section{Genótipos e filogenia de cepas de Escherichia coli uropatogênicas: detecção de padrões epidemiológicos}

Orientador: Prof ${ }^{\circ}$. Dro‥ Alex Leite Pereira

(FCE/Universidade de Brasília)

Prof ${ }^{a}$. Dr ${ }^{a}$. Cynthia Maria Kyaw

(IB/Universidade de Brasília)

Prof ${ }^{a}$. Dr ${ }^{\mathrm{a}}$ Nádia Skorupa Parachin

(IB/Universidade de Brasília)

Profa . Dr ${ }^{\mathrm{a}}$ Larissa Fernandes Matos

(FCE/Universidade de Brasília)

$$
\begin{gathered}
\text { BRASÍLIA, DF } \\
2017
\end{gathered}
$$


Aos meus amados pais, Suzana e Jorge. 


\section{AGRADECIMENTOS}

Primeiramente, gostaria de agradecer a Deus, pois sem Ele nada disso seria possível. Agradeço a Deus por Ele ter me mantido firme nessa caminhada, sem desviar o olhar das minhas fraquezas e das minhas dificuldades.

Agradeço aos meus pais, Suzana e Jorge, que sempre me apoiaram nas minhas decisões e se fizeram presentes em todos os momentos da minha vida. Nem mesmo todas as palavras desse mundo serão suficientes para expressar minha gratidão. Meus pais amados, vocês me educaram com amor e carinho, se dedicaram a minha educação com paciência, compreensão, sensibilidade e respeito. Me ensinaram os mais puros sentimentos e a nunca desistir dos meus sonhos, e estiveram ao meu lado para juntos lutarmos por eles. Sem vocês, certamente eu não teria chegado até aqui. Obrigada por serem meus exemplos e por serem esses pais maravilhosos.

Agradeço aos meus irmãos, Fabrício, Fabiane e Flávia, por essa amizade que compartilhamos, pela cumplicidade. Obrigada, de coração, por estarem sempre dispostos a ajudar quando preciso, pelos conselhos, pela sinceridade, por serem exatemento como vocês são, isso basta. Devo um agradecimento especial a minha irmã Fabiane por ter me ajudado nas correções de inglês, inclusive do artigo.

Agradeço ao meu noivo, Petrônio Amorim, pela compreensão e por sempre me incentivar na minha vida profissional. Agradeço pelo nosso relacionamento cúmplice, verdadeiro e divertido e pelos momentos que esteve ao meu lado nessa caminhada. Obrigada, meu amor!

Quero agradecer também meu orientador, Alex, por sempre acreditar em mim. Agradeço por todas as lições de vida, as histórias repetidas (rsrsrs) e os ensinamentos em microbiologia, que foram muitos. Agradeço pela paciência, pela confiança, pela compreensão. Agradeço por você ser um ótimo professor/orientador e amigo. Alex, você sempre será a minha melhor referência em microbiologia.

Quero fazer também um agradecimento super especial as minhas queridíssimas meninas, Danielly, Pâmela, Mayana, Fabiana, Lorena e Stefany por toda ajuda, pelo conhecimento que compartilhamos, espero um dia retribuir tudo 
isso. Enquanto isso, espero que o amor por essa ciência floresça e que vocês possam colher bons frutos. Dani, devo um agradecimento especial a você por ser esse exemplo de fé e otimismo, obrigada por todos os conselhos.

Por fim, agradeço a todos os meus amigos que de diversas formas contribuíram para esse momento. 


\section{RESUMO}

Escherichia coli uropatogênica (UPEC) é marcada pela sua versatilidade genética, sendo capaz de causar infecções em diferentes níveis do trato urinário bem como sepse urinária. Este estudo teve por objetivo estudar cepas de $E$. coli isoladas de casos de infecção do trato urinário (ITU) e sepse urinária (SU) atendidos no Hospital Regional de Ceilândia do Distrito Federal. A presença de 15 preditores genéticos de 3 patotipos de E. coli (UPEC, EAEC e MNEC) foi testada em 401 cepas. Análises filogenéticas baseadas na determinação de filogrupos e de tipos de sequências (sequence type - ST) foram realizadas. Os preditores moleculares de UPEC foram detectados em mais de $70 \%$ das cepas. Preditores moleculares de EAEC (aatA e aggR) foram detectados em apenas 2,4\% (9/377) das cepas envolvendo dois casos de cistite e um de sepse urinária (SU). Marcadores de UPEC foram estatisticamente associados a diferentes aspectos epidemiológicos e analíticos da uropatogênese. Os marcadores fyuA (sistema sideróforo), chuA (sistema sideróforo), vat (toxina vacuolizante) e pic (mucinase) foram estatisticamente associados $(p<0,05)$ aos casos de infecção adquiridos na comunidade. Cepas positivas para $\operatorname{csg} A$ (fímbria curli), chuA (sistema sideróforo) ou ag43 (adesina de agregação) mostraram associação estatística com os casos de SU. Cepas positivas para pap (pilus associado a pielonefrite) foram associadas a piúria $(p=0,000)$ e a presença de muco nas amostras de urina $(p=0,003)$. Cepas com genótipo fyuA-pap-csgA ( $p=$ $0,020$ ) ou pap-csgA-ag43 ( $p=0,000)$ foram associadas a casos de SU e predominantes no filogrupo $D$. Análises filogenéticas mostraram que duas das três cepas híbridas EAEC/UPEC estudadas foram posicionadas em um clado característico de cepas de UPEC compartilhado por cepas de filogrupo D e ST3 (filogrupo D-ST3). A outra cepa EAEC/UPEC foi classificada como filogrupo A-ST478 e posicionada em um clado distinto juntamente com uma cepa comensal. Nossos resultados endossam a heterogeneidade genética de cepas uropatogênicas mostrando padrões moleculares especificos associados a casos de SU (cepas de filogrupo $\mathrm{D}$ e genótipo fyuA-pap-csgA ou pap-csgA-ag43), como também a participação de cepas híbridas EAEC/UPEC de linhagens extraintestinais (filogrupo D-ST3) e intestinais (filogrupo A-ST478) como uropatógenos.

Palavras-chave: UPEC, EAEC, cepas híbridas, genotipagem, fatores de virulência. 


\begin{abstract}
Uropathogenic Escherichia coli (UPEC) is marked by its genetic diversity and is responsible for infections in different levels of the urinary tract as well as urinary sepsis. This work aimed to study $E$. coli strains isolated from cases of urinary tract infections (UTI) and urosepsis that were attended in the Hospital Regional de Ceilândia in the Brazilian Federal District. Four hundred one strains were tested for the presence of 15 genetic predictors of 3 E. coli pathotypes (UPEC, EAEC and MNEC). Phylogenetic analysis based on the determination of phylogroups and sequence type (ST) were carried out. UPEC genetic predictors were detected in more than $70 \%$ of the strains. EAEC molecular predictors (aatA and aggR) were detected in only $2.4 \%(9 / 377)$ of the strains that were recovered from two cases of UTI and from one case of US. UPEC markers were statistically associated with distinct epidemiologic and analytic aspects of the uropathogenesis. The markers fyu $A$ (siderophore system), chuA (siderophore system), vat (vacuolating toxin) and pic (mucinase) were statistically associated $(\mathrm{p}<0.05)$ with community-onset infections. Strains positive for $\operatorname{csg} A$ (curli fimbria), chuA (siderophore system) or ag43 (aggregation adhesin) were associated with urosepsis cases. pap-positive strains were associated with pyuria $(p=0.000)$ and the presence of mucous in urine samples $(p=0.003)$. Strains displaying the genotype fyuA-pap-csgA $(p=0,020)$ or pap-csgA-ag43 ( $\mathrm{p}=0.000)$ were associated with urosepsis cases and were predominant in phylogroup D. Phylogenetic analysis show that two of out three studied hybrid EAEC/UPEC strains were positioned on a characteristic clade of UPEC strains that was shared by strains with phylogroup D and ST3 (phylogroup DST3). Another EAEC/UPEC strain was classified as phylogroup A-ST478 and was positioned on a different clade along with a commensal strain. Our findings endorse the genetic heterogeneity displayed by uropathogenic strains showing specific molecular pattern associated with urosepsis cases (strains displaying phylogroup D and genotype fyuA-pap-csgA or pap-csgA-ag43) as well as the participation of hybrid EAEC/UPEC strains from both extraintestinal (phygroup D-ST3) and intestinal lineages as uropathogens.
\end{abstract}

Keywords: UPEC, EAEC, hybrid strains, genotyping, virulence factors. 


\section{SUMÁRIO}

Página

LISTA DE FIGURAS 10

LISTA DE TABELAS

LISTA DE ABREVIAÇÕES E SÍMBOLOS

1. INTRODUÇÃO

2. JUSTIFICATIVA 23

3. OBJETIVO 24

3.1. OBJETIVO GERAL

3.2 OBJETIVOS ESPECÍFICO

4. MATERIAIS E MÉTODOS

4.1. COMITÊ DE ÉTICA E FINANCIAMENTO 26

4.2. COLETA DAS AMOSTRAS E DADOS 26

4.3. DEFINIÇÃO DE CASOS

4.4. MEIOS DE CULTIVO E SOLUÇÕES

4.5. IDENTIFICAÇÃO BACTERIANA 28

4.6. CARACTERIZAÇÃO MOLECULAR 28

4.7. DETERMINAÇÃO DE GRUPOS FILOGENÉTICOS $\mathbf{3 1}$

4.8. TIPAGEM POR SEQUENCIAMENTO DE MÚLTIPLOS LOCI $\mathbf{3 1}$ (MLST)

4.9. ANÁLISE FILOGENÉTICA E CONSTRUÇÃO DO 33 DENDROGRAMA

4.10. ENSAIO DE FORMAÇÃO DE BIOFILME 33

4.10.1 COLETA DE AMOSTRAS DE URINA 33

4.10.2. FORMAÇÃO DE BIOFILMES 33

4.11. ANÁLISE DE DADOS 35

4.11.1 CATEGORIZAÇÃO 35

4.11.2. ANÁLISE ESTATÍSTICA 36

5. RESULTADOS E DISCUSSÃO

5.1 EPIDEMIOLOGIA MOLECULAR DE CEPAS UROPATOGÊNICAS 37

5.1.1 CEPAS DE E. COLI ISOLADAS DE INFECÇÃO DO TRATO 37

URINÁRIO E DE SEPSE URINÁRIA

5.1.2. FREQUÊNCIA DOS FATORES DE VIRULÊNCIA EM CEPAS E. 38 
COLI ISOLADAS DE ITU E SU

5.1.3. PERFIS GENÉTICOS ASSOCIADOS A PADRÕES CLÍNICOEPIDEMIOLÓGICOS

5.1.4. PERFIS GENÉTICOS ASSOCIADOS A PADRÕES ANALÍTICOS

FLAGRADOS NO EAS

5.1.5. PERFIL DE FILOGRUPOS EM CEPAS DE UPEC 53

5.1.6. DISTRIBUIÇÃO DE FATORES DE VIRULÊNCIA EM 54 FILOGRUPOS DE E. COLI

5.1.7. GENÓTIPOS ASSOCIADOS A SEPSE URINÁRIA DE 55 FILOGRUPOS VINCULADOS

5.1.8. GENÓTIPOS DETECTADOS EM FILOGRUPOS INTESTINAIS E 58 EXTRAINTESTINAIS

5.2. CARACTERIZAÇÃO FILOGENÉTICA DE CEPAS PORTANDO 60 GENÓTIPO HÍBRIDO EAEC/UPEC

6. CONCLUSÃO 69

7. PERSPECTIVAS 70

8. REFERÊNCIAS BIBLIOGRÁFICAS 71 ANEXO 1 - ARTIGO PUBLICADO 81 


\section{LISTA DE FIGURAS}

Figura 1 - Classificação das infecções do trato urinário em virtude dos sítios anatômicos afetados

Figura 2 - Patogênese da infecção do trato urinário por E. coli uropatogênica

Figura 3 - Chave dicotômica empregada na definição dos filogrupos de E. coli como proposta por Clermont e colaboradores

Figura 4 - Processos de colonização do trato urinário em infecções comunitárias e associadas a catéter urinário

Figura 5 - Carga de virulência em cepas de E. coli isoladas de caso de infecções extraintestinais em mulheres

Figura 6 - Carga de virulência em cepas de E. coli isoladas de caso de infecções extraintestinais em homens

Figura 7 - Relação filogenética de cepas com genótipos clássicos de UPEC e com genótipos híbridos EAEC/UPEC

Figura 8 - Biofilme formado pos cepas de E. coli em DMEM e urina humana 


\section{LISTA DE TABELAS}

Tabela 1 - Descrição e evidências experimentais de genes de virulência de patotipos E. coli

Tabela 2 - Oligonucleotídeos iniciadores utilizados para detecção dos fatores de virulência

Tabela 3 - Oligonucleotídeos iniciadores utilizados para determinação do filogrupos

Tabela 4 - Alvos e oligonucleotídeos iniciadores utilizados no protocolo (MLST) para determinação do ST

Tabela 5 - Genótipos, filogrupos e número de cepas selecionados para a realização dos ensaios de biofilme

Tabela 6 - Número de casos, fontes de isolamento e quantitativo de cepas arroladas neste estudo

Tabela 7 - Frequência de distribuição de fatores de virulência em cepas de E. coli isoladas de infecção do trato urinário e sepse urinária

Tabela 8 - Perfil epidemiológico dos casos de infecção extraintestinal por Escherichia coli analisados

Tabela 9 - Nível de significância (valor de p) calculado (teste de Kruskall-Wallis) para a distribuição dos fatores de virulência em função de perfil clínicoepidemiológico dos pacientes

Tabela 10 - Análise de frequência (teste exato de Fisher) de fatores de virulência com distribuição desigual entre as categorias clínico-epidemiológicas analisadas

Tabela 11 - Nível de significância (valor de p) calculado (teste de Kruskall-Wallis) para a distribuição dos fatores de virulência em função dos parâmetros analíticos testados para as amostras de urina

Tabela 12 - Análise de frequência (teste exato de Fisher) de fatores de virulência com distribuição desigual entre os parâmetros analíticos observados no exame de urina (EAS) 
Tabela 13 - Distribuição dos filogropos em ITU e SU

Tabela 14 - Distribuição de fatores de virulência em filogrupos intestinais e extraintestinais de E. coli

Tabela 15 - Distribuição de genótipos em função da gravidade da infecção (ITU vs. SU) e dos filogrupos detectados

Tabela 16 - Perfil de genótipos detectados em 350 cepas de UPEC analisadas para filogrupo

Tabela 17 - Cepas isoladas de infecções extraintestinais albergam marcadores de EAEC

Tabela 18 - Perfil alélico, tipo de sequência (ST) e genótipo associados a cepas de UPEC 


\section{LISTA DE ABREVIAÇÕES E SÍMBOLOS}

EAEC - Escherichia coli enteroagregativa

EAHEC - Escherichia coli enteroagregativa-hemorrágica

EAS - Elementos Anormais do Sedimento urinário

EHEC - Escherichia coli enterohemorrágica

EIEC - Escherichia coli enteroinvasiva

EPEC - Escherichia coli enteropatogênica

ETEC - Escherichia coli enterotoxigênica

ExPEC - Escherichia coli patogênica extraintestinal

Frag. - Fragmento

HRC - Hospital Regional de Ceilândia

ITU - Infecção do Trato Urinário

$\mu \mathrm{L}$ - microlitro

$\mathrm{mL}$ - mililitro

MLST - Tipagem por Sequenciamento de Múltiplos Loci

MNEC - Escherichia coli associada à meningite neonatal

PCR- Reação em Cadeia da Polimerase

RCF - Força Centrífuga Relativa

Ref. - Referência

SUH- Síndrome urêmica hemolítica

TCLE - Termo de Consentimento Livre e Esclarecido

UFC/mL - Unidades Formadoras de Colônias por mililitro

UPEC - Escherichia coli uropatogênica 


\section{INTRODUÇÃO}

A infecção do trato urinário (ITU) é considerada a mais prevalente infecção bacteriana em humanos (STAPLETON, 2014), respondendo por aproximadamente 7 milhões de consultas médicas e 100.000 hospitalizações por ano nos Estados Unidos a um custo estimado de 1,6 bilhão de dólares anuais (FOXMAN, 2002). As ITUs possuem maior incidência no sexo feminino em virtude da anatomia genital feminina, que apresenta uretra mais curta e vestíbulo vaginal em proximidade com o ânus (AL-BADR; AL-SHAIKH, 2013; VALIQUETTE, 2001). Em crianças, especialmente nos primeiros anos de vida, a ITU também é muito comum, o que pode estar associado à facilidade de contaminação das vias urinárias por agentes da microbiota intestinal durante a higienização ou em virtude de malformações congênitas (BHAT; KATY; PLACE, 2011). Além disso, os idosos também representam um grupo etário com alta prevalência de ITU, devido à queda da imunidade, doenças crônicas e também hospitalizações (STAPLETON, 2014).

A ITU é habitualmente classificada como complicada e não complicada, de acordo com sua gravidade (HOOTON; STAMM, 1997). Do ponto de vista anatômico, as não complicadas comprometem estruturas da via urinária inferior, ou seja, uretra e bexiga, e são chamadas de cistites (Figura 1). Além das vias urinárias inferiores, as ITUs complicadas afetam também as vias urinárias superiores, ureteres e rins, e são usualmente chamadas de pielonefrites, como demonstra a figura 1 (LICHTENBERGER; HOOTON, 2008; VALIQUETTE, 2001). A ITU complicada é precursora da sepse urinária (SU), quadro infeccioso caracterizado por dispersão hematogênica de bactérias que pode levar ao comprometimento de múltiplos órgãos.
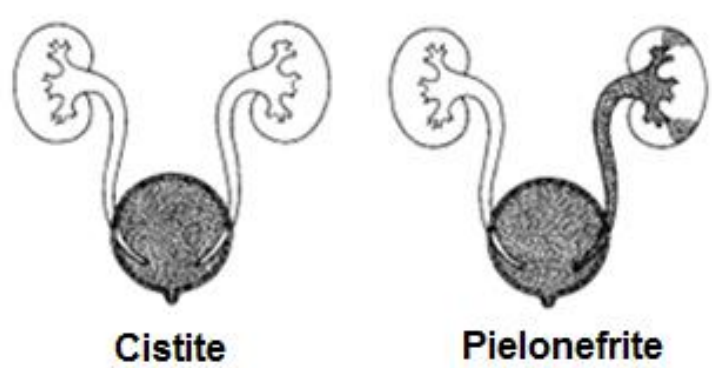

Pielonefrite

Figura 1 - Classificação das infecções do trato urinário em virtude dos sítios anatômicos afetados. Fonte: Adaptado de RUSHTON et al., 1992 
A ITU é caracterizada pela colonização microbiana do trato urinário que pode estar associada à invasão tecidual de qualquer estrutura do aparelho urinário, tendo como principais sintomas a disúria, polaciúria, urgência miccional, dor abdominal e/ou lombar (STAPLETON, 2014). As infecções geralmente são marcadas pela bacteriúria e piúria. A bacteriúria é definida como a presença de bactérias em quantidade maior ou igual a $10^{5}$ bactérias por $\mathrm{mL}$ de urina, detectadas por meio de urocultura ( $10^{5}$ unidades formadoras de colônias - UFC $/ \mathrm{mL}$ ) em amostras de jato médio de urina colhidas de forma asséptica. Segundo Kass, piúria é definida como a contagem superior a 10 leucócitos por campo de observação microscópica (com aumento de 400 vezes), através do exame de elementos anormais do sedimento urinário (EAS) (KASS, 1962). Outras alterações no EAS como a presença de nitrito podem caracterizar um quadro de infecção urinária, indicando a ação de bactérias redutoras de nitrato, geralmente enterobactérias. Em amostras de urina, a presença de muco também pode estar relacionada a irritação de mucosas das vias urinárias em virtude de quadros infecciosos.

A maioria das infecções urinárias é causada por enterobactérias - bacilos Gram negativos fermentadores de glicose e redutores de nitrato - provenientes da microbiota intestinal, que transitam constantemente para 0 trato geniturinário podendo ascender uretra e potencialmente colonizar a bexiga. $O$ agente etiológico mais comumente envolvido nos quadros de ITU é Escherichia coli que responde por aproximadamente 80 a 90\% dos casos em escala global (HEILBERG; SCHOR, 2003).

E. coli é uma das espécies bacterianas conhecidas mais versáteis e também uma das mais bem estudadas. Embora tenha como habitat primário o intestino de animais vertebrados, onde usualmente atua como organismo comensal, esta espécie é amplamente distribuída na natureza tendo como habitat secundário corpos d'água e diversos sedimentos (KAPER; NATARO; MOBLEY, 2004). Cepas comensais de $E$. coli colonizam o trato gastrointestinal dos humanos poucas horas após o nascimento permanecendo restritas ao íleo distal e ao colo (KAPER; NATARO; MOBLEY, 2004). Enquanto as cepas de E. coli restringem-se ao lúmen intestinal e à camada externa do muco intestinal, elas participam de uma relação de simbiose com seu hospedeiro (NATARO; KAPER, 1998). Assim, cepas comensais de $E$. coli raramente causam doença exceto quando a barreira gastrointestinal é 
violada. Contudo, existem linhagens genéticas de E. coli que evoluíram com a aquisição de inúmeros fatores de virulência que contribuem para a adaptação de linhagens patogênicas a diferentes sítios de colonização em humanos, permitindo que E. coli produza um amplo espectro de infecções (KAPER; NATARO; MOBLEY, 2004; NATARO; KAPER, 1998; PEREIRA et al., 2007). Desta forma, a espécie E. coli é responsável por parte considerável da morbidade e mortalidade associadas a infecções bacterianas na espécie humana. Por ano é estimado que a espécie $E$. coli responda por 150 milhões de casos de cistite e 2 milhões de óbitos devido à diarreia infantil e infecções extraintestinais (DE MUINCK, 2013).

Essa diversidade de comportamentos encontrada em E. coli é sustentada pela sua alta plasticidade genética que permite a aquisição e a perda de atributos genéticos por meio de eventos de transferência horizontal de genes, dentre eles a conjugação (KAPER; NATARO; MOBLEY, 2004). Embora, cepas patogênicas de $E$. coli sejam mantidas e profundamente estudadas em laboratório ao redor do mundo, estes isolados não representam de maneira adequada a diversidade e a plasticidade genética associadas ao genoma e virulência da espécie E. coli. Possuindo um genoma comum formado por 1.976 genes em meio a 17.838 genes conhecidos, e com uma variação de conteúdo genético que pode alcançar $30 \%$ na comparação entre dois isolados, E. coli pode ser a espécie com maior diversificação genética conhecida (TOUCHON et al., 2009).

Em relação ao potencial patogênico desta espécie, fatores de virulência podem ser transferidos para linhagens específicas de E. coli, originando clones altamente adaptados capazes de causar doenças em indivíduos saudáveis. Apenas as combinações genéticas de melhor sucesso adaptativo persistem e passam a compor as chamadas categorias patogênicas de $E$. coli, ou patotipos de $E$. coli (KAPER; NATARO; MOBLEY, 2004). Infecções por patotipos de E. coli não se limitam à mucosa intestinal, seu habitat primário, e podem atingir sítios extraintestinais. Em humanos três síndromes clínicas estão frequentemente associadas à patotipos de E. coli: doenças entéricas/diarreicas; infecções do trato urinário e sepse/meningite. Dentre os patógenos intestinais, atualmente são reconhecidos pelo menos seis patotipos: E. coli enterohemorrágica (EHEC), enteropatogênica (EPEC), enterotoxigênica (ETEC), enteroagregativa (EAEC), enteroinvasiva (EIEC) e E. coli de adesão difusa (DAEC) (KAPER; NATARO; 
MOBLEY, 2004; NATARO \& KAPER, 1998). Dentre os patotipos extraintestinais, são, claramente, reconhecidos $E$. coli uropatogênica (UPEC) e E. coli associada a meningite/sepse (MNEC) (KAPER; NATARO; MOBLEY, 2004). A classificação dos patotipos de $E$. coli está baseada na detecção molecular de arranjos específicos de genes de virulência associados à adesão bacteriana (fímbrias e adesinas patotipoespecíficas); a toxinas e hemolisinas; a sistemas de secreção, e a sistemas de aquisição de ferro (sideróforos) (KAPER; NATARO; MOBLEY, 2004; NATARO \& KAPER, 1998) (Tabela 1).

Fatores de virulência de $E$. coli podem ser codificados por genes cromossomais que são, muitas vezes, parte de regiões cromossômicas grandes e instáveis conhecidas como ilhas de patogenicidade (HACKER et al., 1997; OELSCHLAEGER et al., 2002). Alguns genes de virulência estão também localizados em elementos genéticos móveis como plasmídeos e transposons (BEKAL et al., 2003). A tabela 1 lista alguns fatores de virulência associados a categorias patogênicas de $E$. coli relacionando-os a evidências experimentais e ao papel na patogênese das infecções. Cepas de E. coli uropatogênicas (UPEC) possuem fatores de virulência que permitem a colonização e invasão do trato urinário e da corrente sanguínea, permitindo o desenvolvimento de infecções fora do trato gastrointestinal.

Em relação aos patotipos extraintestinais de E. coli, os genes fyuA, yfcV e chuA são descritos como preditores positivos do potencial uropatogênico em cepas de $E$. coli, ao passo que os genes sfa e cnf são marcadores de virulência associados a infecção do sistema nervoso central (SPURBECK et al., 2012). 
Tabela 1 - Descrição e evidências experimentais de genes de virulência de patotipos E. coli

\begin{tabular}{|c|c|c|}
\hline Categoria Patogênica & Gene de virulência & Descrição \\
\hline \multirow{4}{*}{ E. coli (Vários patotipos) } & $\operatorname{csgA}$ & Fímbrias finas agregativas (curli) \\
\hline & \multicolumn{2}{|c|}{$\begin{array}{l}\text { Evidências experimentais: 1- envolvidas com adesão a células da mucosa e formação de } \\
\text { biofilmes. 2- papel importante adesão de matriz extracelular e colonização da região perianal } \\
\text { (EMODY et al., 2003; WESTERLUND; KORHONEN, 1993). }\end{array}$} \\
\hline & ag43 & Adesina para auto-agregaçãobacteriana \\
\hline & \multicolumn{2}{|c|}{$\begin{array}{l}\text { Evidência experimental: } 1 \text { - em modelo de infecção animal (rato) revelou papel em persistência } \\
\text { de longo prazo no trato urinário (LÜTHJE; BRAUNER, 2010a). }\end{array}$} \\
\hline \multirow{8}{*}{ E. coli diarreiogênica (EAEC) } & $\begin{array}{l}\text { aat } A \text { (anteriormente } \\
\text { conhecido como } p C V D \text { ) }\end{array}$ & $\begin{array}{l}\text { Sistema de transporte classicamente usado como } \\
\text { marcador para detecção do plasmídeo de virulência } p A A\end{array}$ \\
\hline & aggR & Ativador transcricional de genes de virulência \\
\hline & pils & Pilina \\
\hline & \multicolumn{2}{|c|}{$\begin{array}{l}\text { Evidências experimentais: } 1 \text { - envolvidas no processo de adesão agregativa (DUDLEY et al., } \\
\text { 2006). }\end{array}$} \\
\hline & pic & Proteína envolvida na colonização (mucinase) \\
\hline & \multicolumn{2}{|c|}{$\begin{array}{l}\text { Evidências experimentais: 1- atividade mucolítica através da serina protease. 2- estimula a } \\
\text { hipersecreção de muco (NAVARRO-GARCIA et al., 2010). }\end{array}$} \\
\hline & pet & Citotoxina \\
\hline & \multicolumn{2}{|c|}{$\begin{array}{l}\text { Evidências experimentais: } 1 \text { - exerce atividade citotóxica, podendo levar a alterações do } \\
\text { citoesqueleto de células epiteliais (HENDERSON et al., 1999). }\end{array}$} \\
\hline \multirow{4}{*}{$\begin{array}{l}\text { E. coli associada a menigite } \\
\text { neonatal (MNEC) }\end{array}$} & sfa & Fímbria S \\
\hline & \multicolumn{2}{|c|}{$\begin{array}{l}\text { Evidência experimental: em modelo animal (rato) promove a adesão ao endotélio vascular, } \\
\text { células epiteliais do plexo coróide e ventrículos cerebrais (PARKKINEN et al., 1988) }\end{array}$} \\
\hline & cnf & Fator necrosante citotóxico \\
\hline & \multicolumn{2}{|c|}{$\begin{array}{l}\text { Evidência experimental: cepas mutantes demonstraram a participação de CNF na invasão da } \\
\text { barreira hemato-encefálica de ratos (BADGER et al., 2000). }\end{array}$} \\
\hline \multirow{12}{*}{ E. coli uropatogênica (UPEC) } & fyuA & Receptor de sideróforo (yersiniabactina) \\
\hline & \multicolumn{2}{|c|}{$\begin{array}{l}\text { Preditor estatístico de UPEC. Evidência experimental: facilita a colonização da bexiga em } \\
\text { modelo animal e é expresso durante o crescimento em urina humana (SPURBECK et al., } \\
\text { 2012). }\end{array}$} \\
\hline & $y f c V$ & Gene do operon codificador da fímbria YFC \\
\hline & \multicolumn{2}{|c|}{$\begin{array}{l}\text { Preditor estatístico de UPEC. Evidências experimentais: } 1 \text {-facilita a colonização da bexiga em } \\
\text { modelo animal e é expresso durante o crescimento em urina humana. 2- aumenta a adesão } \\
\text { bacteriana a células de bexiga humana (T24) (KOREA et al., 2010; SPURBECK et al., 2012). }\end{array}$} \\
\hline & chuA & Proteína ligadora de grupo heme \\
\hline & \multicolumn{2}{|c|}{$\begin{array}{l}\text { Preditor estatístico de UPEC. Evidência experimental: facilita a colonização da bexiga em } \\
\text { modelo animal e é expresso durante o crescimento em urina humana (SPURBECK et al., } \\
\text { 2012). }\end{array}$} \\
\hline & vat & Toxina vacuolizante \\
\hline & \multicolumn{2}{|c|}{$\begin{array}{l}\text { Evidência experimental: facilita a colonização da bexiga em modelo animal e é expresso } \\
\text { durante o crescimento em urina humana (SPURBECK et al., 2012). }\end{array}$} \\
\hline & focA & Fímbria F1C \\
\hline & \multicolumn{2}{|c|}{$\begin{array}{l}\text { Evidências experimentais: 1- exerce importante papel na formação de biofilme em cepas } \\
\text { comensais. 2- aumenta a adesão bacteriana a células da bexiga e células tubulares renais } \\
\text { (LASARO et al., 2009a; MARRE; KREFT; HACKER, 1990; OTT et al., 1988) }\end{array}$} \\
\hline & pap & Fímbria P \\
\hline & \multicolumn{2}{|c|}{$\begin{array}{l}\text { Evidências experimentais: 1- em modelo de infecção animal (rato) está associado à alta piúria } \\
\text { e é o principal determinante de colonização e invasão da bexiga e do trato urinário superior. 2- } \\
\text { epidemiologicamente associado à pielonefrite (JOHNSON, 1991). }\end{array}$} \\
\hline
\end{tabular}

No tocante a patogênese das infecções urinárias, é possível dizer que, ao alcançarem o trato urinário as cepas de UPEC enfrentam diversos mecanismos de defesa que incluem o fluxo da urina, numerosas moléculas antibacterianas e o influxo de células imunes. Para superar ou evitar essas defesas e persistir colonizando as vias urinárias, cepas de UPEC desenvolveram uma série de mecanismos para aderir e invadir as mucosas do trato urinário estimulando resposta 
inflamatória deletéria ao hospedeiro (GUAY, 2008). A bem-sucedida utilização destes mecanismos de virulência por cepas de UPEC é refletida, em parte, pela prevalência e recorrência de ITUs associadas a $E$. coli, o que posiciona este agente etiológico como a principal causa de ITU. A figura 2 demonstra a atuação de vários fatores de virulência em diferentes estágios da infecção urinária. $\mathrm{Na}$ figura 2, é possível observar a relação direta entre a presença desses fatores e a gravidade do quadro infeccioso ao ilustrar a ascensão da $E$. coli pelas vias urinárias por meio da expressão coordenada de diferentes fatores de virulência. A ascensão de cepas de UPEC pelas vias urinárias facilita a translocação de bactérias para corrente sanguínea e a possibilidade de quadros de sepse urinária (sepse desenvolvida como quadro secundário à disseminação hematogênica de bactérias provenientes de infecção urinária) (Figura 2).

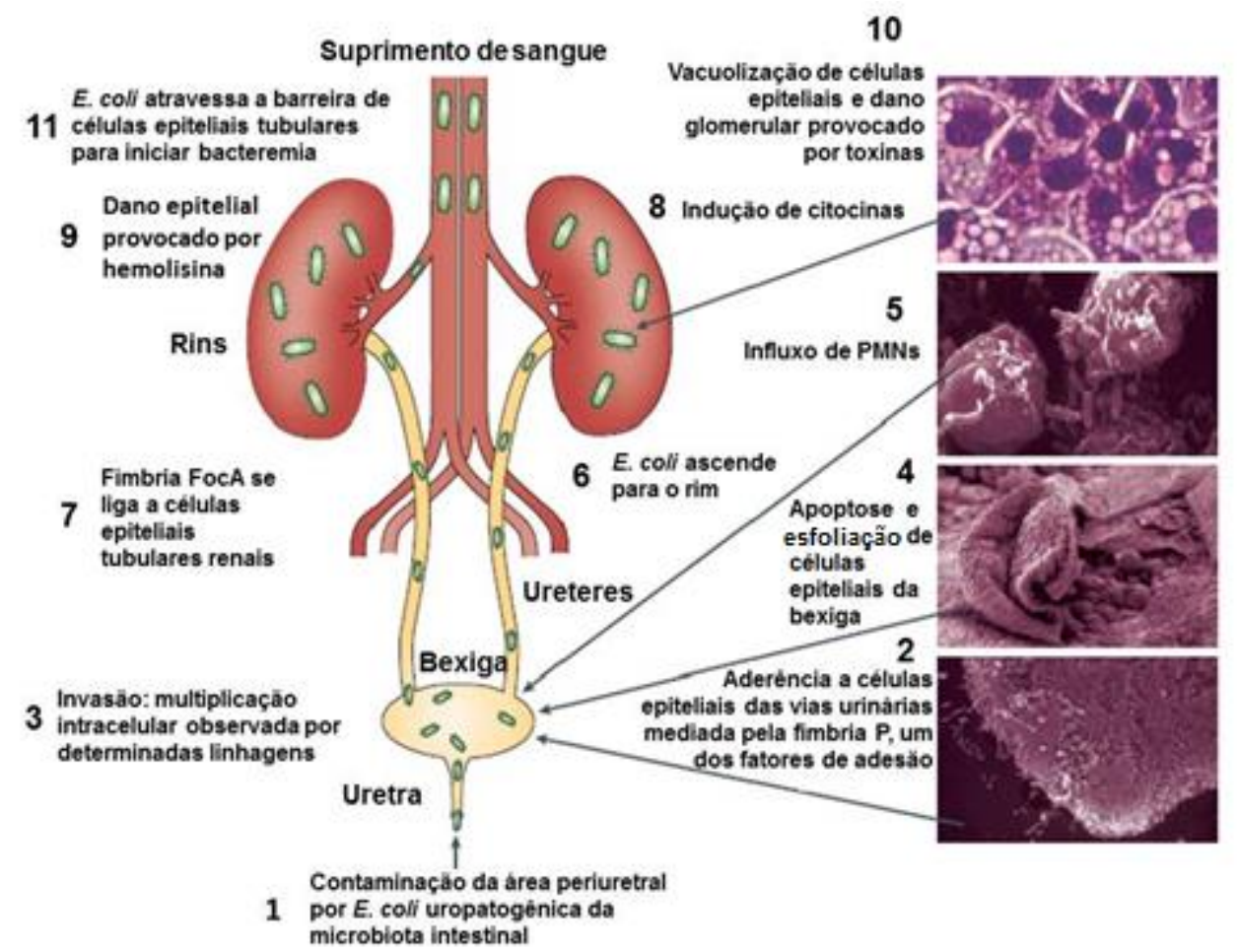

Figura 2 - Patogênese da infecção do trato urinário por $E$. coli uropatogênica Legendas: PMNs - Polimorfonucleares. Fonte: Adaptado de KAPER et al., 2004

Entre os fatores de virulência associados à UPEC, a expressão de fatores de adesão, mesmo em meio à expressão de toxinas ou quaisquer outros fatores de virulência, é o mais importante determinante da patogenicidade, visto que a adesão de UPEC a células do trato urinário evita a depuração provocada pelo fluxo de urina. 
Fatores de adesão podem também contribuir para a virulência de várias outras formas, como por exemplo, desencadeando ativação de vias de sinalização das células do hospedeiro, podendo proporcionar o aumento da adesão bacteriana e a invasão das células hospedeiras (GUAY, 2008).

Enquanto algumas linhagens genéticas de E. coli tendem a manter um arranjo genético constante ao longo da evolução (ex.: EHEC 0157, EPEC 0111), outras são marcadas pela heterogeneidade genética, principalmente associada aos genes de virulência (BIELASZEWSKA et al., 2014; MANSAN-ALMEIDA; PEREIRA; GIUGLIANO, 2013; PEREIRA et al., 2007). Esta versatilidade genética apresentada por alguns clones de $E$. coli tem proporcionado a emergência de novas categorias patogênicas de E. coli, geralmente marcadas pela combinação de fatores de virulência de patotipos diferentes, fato que passou a ser chamado de heteropatogenicidade (BIELASZEWSKA et al., 2014; TOVAL et al., 2014). Em 2011, a Europa registrou um grande surto envolvendo casos de diarreia associados à síndrome urêmica hemolítica (SUH) que foi provocado pela emergência de um patotipo incomum de E. coli. Esta cepa foi caracterizada como um híbrido de duas categorias de E. coli (EAEC e EHEC) e foi denominada de E. coli enteroagregativahemorrágica (EAHEC) (BRZUSZKIEWICZ et al., 2011).

A patogenia de EAEC é baseada na habilidade do organismo de aderir às células intestinais, alta capacidade de formar biofilme, produção de enterotoxinas e citotoxinas capazes de induzir um processo inflamatório. Os genes que medeiam o processo de colonização e formação de biofilmes em EAEC estão contidos em um grande plasmídeo de virulência (plasmídeo pAA) (KAPER; NATARO; MOBLEY, 2004). Neste plasmídeo, o gene para o regulador AggR controla uma série de outros genes de virulência, como o gene para dispersina (aapA) e para seu respectivo sistema de transporte (gene aatA) (MORIN et al., 2013). O gene o aapA não está presente em todas as cepas de EAEC e a sua presença tem sido recentemente descrita em cepas de E. coli não diarreiogênicas (MONTEIRO et al., 2009). Adicionalmente, o plasmídeo $p A A$ pode conter outros genes de virulência específicos de EAEC, incluindo fímbrias de adesão agregativa (aggA, aafA, agg-3A, $h d a A$, agg-5A), e o gene para a toxina codificada por plasmídeo Pet (pet). Cepas protótipos de EAEC, como a 042 e a 17-2, exibem o plasmídeo $p A A$ com o conjunto completo de genes de virulência de EAEC. No entanto, estudos epidemiológicos 
demonstraram que as cepas de tipo selvagem mantêm plasmídeos $p A A$ com carga de virulência muito diferente dos plasmídeos arquetípicos da EAEC. Como exemplo, cepas EAEC coletadas em abordagens epidemiológicas podem apresentar uma baixa frequência para a deteç̧ão dos genes fimbriais (aggA, aafA e agg-3A) (PEREIRA et al., 2007). Dada a plasticidade genética deste patotipo de $E$. coli, foi proposto um conjunto mínimo de genes preditores para definir cepas típicas de EAEC (a ocorrência de aatA junto com aggR) (KAPER; NATARO; MOBLEY, 2004).

Neste cenário de heterogeneidade genética, análises filogenéticas têm se mostrado uma importante ferramenta para reconhecimento da origem e distribuição de linhagens de $E$. coli associadas a infecções humanas. Apesar do alto fluxo genômico, estudos de genética populacional reconhecem 4 principais filogrupos ( $A$, B1, B2 e D) em E. coli. Esses filogrupos assumem diferentes nichos ecológicos e variam em relação ao repertório de genes de virulência e à propensão de causar doenças. É frequentemente aceito que nos filogrupos A e B1 predominam cepas intestinais que densamente colonizam intestino de humanos saudáveis. Em oposição, é geralmente aceito que os filogrupos B2 e D representam linhagens de cepas virulentas associadas a infecções de sítios extraintestinais e que compõem a menor proporção da microbiota intestinal humana (CLERMONT; BONACORSI; BINGEN, 2000). Apesar dessa generalização ser amplamente aceita, estudos populacionais mais recentes têm demonstrado que a prevalência dos filogrupos de E. coli em microbiota intestinal pode variar em função do grupo populacional estudado. Cepas comensais isoladas de amostras de fezes humanas em países da América Latina, África e Ásia pertencem principalmente ao filogrupo A (55\%), B1 (21\%) enquanto cepas do filogrupo B2 e D ocorrem com menor frequência (10 e $14 \%$ respectivamente). Contudo, cepas intestinais comensais isoladas nos Estados Unidos, Europa, Japão e Austrália possuem uma distribuição diferente de filogrupos, com $43 \%$ para B2, $24 \%$ para A, $21 \%$ para D e $12 \%$ para B1 (TENAILLON et al., 2010). Além disso, estudos de filogenética baseados em análises do genoma de $E$. coli tem demonstrado algumas características importantes sobre a evolução dos filogrupos. Em contraposição, o filogrupo B2 é o mais ancestral dos filogrupos e teve origem monofilética. $O$ filogrupo $D$ constitui dois ramos filogenéticos, um surgido primordialmente como sub-grupo de B2 e um outro ramo que emergiu posteriormente (TOUCHON et al., 2009). 
Complementarmente, a determinação de linhagens genéticas em $E$. coli pode ser realizada definindo-se o perfil alélico de um conjunto de genes essenciais (housekeeping genes) para cada cepa analisada. A tipagem por sequenciamento de múltiplos loci (MLST do inglês multiple locus sequence typing) é uma técnica molecular padronizada que é utilizada para determinar a relação genética entre cepas e para identificar linhagens com alto potencial patogênico. Este método tem sido amplamente empregado na classificação de cepas de UPEC. Além do mais, o estabelecimento de bancos de dados digitais de MLST (www.pasteur.fr/mlst) tem facilitado o reconhecimento de clones de dispersão mundial. Estudos de epidemiologia molecular sobre UPEC têm mostrado que a maioria das cepas dotadas de atributos singulares, como alta virulência, pertence a um limitado número de linhagens genéticas (ST14, ST69, ST73, ST95 e ST131).

Estudos conduzidos na região sudeste do Brasil têm demonstrado a existência de uma variabilidade de STs associados à infecção urinária incluindo a descoberta de novas linhagens clonais (ST697, ST706, ST827, ST828 e ST1393) (ADAMS-SAPPER et al., 2013; DIAS; MOREIRA; RILEY, 2010). Embora resultados como estes exponham a variabilidade genética das cepas de $E$. coli isoladas de infecção no Brasil, poucos são os estudos que utilizam desta abordagem em avaliações epidemiológicas no país. Adicionalmente, não se tem conhecimento sobre as linhagens genéticas de cepas de UPEC que circulam em hospitais do Distrito Federal.

Nesse contexto, foi proposto um estudo de epidemiologia molecular de E. coli associada às infecções extraintestinais (ITU e SU) no âmbito do Hospital Regional da Ceilândia (HRC), unidade de saúde hospitalar integrante da Secretaria de Saúde do Distrito Federal. A caracterização dos perfis genéticos (genótipos) e filogrupos de cepas E. coli associadas a ITU e a SU é importante para o entendimento da patogenia. $O$ conhecimento dos genótipos predominantes nas cepas de $E$. coli revelará o potencial patogênico dos isolados circulantes. 


\section{JUSTIFICATIVA}

Ao estabelecer perfis de virulência frequentemente associados a quadros de infecção do trato urinário e sepse urinária, estudos de epidemiologia molecular contribuem para o esclarecimento da patogenia de cepas uropatogênicas. Além disso, a determinação de perfis genéticos de cepas endêmicas permite esclarecer quais os patotipos estão frequentemente associados a uma determinada condição clínica, facilitando prognósticos e o manejo de quadros infecciosos em âmbito local. Por fim, no Brasil são escassos trabalhos de caracterização genética sobre cepas de E. coli uropatogênicas. 


\section{OBJETIVOS}

\subsection{OBJETIVO GERAL}

Realizar a caracterização molecular e filogenética de isolados de $E$. coli recuperados de infecções do trato urinário e sepses urinárias atendidas no Hospital Regional de Ceilândia (HRC).

\subsection{OBJETIVOS ESPECÍFICOS}

- Estabelecer coleção de cepas de E. coli isoladas de infecção do trato urinária (ITU) e de sepse urinária (SU);

- Determinar a positividade dos fatores de virulência testados em cepas isoladas de ITU e SU;

- Detectar marcadores de EAEC em cepas uropatogênicas;

- Identificar associações estatísticas entre fatores de virulência e aspectos clínicoepidemiológicos das ITUs e SUs;

- Identificar a relação entre na carga de virulência em cepas de $E$. coli em função do gênero e faixa etária dos pacientes;

- Identificar a correlação entre fatores de virulência e a alterações analíticas detectadas no exame de sedimentos anormais de urina (EAS);

- Identificar perfis de virulência e epidemiológicos associados a filogrupos de E. coli;

- Definir o posicionamento filogenético de cepas híbridas (EAEC/UPEC);

- Identificar linhagens genéticas e grupos clonais de cepas híbridas de E. coli. 


\section{MATERIAIS E MÉTODOS}

\subsection{COMITÊ DE ÉTICA E FINANCIAMENTO}

Este projeto de pesquisa foi avaliado e aprovado pelo Comitê de Ética em pesquisa FEPECS/SES-DF (número do parecer: 801.964) sob o título "Caracterização de cepas patogênicas de E. coli isoladas no Hospital Regional de Ceilândia" e número de registro CAAE 34392214.0.0000.5553. O trabalho contou com o apoio financeiro da Fundação de Apoio à Pesquisa do Distrito Federal (FAP/DF) por meio das linhas de fomento: 193.000.019/2012 e 193.001.042/2015.

\subsection{COLETA DAS AMOSTRAS E DADOS}

A coleta das amostras foi realizada no Hospital Regional de Ceilândia (HRC) no Distrito Federal, no período de fevereiro de 2014 a fevereiro de 2015. Foram colecionadas para análise 401 cepas de E. coli isoladas de amostras de urina e sangue pacientes admitidos no pronto-socorro ou internados, de ambos os sexos, com idades entre 0 a 95 anos. As culturas foram solicitadas e realizadas no Laboratório de Microbiologia do HRC para fins de diagnóstico por solicitação médica. Além disso, foram coletados dados acerca dos casos de infecção do trato urinário, tais como presença de elementos anormais na amostra de urina (leucócitos e muco).

Os isolados de $E$. coli recuperados no HRC foram preservados em meio de cultura (ágar nutriente) e encaminhados aos laboratórios da Faculdade de Ceilândia (FCE/UnB), onde foram realizados estudos de caracterização molecular e fenotípica.

\subsection{DEFINIÇÃO DE CASOS}

A definição dos casos de infecção do trato urinário e sepse urinária seguiu critérios clínicos e laboratoriais estabelecidos pela Agência Nacional de Vigilância Sanitária (2009):

a) Infecção do trato urinário - paciente com sinais ou sintomas e cultura de urina positiva com contagem superior a $10^{5}$ unidades formadoras de colônias por mililitro de urina $(\mathrm{mL})$; ou paciente com sinais ou sintomas e alterações típicas de ITU no EAS ou diagnóstico de ITU pelo médico. 
b) Sepse urinária - paciente com uma ou mais hemoculturas positivas coletadas preferencialmente de sangue periférico com isolamento concomitante do mesmo patógeno em urocultura ou paciente com sinais ou sintomas de sepse e uma ou mais hemoculturas positivas com definição clínica de foco urinário (sem nenhuma infecção aparente em outro sítio).

As infecções também foram classificadas como comunitárias e hospitalares:

a) Infecções comunitárias - infecções constatas na admissão do paciente (pronto-socorro) sem qualquer relação com o ambiente hospitalar.

b) Infecções hospitalares - qualquer tipo de infecção adquirida após 72 horas de internação ou 30 dias após a alta do paciente, quando essa infecção estiver diretamente relacionada com a internação ou procedimento hospitalar.

\subsection{MEIOS DE CULTURA E SOLUÇÕES}

\subsubsection{CALDO LB (LURIA BROTH)}

Peptona $10 \mathrm{~g}$

$\mathrm{NaCl}$ $10 \mathrm{~g}$

Extrato de levedura $5 \mathrm{~g}$

Água destilada q.s.p $1000 \mathrm{~mL}$

$\mathrm{O} \mathrm{pH}$ foi ajustado para 7,4 e o meio autoclavado a $120^{\circ} \mathrm{C}\left(1 \mathrm{kgf} / \mathrm{cm}^{2}\right)$ por 15 minutos.

\subsubsection{MEIO DMEM (DULBECCO'S MODIFIED EAGLE MEDIUM)}

Para os ensaios de formação de biofilme foi utilizado o meio DMEM com glicose $(4,5 \mathrm{~g} / \mathrm{L})$ (Gibco BRL). Após o preparo, o meio foi esterilizado utilizando filtros de $0,22 \mu \mathrm{m}$ (Sterivex ${ }^{\mathrm{TM}}-\mathrm{GP}$ ) e acondicionado a $4^{\circ} \mathrm{C}$.

\subsubsection{SOLUÇÃO AQUOSA DE CRISTA VIOLETA (CV)}

Cristal violeta em concentração de $0,1 \%$ foi mantido em solução aquosa armazenado em frasco de cor âmbar a temperatura ambiente. No momento do uso, a solução de cristal violeta foi filtrada utilizando membrana filtrante (Millipore - 0,22 $\mu \mathrm{m})$. 


\subsubsection{TAMPÃO ACETATO 40X (TAE)}

Trizma base $\left(\mathrm{CO}_{4} \mathrm{H}_{11} \mathrm{NO}_{3}\right)$ $193,8 \mathrm{~g}$

Acetado de Sódio (tri-hidratado) $108,9 \mathrm{~g}$

EDTA (Merck, titriplex)

Água destilada q.s.p

Ajustar $\circ \mathrm{pH}$ da solução para 8,2 e armazenar a temperatura ambiente. Concentração de uso $1 \mathrm{X}$.

\subsubsection{TAMPÃO PARA AMOSTRA DE DNA (10X)}

Sacarose $65 \%(\mathrm{~m} / \mathrm{v})$

Tris- $\mathrm{HCl}(\mathrm{pH} 8.0)$ $10 \mathrm{mM}$ EDTA $10 \mathrm{mM}$

Azul de Bromofenol

\subsubsection{SOLUÇÃO DE BROMETO DE ETÍDIO PARA DETECÇÃO DE} FRAGMENTO DE DNA

Solução aquosa de brometo de etídio com concentração de $10 \mathrm{mg} / \mathrm{ml}$ foi utilizada como solução estoque e mantida a $5^{\circ} \mathrm{C}$ em franco de cor âmbar. Para coloração de fragmentos de DNA separados em gel de agarose a solução de uso foi preparada adicionando $25 \mu \mathrm{L}$ da solução estoque em $500 \mathrm{~mL}$ de água destilada.

\subsection{IDENTIFICAÇÃO BACTERIANA}

A identificação seguiu o protocolo especificado na bulo do equipamento automatizado MicroScan WalkAway®.

\subsection{CARACTERIZAÇÃO MOLECULAR}

As culturas mantidas em ágar nutriente foram recuperadas em caldo LB, incubando-se a $37^{\circ} \mathrm{C}$ por 24 horas. Após cultivo em meio sólido seletivo e diferencial (ágar MacConkey), 3 colônias de $E$. coli foram reisoladas e encaminhadas para a caracterização genética. Para extração do DNA, foi centrifugado (3.000 RCF/3 min) $1 \mathrm{~mL}$ de cultura bacteriana e o precipitado celular ressuspenso em $500 \mu \mathrm{L}$ de água desionizada. A suspensão foi colocada em banho-maria a $100 \stackrel{\circ}{\circ}$ por 15 minutos e centrifugada (10.000 RCF/3 min). O sobrenadante foi utilizado como fonte de DNA 
total para as reações de amplificação. A solução de amplificação era composta por água desionizada, tampão de PCR (100 mM Tris- $\mathrm{HCl}$, pH 8,3 a $25{ }^{\circ} \mathrm{C} ; \mathrm{KCl} 500$ $\mathrm{mM} ; 0,01 \%$ de gelatina), desoxinucleotídeos trifosfatos $25 \mathrm{mM}$, pares de oligonucleotídeos iniciadores (primers) para os alvos de interesse (Tabela 2) e enzima Taq DNA polimerase 0,5 U, em um volume final de $30 \mu \mathrm{L}$. Os fragmentos amplificados foram separados por eletrofose em gel de agarose (1\% tampão acetato pH 8,2) e visualizados por transiluminação de luz UV após coloração com brometo de etídio $(1 \mu \mathrm{g} / \mathrm{mL})$.

Os oligonucleotídeos iniadores (primers) descritos na tabela 2 foram usados para detecção de fatores de virulência (toxinas e adesinas) albergados por diferentes patotipos de $E$. coli. As cepas protótipo 042 (positiva para aat $A$, aggR, aapA, aafA, ast $A$, pet e pic) e 17-2 (positiva para aat $A$, aggR, aapA, agg $A$ e ast $A$ ) foram usadas como controles positivos para a detecção dos marcadores de EAEC. As cepas referenciadas no Intituto Pasteur FVL2 (positiva para fyuA, yfcV, chuA, vat, sfa, pap, cnf) e FV34 (positiva para fyuA, yfcV, chuA, vat, pap, sfa) foram usadas como controles positivos para os marcadores de UPEC. Como controle negativo, foi utilizada a cepa $E$. coli HS. Os oligonucleotídeos iniciadores desiginados como este estudo (Tabela 2) foram construídos baseados nas seguintes sequências do GenBank: FN554767.1 da EAEC 042 (aapA); EU637023.1 da E. coli C1010-00 (hdaB-A); KP202151.1 do plasmídeo pAA da E. coli (agg-5A); HG941718.1 da E. coli EC958 (fyuA); CP000243.1 da E. coli UTI89 (yfch); AF280396.1 da E. coli receptor heme ChuA (chuA); KR094957.1 da E. coli PAB72 (vat); AF298200.1 da E. coli AD110 (focA); AF483829.1 da E. coli 5383-2 (cnf); L04979.1 da E. coli gene curli (csgA); e AF233272.1 da E. coligene precursor de antígeno 43 (ag43).

Todas as cepas foram testadas para a presença de 8 marcadores de virulência de UPEC (fyuA, yfcV, chuA, vat, focA, pap, sfa, cnf), fímbria curli (cgsA), antígeno 43 (ag43), pili tipo IV codificado por plasmídeo (pilS), a mucinase de EAEC (pic) e a toxina (pet). Para a detecção de cepas de EAEC, 3 preditores foram testados: aatA (também conhecido como pCVD432), aggR (regulador de virulência de EAEC) e aapA (dispersina) (Tabela 2). A presença de 5 alelos de adesão agregativa e as fímbrias (AAF-I a AAF-V) foram testadas para as cepas positivas para aatA e aggR. 
Tabela 2 - Oligonucleotídeos iniciadores utilizados para detecção dos fatores de virulência

\begin{tabular}{|c|c|c|c|c|c|}
\hline Genes & Descrição & $\begin{array}{l}\text { Oligonucleotídeos iniadores } \\
\left(5^{\prime}-3^{\prime}\right)\end{array}$ & $\begin{array}{c}\text { Fragmento } \\
\text { esperado } \\
\text { (bp) }\end{array}$ & $\begin{array}{c}\text { Temp. de } \\
\text { anelamento } \\
\left({ }^{\circ} \mathrm{C}\right)\end{array}$ & Ref. \\
\hline \multicolumn{6}{|c|}{ Marcadores de E. coli enteroagregativa (EAEC) } \\
\hline \multirow{2}{*}{$\begin{array}{l}\text { aatAou } \\
\text { pCVD }\end{array}$} & \multirow{2}{*}{$\begin{array}{l}\text { Transportador de } \\
\text { dipersina }\end{array}$} & CTGGCGAAAGACTGTATCAT & \multirow[t]{2}{*}{630} & \multirow[t]{2}{*}{60} & \multirow{2}{*}{$\begin{array}{l}\text { (PEREIRA et } \\
\text { al., 2007) }\end{array}$} \\
\hline & & CCATGTATAGAAATCCGCTGTT & & & \\
\hline \multirow{2}{*}{$a g g R$} & \multirow{2}{*}{$\begin{array}{c}\text { Ativador } \\
\text { Transcricional }\end{array}$} & CTAATTGTACAATCGATGTA & \multirow[t]{2}{*}{324} & \multirow[t]{2}{*}{50} & \multirow{2}{*}{$\begin{array}{l}\text { (PEREIRA et } \\
\text { al., 2010) }\end{array}$} \\
\hline & & CTGAAGTAATTCTTGAAT & & & \\
\hline \multirow[t]{2}{*}{ aаpA } & \multirow[t]{2}{*}{ Dispersina } & CTTTTCTGGCATCTTGGGT & \multirow[t]{2}{*}{328} & \multirow[t]{2}{*}{56} & \multirow[t]{2}{*}{ Esse estudo } \\
\hline & & TTATTTAACCCATTCGGTTAGAGC & & & \\
\hline \multirow[t]{2}{*}{$\operatorname{aggA}$} & \multirow{2}{*}{$\begin{array}{l}\text { Fímbria de adesão } \\
\text { agregativa (AAF-I) }\end{array}$} & GCTAACGCTGCGTTAGAAAGACC & \multirow[t]{2}{*}{421} & \multirow[t]{2}{*}{60} & \multirow{2}{*}{$\begin{array}{l}\text { (PEREIRA et } \\
\text { al., 2007) }\end{array}$} \\
\hline & & GGAGTATCATTCTATATTCGCC & & & \\
\hline \multirow[t]{2}{*}{ aafA } & \multirow{2}{*}{$\begin{array}{l}\text { Fímbria de adesão } \\
\text { agregativa (AAF-II) }\end{array}$} & GACAACCGCAACGCTGCGCTG & 233 & 50 & (PEREIRA et \\
\hline & & GATAGCCGGTGTAATTGAGCC & & & al., 2007) \\
\hline$a g g-3 A$ & Fímbria de adesão & GTATCATTGCGAGTCTGGTATTCAG & 462 & 56 & (BERNIER; \\
\hline & agregativa (AAF-III) & GGGCTGTTATAGAGTAACTTCCAG & & & $\begin{array}{l}\text { GOUNON; LE } \\
\text { BOUGUÉNEC } \\
\text { 2002) }\end{array}$ \\
\hline$h d a B-A$ & Fímbria de adesão & CTGTAGGACGTAGGTAATGAAACTG & 993 & 58 & Esse estudo \\
\hline & agregativa (AAF-IV) & AAACTCCAGGCGTTAACGTCTG & & & \\
\hline $\operatorname{agg}-5 A$ & Fímbria de adesão & AGCAGCAACAGCAAATCC & 342 & 56 & Esse estudo \\
\hline & agregativa (AAF-V) & CCGTAACCACTTCCTCGT & & & \\
\hline pet & Toxina codificada & CCGCAAATGGAGCTGCAAC & 1.133 & 60 & (PEREIRA \\
\hline & por plasmídeo & CGAGTTTTCCGCCGTTTTC & & & al., 2007) \\
\hline pic & Mucinase & TTCAGCGGAAAGACGAA & 500 & 60 & (PEREIRA et \\
\hline & & TCTGCGCATTCATACCA & & & al., 2007) \\
\hline & $\mathrm{Ma}$ & Eadores de $E$. coli uropatogênica (UPEC & & & \\
\hline fyuA & Receptor de & TGAGTGGGAAATACACCACC & 715 & 54 & Esse estudo \\
\hline & sideróforo & TTACCCGCATTGCTTAATGTC & & & \\
\hline$y f c V$ & Fímbria YFC & ATCCGTGTTGGCTGGC & 280 & 54 & Esse estudo \\
\hline & & GGTCATGGGCGCAGTT & & & \\
\hline chuA & Proteína ligadora & TAACTGTCATAGCGGGTTCC & 439 & 55 & Esse estudo \\
\hline & de grupo heme & AGTCTCTGAGCGGTTTAGTG & & & \\
\hline vat & Toxina & CAGAACATTTGCTCCCTTGT & 1102 & 53 & Esse estudo \\
\hline & vacuolizante & ACACGTTCAGGATTCAGT & & & \\
\hline papC & Pilus $\mathrm{P}$ & GACGGCTGTACTGCAGGGTGTGGCG & 328 & 60 & (DAIGLE \\
\hline & & ATATCCTTTCTGCAGGGATGCAATA & & & al., 1994) \\
\hline focA & Fímbria F1C & GAAAGTAGATGGAGCTAAAAGCAAT & 496 & 54 & \\
\hline & & CATGACATGCCAGTGGTTTC & & & Esse estudo \\
\hline & Marcador & de E.coli associada a meningite neonat & MNEC) & & \\
\hline sfa & Fímbria S & CTCCGGAGAACTGGGTGCATCTTAC & 407 & 60 & (DAIGLE \\
\hline & & CGGAGGAGTAATTACAAACCTGGCA & & & al., 1994) \\
\hline cnf & Fator necrosante & GTGAAGCTCAACGAGACTAT & 826 & 53 & Esse estudo \\
\hline & citotóxico & TCAGTAGCTCCTCTCATCAA & & & \\
\hline & & inas de diversos patotipos de $E$. $c c$ & & & \\
\hline $\operatorname{csg} A$ & Fímbria curli & CTCTGACTTGACTATTACC & 199 & 50 & Esse estudo \\
\hline & & AGATGCAGTCTGGTCAAC & & & \\
\hline ag43 & Antígeno 43 & CGATCGATAAGCTAATAATAACC & 552 & 55 & Esse estudo \\
\hline & (Adesina) & GAAGACCACCACTGGTGACA & & & \\
\hline pils & Pilus tipo IV & ATGAGCGTCATAACCTGTTC & 532 & 58 & (DUDLEY \\
\hline & & CTGTTGGTTTCCAGTTTGAT & & & al., 2006) \\
\hline
\end{tabular}




\subsection{DETERMINAÇÃO DE GRUPOS FILOGENÉTICOS}

Grupos filogenéticos de E. coli (A, B1, B2 e D) foram definidos por meio do método desenvolvido por Doumith e colaboradores (DOUMITH et al., 2012). Reações de PCR multiplex foram conduzidas para a detecção de 3 locus genéticos chuA, yjaA e TspE4.C2 (Tabela 3), o gene gadA foi utilizado como controle interno de reação. $O$ grupo filogenético foi determinado seguindo o modelo dicotômico de decisão proposto por Clermont e colaboradores (Figura 3) (CLERMONT et al., 2013).

Tabela 3 - Oligonucleotídeos iniciadores utilizados para determinação do filogrupos

\begin{tabular}{|c|c|c|c|}
\hline Genes & $\begin{array}{c}\text { Sequência dos oligonucleotídeos iniciadores } \\
\left(\mathbf{5}^{\prime} \mathbf{- 3}^{\prime} \mathbf{)}\right.\end{array}$ & $\begin{array}{c}\text { Fragmento esperado } \\
(\mathbf{p b})\end{array}$ & $\begin{array}{c}\text { Temperatura de } \\
\text { analamento } \\
(\mathbf{(} \mathbf{C})\end{array}$ \\
\hline gadA & GATGAAATGGCGTTGGCGCAAG & 373 & 60 \\
\hline chuA & GGCGGAAGTCCCAGACGATATCC & 281 & 60 \\
\hline & ATGATCATCGCGGCGTGCTG & & 62 \\
\hline$y j a A$ & AAACGCGCTCGCGCCTAAT & 216 & 60 \\
\hline TSPE4.C2 & ACCTGTGACAAACCGCCCTCA & & \\
\hline & GCGGGTGAGACAGAAACGCG & & \\
\hline
\end{tabular}

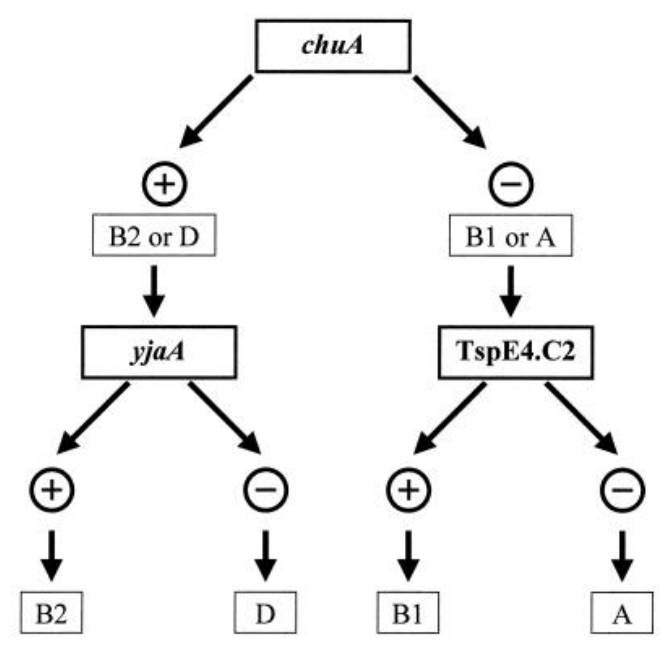

Figura 3 - Chave dicotômica empregada na definição dos filogrupos de E. coli como proposta por Clermont e colaboradores (2013)

\subsection{TIPAGEM POR SEQUENCIAMENTO DE MÚLTIPLOS LOCI (MLST)}

MLST foi realizado empregando protocolo previamente padronizado pelo Instituto Pasteur para E. coli (www.pasteur.fr/mlst). O protocolo explora a amplificação e o sequenciamento de oito loci genéticos para a determinação do tipo de sequência (ST - sequence type): $\operatorname{din} B$ (DNA polimerase); icdA (isocitrato 
desidrogenase); pabB (p-aminobenzoato sintase); polB (polimerase PollI); putP (proline permease); $\operatorname{trp} A$ (subunidade $\mathrm{A}$ da triptofano sintase); $\operatorname{trp} B$ (subunidade $\mathrm{B}$ tryptofano sintase); e uidA (beta-glucuronidase). As reações de amplificação foram realizadas utilizando a mesma mistura de reação e o conjunto de iniciadores padronizados pelo Instituto Pasteur. As reações de sequenciamento foram realizadas usando BigDye Terminator v3.1 Cycle Sequencing Kit (Applied Biosystems Inc., Foster City, CA, USA) com o iniciador $\mathrm{F}$ desenhado para o sequenciamento universal de todos os alelos (Tabela 4). Os produtos das reações foram analisados empregando a plataforma Genetic Analyzers 3500 (Applied Biosystems). As sequências geradas foram editadas no programa BioEdit (Sequence Alignment Editor) para estabelecimento das sequências consensos dos loci analisados. O ST (sequence type) de cada cepa foi estabelecido por meio da análise do perfil alélico explorando o banco de dados digital mantido pelo Instituto Pasteur.

Tabela 4 - Alvos e oligonucleotídeos iniciadores utilizados no protocolo (MLST) para determinação do ST

\begin{tabular}{|c|c|c|c|}
\hline Gene & Sequência dos oligonucleotídeos iniciadores (5’-3') & $\begin{array}{c}\text { Fragmento } \\
\text { esperado } \\
\text { (pb) }\end{array}$ & $\begin{array}{c}\text { Temperatura } \\
\text { de } \\
\text { analamento } \\
(\stackrel{\circ}{ } \text { C) }\end{array}$ \\
\hline \multirow[t]{2}{*}{$\operatorname{din} B$} & GTTTTCCCAGTCACGACGTTGTATGAGAGGTGAGCAATGCGTA & \multirow{2}{*}{450} & \multirow{2}{*}{55} \\
\hline & TTGTGAGCGGATAACAATTTCCGTAGCCCCATCGCTTCCAG & & \\
\hline \multirow[t]{2}{*}{$i c d A$} & GTTTTCCCAGTCACGACGTTGTAATTCGCTTCCCGGAACATTG & \multirow[t]{2}{*}{516} & \multirow[t]{2}{*}{55} \\
\hline & TTGTGAGCGGATAACAATTTCATGATCGCGTCACCAAAYTC & & \\
\hline \multirow[t]{2}{*}{$p a b B$} & GTTTTCCCAGTCACGACGTTGTAAATCCAATATGACCCGCGAG & \multirow[t]{2}{*}{468} & \multirow[t]{2}{*}{55} \\
\hline & TTGTGAGCGGATAACAATTTCGGTTCCAGTTCGTCGATAAT & & \\
\hline \multirow[t]{2}{*}{ polB } & GTTTTCCCAGTCACGACGTTGTAGGCGGCTATGTGATGGATTC & \multirow[t]{2}{*}{450} & \multirow[t]{2}{*}{55} \\
\hline & TTGTGAGCGGATAACAATTTCGGTTGGCATCAGAAAACGGC & & \\
\hline \multirow[t]{2}{*}{ putB } & GTTTTCCCAGTCACGACGTTGTACTGTTTAACCCGTGGATTGC & \multirow{2}{*}{456} & \multirow{2}{*}{55} \\
\hline & TTGTGAGCGGATAACAATTTCGCATCGGCCTCGGCAAAGCG & & \\
\hline \multirow[t]{2}{*}{$\operatorname{trp} A$} & GTTTTCCCAGTCACGACGTTGTAGCTACGAATCTCTGTTTGCC & \multirow[t]{2}{*}{561} & \multirow[t]{2}{*}{55} \\
\hline & TTGTGAGCGGATAACAATTTCGCTTTCATCGGTTGTACAAA & & \\
\hline \multirow[t]{2}{*}{$\operatorname{trp} B$} & GTTTTCCCAGTCACGACGTTGTACACTATATGCTGGGCACCGC & \multirow{2}{*}{594} & \multirow{2}{*}{55} \\
\hline & TTGTGAGCGGATAACAATTTCCCTCGTGCTTTCAAAATATC & & \\
\hline \multirow[t]{2}{*}{ uidA } & GTTTTCCCAGTCACGACGTTGTACATTACGGCAAAGTGTGGGTCAAT & \multirow[t]{2}{*}{600} & \multirow[t]{2}{*}{55} \\
\hline & TTGTGAGCGGATAACAATTTCCCATCAGCACGTTATCGAATCCTT & & \\
\hline \multirow{2}{*}{$\begin{array}{l}\text { Sequencia- } \\
\text { mento }\end{array}$} & oF :GTT TTC CCA GTC ACG ACG TTG TA & & \\
\hline & oR: TTG TGA GCG GAT AAC AAT TTC & & \\
\hline
\end{tabular}




\subsection{ANÁLISE FILOGENÉTICA E CONSTRUÇÃO DO DENDROGRAMA}

Para a análise filogenética das cepas de $E$. coli foi explorada uma sequência concatenada de 2.901 pares de base formada pelas sequências $\operatorname{din} B, i c d A$, polB, putP e trpA. O dendrograma foi construído utilizando o programa MEGA6, aplicando o método de Máxima Verossimilhança, baseado no modelo de Tamura-Nei (TAMURA et al., 2013). Inicialmente as árvores construídas para investigação foram obtidas aplicando o método Neighbor-Joining a uma matriz de distâncias estimada usando a abordagem de Probabilidade de Composição Máxima. A fim de testar a acurácia da filogenia foi aplicado o método de Bootstrap com 1500 replicações.

\subsection{ENSAIO DE FORMAÇÃO DE BIOFILME}

\subsubsection{COLETA DE AMOSTRAS DE URINA}

Foram coletadas 15 amostras de urinas de jato médio em recipientes estéreis (tubos cônicos de $50 \mathrm{~mL}$ ) por micção espontânea de indivíduos assintomáticos e sem registro de uso de antibióticos nas duas semanas anteriores. Os voluntários foram devidamente informados quanto ao objetivo da pesquisa e à utilização da amostra e atestaram consentimento por meio da assinatura do Termo de Consentimento Livre e Esclarecido (TCLE). As urinas coletadas foram submetidas à centrifugação (3.000 RCF por 5 min.), esterilização por filtração $(0,22 \mu \mathrm{m})$ e armazenadas a $-20^{\circ} \mathrm{C}$ até o momento do uso.

\subsubsection{FORMAÇÃO DE BIOFILME}

Foram escolhidas 77 cepas de E. coli representando os genótipos frequentemente detectados e também os mais virulentos (Tabela 5). Para avaliar a formação de biofilme foi avaliada com base no método descrito por Wakimoto et al. (2004) empregando placas de poliestireno contendo 96 poços (WAKIMOTO et al., 2004). As análises de biofilme foram feitas com dois tipos de meio de cultura: meio DMEM (Dulbecco's Modified Eagle's Medium) e urina humana suplementada com casaminoácido $(0,5 \%)$. Concisamente, $200 \mu \mathrm{L}$ de meio por poço foram inoculados com $5 \mu \mathrm{L}$ de cultura bacteriana (crescida em caldo LB overnight a $37^{\circ} \mathrm{C}$ ). As placas foram incubadas por $18 \mathrm{~h}$ a $37^{\circ} \mathrm{C}$ e os biofilmes formados foram corados com cristal 
violeta (CV) por 15 minutos e lavados com D-PBS (200 $\mu \mathrm{L} /$ poço). Os biofilmes foram quantificados utilizando a média do CV adsorvido (OD $630 \mathrm{~nm}$ ) no fundo do poço somado ao CV solubilizado por etanol ( $200 \mu \mathrm{L} /$ poço). O ensaio foi realizado em triplicata. Nele, foram utilizados como controles as cepas de EAEC 042 e 17-2 e a cepa de UPEC FVL2.

Tabela 5 - Genótipos, filogrupos e número de cepas selecionados para a realização dos ensaios de biofilme

\begin{tabular}{|l|l|}
\hline Genótipo & Filogrupo (número de cepas) \\
\hline chuA csgA & D (2); B2 (1); ND* (1) \\
\hline csgA & B1 (3); A (2) \\
\hline focA & B1 (1) \\
\hline fyuA chuA csgA & B2 (5); D (5) \\
\hline fyuA chuA focA pap csgA & D (2) \\
\hline fyuA chuA pap & B2 (1) \\
\hline fyuA chuA pap csgA & D (6) \\
\hline fyuA chuA pap csgA ag43 aatA aggR & D (1) \\
\hline fyuA chuA pap csgA ag43 pilS & D (2) \\
\hline fyuA chuA pap csgA aatA aggR & D (1) \\
\hline fyuA chuA vat csgA & D (1) \\
\hline fyuA chuA vat pap csgA ag43 & D (1) \\
\hline fyuAchuA vat pap sfa cnf csgA & B2 (1) \\
\hline fyuA csgA ag43 & B1 (1) \\
\hline fyuA vat csgA & A (1) \\
\hline fyuA vat focA csgA & A (1) \\
\hline fyuA vat focA pap csgA ag43 aatA aggR & A (1) \\
\hline fyuA yfcV chuA & B2 (1) \\
\hline fyuA yfcV chuA csgA & B2 (2); D (2) \\
\hline fyuA yfcV chuA pap csgA & D (7) \\
\hline fyuA yfcV chuA vat focA pap csgA ag43 pilS & B2 (1) \\
\hline fyuA yfcV chuA vat focA pap sfa cnf csgA & B2 (1) \\
\hline fyuA yfcV chuA vat focA pap sfa cnf csgA ag43 pilS & B2 (1) \\
\hline fyuA yfcV chuA vat focA pap sfa cnf csgA pic pilS & B2 (1) \\
\hline fyuA yfcV chuA vat focA pap sfa cnf pic & B2 (1) \\
\hline fyuA yfcV chuA vat focA sfa csgA pic & B2 (1) \\
\hline fyuA yfcV chuA vat pap cnf csgA & B2 (1) \\
\hline fyuA yfcV chuA vat pap cnf csgA ag43 pilS & B2 (1) \\
\hline fyuA yfcV chuA vat pap cnf csgA pic & B2 (1) \\
\hline fyuA yfcV chuA vat pap csgA & B2 (5) \\
\hline fyuA yfcV chuA vat pap sfa cnf csgA & B2 (2) \\
\hline fyuA yfcV chuA vat sfa cnf csgA pic & B2 (1) \\
\hline fyuA yfcV pap csgA ag43 & B1 (1) \\
\hline
\end{tabular}




\begin{tabular}{|c|c|}
\hline fyuA yfcV vat $\operatorname{csg} A$ & A (1) \\
\hline pap csgA & B1 (1); A (1) \\
\hline vat $\operatorname{csg} A$ & $\mathrm{~B} 1$ (1) \\
\hline yfc $V$ chuA vat $\operatorname{csg} A$ & $\mathrm{D}(1)$ \\
\hline yfcV chuA vat pap csgA & B2 (1) \\
\hline$y f c V$ vat foc $A \operatorname{csg} A$ & $A(1)$ \\
\hline Total & 77 \\
\hline
\end{tabular}

*Não determinado

\subsection{ANÁLISE DE DADOS}

\subsubsection{CATEGORIZAÇÃO}

No intuito de organizar os objetos de análise, melhorar a percepção dos resultados e minimizar possíveis vieses, alguns dados foram classificados em categorias como a idade dos pacientes e parâmetros do EAS (número de piócitos e presença de muco).

Os dados referentes a idade dos pacientes foram agrupados em 4 faixas etárias, marcadas por eventos fisiológicos que definem etapas do envelhecimento e que exercem influência na susceptibilidade dos indivíduos a infecções. Assim, os marcadores utilizados para a definição das faixas etárias foram o período de amamentação (para homens e mulheres) na faixa etária $\leq 2$ anos; a ausência da amamentação e período anterior a atividade sexual (para homens e mulheres) na faixa etária de 3 a 15 anos; o início da atividade sexual (para homens e mulheres) na faixa etária de 16 a 50 anos; e a menopausa (para mulheres) e a hiperplasia prostática (para homens) na faixa etária > 50 anos. Uma vez que os eventos biológicos que definiram a faixa etária > 50 anos são diferentes entre homens e mulheres, as análises utilizando as faixas etárias foram realizadas separadamente especificando o gênero.

Com relação aos parâmetros analisados no EAS, a contagem de piócitos, como parâmetro numérico, foi distribuída em 3 categorias que levava em consideração o valor normal de referência e o intervalo de precisão na contagem de células. Para o número de piócitos as categorias definidas foram contagem de até 10 piócitos/campo (valor de referência normal), de 11 a 30 /campo (passíveis de uma contagem precisa) e > 30/campo (Numerosos). Já a presença de muco, por ser um parâmetro subjetivo, foi divido em apenas 2 categorias: muco escasso ("ausente" 
ou escasso) e muco evidente (categoria levou em consideração a presença aumentada de muco seja ela $1+$ ou $2++$ ).

\subsubsection{ANÁLISE ESTATÍSTICA}

Para a análise dos dados categóricos, como a frequência de genes de virulência, foi inicialmente empregado o teste não paramétrico Kruskal-Wallis para avaliar a ocorrência de distribuição similar de um evento ou dado categórico (hipótese nula) entre 3 populações ou mais. As análises de distribuição de frequência para identificar possíveis associações estatísticas foram realizadas por meio do teste Qui-quadrado ou teste exato de Fisher, observadas as limitações dos testes em relação ao tamanho das amostras analisadas. O teste de Mantel-Haenszel foi utilizado para avaliar a existência de associações lineares entre as variáveis categóricas (as posicionadas em linhas e em colunas) analisadas em tabelas de contingência (POURHOSEINGHOLI; BAGHESTANI; VAHEDI, 2012). Dados paramétricos foram analisados utilizando o teste $\mathrm{T}$ de Student, respeitando o teste de Levene para a análise de variância entre as amostras. Resultados com valor de $p$ menor ou igual a 0,05 foram considerados estatisticamente significativos. Os dados estatísticos foram processados no programa SPSS (Statistical Package for the Social Sciences ${ }^{\circledR}-$ IBM $^{\circledR}$ ) versão 20. 


\section{RESULTADOS E DISCUSSÃO}

\subsection{EPIDEMIOLOGIA MOLECULAR DE CEPAS DE E. COLIUROPATOGÊNICAS}

\subsubsection{CEPAS DE E. COLIISOLADAS DE INFECÇÃO DO TRATO URINÁRIO E DE}

SEPSE URINÁRIA

Um total de 118 casos de infecções do trato urinário e 9 de sepse urinária por E. coli foram detectados ao longo do estudo (Tabela 6). Das amostras clínicas analisadas foram isoladas 401 cepas de E. coli (geralmente 3 cepas isoladas por amostra coletada) que foram todas genotipadas.

As cepas isoladas foram classificadas de acordo com a gravidade do quadro infeccioso (infecção do trato urinário - ITU - e sepse urinária - SU -). As cepas distribuídas nos casos de ITU, foram aquelas isoladas de casos de infecções que se restringiam ao trato urinário; enquanto que, nos casos de SU houve necessariamente um acometimento sistêmico com disseminação hematogênica e, por isso, obrigatoriamente a fonte de isolamento dos patógenos foi amostra de sangue. Os casos de SU foram classificados de duas formas: cepas isoladas de amostras de sangue com identificação clínica do foco urinário (1/9 casos), e pelo isolamento concomitante de cepas do mesmo genótipo de amostras de urina e sangue do mesmo paciente (8/9 casos). Este fato justifica a presença de isolados de urina no grupo de casos de sepse urinária. Para evitar o viés gerado por redundância de amostragem, as cepas de SU isoladas de urina foram excluídas das análises subsequentes, permanecendo 377 cepas para análise (351 de ITU e 26 de SU) (Tabela 6).

Tabela 6 - Número de casos, fontes de isolamento e quantitativo de cepas arroladas neste estudo

\begin{tabular}{|cccc|}
\hline & Casos & \multicolumn{2}{c|}{ Cepas } \\
\hline & $\begin{array}{c}\text { Contagem } \\
(\mathbf{N}=\mathbf{1 2 7})\end{array}$ & $\begin{array}{c}\text { Fonte de } \\
\text { isolamento }\end{array}$ & $\begin{array}{c}\text { Contagem } \\
(\mathbf{N}=\mathbf{4 0 1})\end{array}$ \\
\hline $\begin{array}{c}\text { Infecção do trato } \\
\text { urinário }\end{array}$ & 118 & Urina & 351 \\
\hline Sepse urinária & 9 & Urina & 24 \\
\cline { 2 - 4 } & & Sangue & 26 \\
\hline
\end{tabular}




\subsubsection{FREQUÊNCIA DOS FATORES DE VIRULÊNCIA EM CEPAS E. COLI ISOLADAS DE ITU E SU}

A frequência de distribuição de 14 fatores de virulência característicos de 3 patotipos de E. coli (UPEC, MNEC e EAEC) é mostrada na tabela 7, que aborda as 377 cepas analisadas distribuídas em casos de ITU e SU. Um dos fatores de virulência testado, a toxina pet, não foi detectado nas cepas analisadas e por isso não está representado nas análises que se seguem.

O gene $\operatorname{csg} A$ - para fímbia curli - foi detectado em $84,4 \%$ das cepas analisadas (maior positividade geral detectada), seguido dos genes associados a sistemas de aquisição de ferro chuA (positividade de 78,8\%) e fyuA (positividade de $73,7 \%$ ). O gene pap - pilus associado à pielonefrite - foi detectado em $48 \%$ das cepas analisadas, enquanto que, os genes cnf - para fator de necrose tumoral - e sfa - para fímbria S-, que são associados a cepas causadoras de meningite (MNEC), foram detectados em $20,7 \%$ e $14,3 \%$ das cepas de E. coli estudadas. Marcadores genéticos da categoria diarreiogênica EAEC (aatA e aggR) também foram detectados em 9 cepas (2,4\% dos isolados) (Tabela 7 ).

A tabela 7 ainda mostra que a frequência de alguns fatores de virulência apresentou distribuição estatisticamente diferente em função da gravidade do caso (ITU versus SU). Fatores de virulência como $\operatorname{csg} A(p=0,021)$, chuA $(p=0,002)$, ag43 $(p=0,001)$, aat $A(p=0,019)$ e aggR $(p=0,019)$ foram estatisticamente associados às cepas isoladas de $\mathrm{SU}$; enquanto que o gene focA foi associado as ITU ( $p=0,002)$, dada a ausência da deteç̧ão desse gene nas cepas de SU. O papel de alguns desses fatores na patogênese da sepse urinária já é caracterizado na literatura (HUNG et al., 2014).

O gene $\operatorname{csg} A$ (fimbria curli) está envolvido na agregação bacteriana, na adesão a uma série de proteínas do hospedeiro, incluindo proteínas de matriz extracelular; na formação de biofilmes, e na ativação do sistema imune inato (JOHNSON; RUSSO, 2005; KIKUCHI et al., 2005; TÜKEL et al., 2009). Dados da literatura demonstram que curli é expresso por cerca de $90 \%$ dos isolados de E. coli associados a infecções extraintestinais. Em parte das cepas, a expressão de curli 
acontece em temperaturas abaixo dos $30^{\circ} \mathrm{C}$, o que favoreceria a colonização da região perianal, tendo em vista que a temperatura corporal periférica é, geralmente, inferior a 36ํㅡ (EMODY et al., 2003). Não obstante o papel de curli na colonização perianal, estudos mostram que cepas de E. coli expressam curli em diferentes temperaturas, apontado para o papel multifuncional de curli (BARNHART; CHAPMAN, 2006). Neste cenário, cepas de E. coli isoladas de casos de septicemia, geralmente, apresentam expressão de curli a $37^{\circ} \mathrm{C}$, mas não a $30^{\circ} \mathrm{C}$ (BARNHART; CHAPMAN, 2006). Endossando a importância de fimbria curli em infecções sistêmicas, em nosso estudo, cepas de E. coli positivas para $\operatorname{csg} A$ foram estatisticamente associadas a sepse independente da alta positividade geral ( $\mathrm{p}=$ 0,021) (Tabela 7). Recentemente, tem sido relatado que a fímbria curli está envolvida na ativação de proteínas de fase aguda, o que demonstra o seu papel no desenvolvimento de quadros inflamatórios graves (BARNHART; CHAPMAN, 2006). O aumento sérico dessas proteínas acarreta em efeitos tais como a anticoagulação sanguínea e a geração do mediador celular vasodilatador bradicinina, que contribuem para a caracterização e evolução do quadro séptico. Adicionalmente, estudos in vitro com cepas de $E$. coli isoladas de sepse demonstram que a expressão de curli induz uma hiperprodução de fator de necrose tumoral $\alpha$ (TNF- $\alpha$ ), e de interleucina (IL) 6 e 8, que são importantes mediadores pró-inflamatórios frente a infecções bacterianas (BIAN et al., 2000).

A associação de ag43 com casos graves decorrente de ITU, como infecções recorrentes e sepse urinária, pode estar relacionada com a ação de Ag43 em facilitar a persistência de $E$. coli no trato urinário já demonstrada em vários trabalhos (LÜTHJE; BRAUNER, 2010b; SOTO et al., 2006; ULETT et al., 2007). Cepas isoladas de infecções recorrentes do trato urinário apresentam frequência estatisticamente aumentada de ag43 (11/12 - 92\%), em comparação a cepas isoladas de infecções esporádicas (44/73 - 60\%) ( $p \leq 0,005)$ (LÜTHJE; BRAUNER, 2010b; ULETT et al., 2007). Uma possível contribuição de Ag43 para a patogênese da SU seria a participação dessa proteína na resistência das células bacterianas a condições de estresse oxidativo, tendo em vista que durante a sepse ocorre um aumento de espécies reativas de oxigênio induzido pelo processo de lesão tecidual e resposta imune (SCHEMBRI et al., 2003). 
A expressão de sistemas de aquisição de ferro (sideróforos) como chuA (proteína ligadora de grupo heme) e fyuA (receptor sideróforo) é essencial para a sobrevivência, colonização e persistência de bactérias no trato urinário, visto que neste habitat operam processos que sequestram e limitam a disponibilidade de ferro funcionando como mecanismo de defesa do hospedeiro (NAGY et al., 2001).

Os genes aat $A(p C V D)$ e agg $R$ também foram estatisticamente associados as cepas de SU $(p=0,0019)$. Embora reconheçamos que a pequena coleção de cepas aatA-agg $R^{+}(\mathrm{n}=9)$ constitua uma importante fragilidade dessa associação estatística, outros trabalhos têm relatado o envolvimento de cepas com preditores de EAEC (aatA e aggR) em sepses urinárias (ANG et al., 2016; CHATTAWAY et al., 2014). A participação do patotipo EAEC em infecções extraintestinais tem ganhado importância na literatura, mas ainda é pouco compreendida. AggR é um regulador universal da virulência de EAEC, que é mediada principalmente por fímbrias de adesão agregativa (AAF) e dispersina. AAFs têm demonstrado mediar a adesão bacteriana a células da uretra e bexiga e também medeiam a formação de biofilme em catéteres uretrais, que implica num papel multifuncional dessas adesinas, conferindo aptidão uropatogênica às cepas de EAEC (BOLL et al., 2013; CHATTAWAY et al., 2014). Para melhor compreensão, as cepas positivas para os marcadores de EAEC foram também testadas quanto a presença das fímbrias AAFs e dispersina, esses resultados serão tratados posteriormente em seção a parte dedicada a essas cepas.

A fímbria Pap - pilus associado à pielonefrite - é considerada o fator de adesão mais importante em cepas de UPEC, uma vez que permite não só a colonização da bexiga bem como das vias urinárias superiores. Estudos epidemiológicos sobre virulência de UPEC mostram que a frequência de pap pode apresentar grandes variações com relatos de 0 a 54\% para a ocorrência deste gene entre as cepas de UPEC (BLANCO et al., 1997; TAKAHASHI et al., 2006). Em nosso estudo, pap foi detectado em $48 \%$ das cepas, com distribuição de frequências mostrando um valor de $p$ muito próximo do nível de significância $(0,05)$ para a associação com casos de SU $(p=0,071)$ (Tabela 7$)$. 
Tabela 7 - Frequência de distribuição de fatores de virulência em cepas de $E$. coli isoladas de infecção do trato urinário e sepse urinária

\begin{tabular}{|c|c|c|c|c|c|c|c|}
\hline \multirow[b]{2}{*}{ Gene } & \multicolumn{2}{|c|}{$\begin{array}{c}\text { Positividade } \\
\text { geral }\end{array}$} & \multicolumn{2}{|c|}{$\begin{array}{l}\text { Infecção do trato } \\
\text { Urinário }\end{array}$} & \multicolumn{2}{|c|}{ Sepse Urinária } & \multirow[b]{2}{*}{$\begin{array}{l}\text { Teste Exato } \\
\text { de Fisher } \\
\text { (Sig.) }\end{array}$} \\
\hline & $\begin{array}{c}\text { Contagem } \\
(\mathrm{N}=377)\end{array}$ & $\%$ & $\begin{array}{c}\text { Contagem } \\
(\mathrm{N}=351)\end{array}$ & $\%$ & $\begin{array}{c}\text { Contagem } \\
(\mathrm{N}=26)\end{array}$ & $\%$ & \\
\hline $\operatorname{csg} A$ & 318 & 84,4 & 292 & 83,2 & 26 & 100 & 0,021 \\
\hline chuA & 297 & 78,8 & 271 & 77,2 & 26 & 100 & 0,002 \\
\hline fyuA & 278 & 73,7 & 255 & 72,6 & 23 & 88,5 & 0,104 \\
\hline pap & 181 & 48,0 & 164 & 46,7 & 17 & 65,4 & 0,071 \\
\hline$y f c V$ & 151 & 40,1 & 142 & 40,5 & 9 & 34,6 & 0,680 \\
\hline vat & 143 & 37,9 & 135 & 38,5 & 8 & 30,8 & 0,532 \\
\hline cnf & 78 & 20,7 & 72 & 20,5 & 6 & 23,1 & 0,802 \\
\hline focA & 77 & 20,4 & 77 & 21,4 & 0 & 0,0 & 0,002 \\
\hline$c f a$ & 54 & 14,3 & 48 & 13,7 & 6 & 23,1 & 0,239 \\
\hline ag43 & 42 & 11,1 & 33 & 9,4 & 19 & 34,6 & 0,001 \\
\hline pic & 22 & 5,8 & 20 & 5,7 & 2 & 7,7 & 0,657 \\
\hline pils & 21 & 5,6 & 21 & 6,0 & 0 & 0,0 & 0,382 \\
\hline $\begin{array}{c}\text { aatA } \\
\text { (pCVD) }\end{array}$ & 9 & 2,4 & 6 & 1,7 & 3 & 11,5 & 0,019 \\
\hline aggR & 9 & 2,4 & 6 & 1,7 & 3 & 11,5 & 0,019 \\
\hline
\end{tabular}

\subsubsection{PERFIS GENÉTICOS ASSOCIADOS A PADRÕES CLÍNICO- EPIDEMIOLÓGICOS}

A análise de possíveis associações de perfis moleculares com padrões clínico-epidemiológicos foi realizada com 377 cepas (351 cepas de ITU e 26 isolados sanguíneos de SU) recuperadas dos 127 casos (Tabela 6). A Tabela 8 mostra que, de uma forma geral, maior parte dos casos são representados pelo gênero feminino (87/127 - 68,5\%). Esse dado corrobora com observações universais do predomínio do gênero feminino nas ITU, principalmente em virtude da anatomia feminina (FOXMAN, 2002).

Quando especificado o local de atendimento (pronto-socorro versus internação), o predomínio do gênero feminino nos casos de infecções comunitárias (pronto-socorro), é mantido, representando mais de 68,7\% (66/96) dos pacientes atendidos no pronto-socorro (Tabela 8). Fora do ambiente hospitalar, os casos de ITU também são mais frequentes em mulheres do que em homens (FOXMAN et al., 2002; STAPLETON, 2014). No entanto, com relação aos casos de infecções 
hospitalares, a frequência do gênero feminino reduz para 59,1\% (13/22), uma vez que as infecções do trato urinário hospitalares são em $80 \%$ dos casos associadas ao uso dispositivos invasivos como a sonda vesical de demora, que são utilizados indiscriminadamente em ambos os sexos (QUEIRÓS et al., 2011; STAMM, 1991).

Tabela 8 - Perfil epidemiológico dos casos de infecção extraintestinal por E. coli

\begin{tabular}{|c|c|c|c|c|c|}
\hline & & N. ${ }^{\circ}$ & $\begin{array}{c}\text { Pronto- } \\
\text { Socorro } \\
{[\%]}\end{array}$ & $\begin{array}{c}\text { Internação } \\
{[\%]}\end{array}$ & ND \\
\hline $\begin{array}{c}\mathrm{n}^{\circ} \text { de paciente } \\
{[\%]}\end{array}$ & & 127 [100\%] & $96[75,6 \%]$ & $22[17,3 \%]$ & $9[7,1 \%]$ \\
\hline Gênero [\%] & $F$ & $87[68,5 \%]$ & $66[75,9 \%]$ & 13 [14,9\%] & $8[9,2 \%]$ \\
\hline & $M$ & $40[31,5 \%]$ & $30[75,0 \%]$ & $9[22,5 \%]$ & $1[2,5 \%]$ \\
\hline $\begin{array}{r}\text { Idade mediana } \\
\text { [Min-Max ](anos }\end{array}$ & & & $\begin{array}{c}26 \\
{[0-95]}\end{array}$ & $\begin{array}{c}47 \\
{[0-88]}\end{array}$ & \\
\hline
\end{tabular}

Inicialmente, a frequência dos fatores de virulência foi analisada estratificando o setor de atendimento (pronto-socorro ou internado), o sexo e a faixa etária dos pacientes atendidos para avaliar a ocorrência de distribuição desigual dos fatores em função das categorias analisadas (Teste de Kruskall-Wallis) (Tabela 9).

Dos 14 fatores de virulência estudados, os genes fyuA, chuA, vat e pic apresentaram frequência de distribuição diferente quando analisados em relação ao setor de atendimento (Tabela 9). Enquanto que os genes chuA e cnf apresentaram distribuição estatisticamente diferente quando analisados em decorrência do gênero (Tabela 9). A distribuição da frequência dos fatores de virulência também se mostrou diferente quando analisadas em relação as faixas etárias (feminina e masculina). $\mathrm{A}$ frequência dos genes fyuA, yfcV, chuA, vat, focA, pap, sfa e pic foi distribuída de forma desigual para as faixas etárias dos pacientes do gênero masculino. Também houve diferenças na distribuição da frequência dos genes fyuA, chuA, pap, sfa, cnf, $\operatorname{csg} A$, ag43, pilS, aatA e agg $R$ em relação as faixas etárias do gênero feminino. 
Tabela 9 - Nível de significância (valor de p) calculado (teste de Kruskall-Wallis) para a distribuição dos fatores de virulência em função de perfil clínicoepidemiológico dos pacientes

\begin{tabular}{|c|c|c|c|c|}
\hline \multicolumn{5}{|c|}{$\begin{array}{c}\text { Hipótese: Frequência dos genes é distribuída igualmente nos grupos } \\
\text { estudados? }\end{array}$} \\
\hline \multirow[t]{2}{*}{ Genes } & \multirow{2}{*}{$\begin{array}{c}\text { Pronto- } \\
\text { Socorro X } \\
\text { Internação } \\
\text { (valor de p) }\end{array}$} & \multirow{2}{*}{$\begin{array}{l}\text { Masculino } x \\
\text { Feminino } \\
\text { (valor de } p \text { ) }\end{array}$} & \multicolumn{2}{|c|}{$\begin{array}{l}\text { Faixa etária } \\
\text { (valor de } p \text { ) }\end{array}$} \\
\hline & & & Homens & Mulheres \\
\hline fyuA & 0,003 & 0,898 & 0,001 & 0,000 \\
\hline$y f c V$ & 0,052 & 0,490 & 0,000 & 0,445 \\
\hline chuA & 0,012 & 0,000 & 0,043 & 0,005 \\
\hline vat & 0,011 & 0,212 & 0,026 & 0,374 \\
\hline focA & 0,392 & 0,495 & 0,001 & 0,473 \\
\hline pap & 0,079 & 0,892 & 0,030 & 0,000 \\
\hline sfa & 0,929 & 0,490 & 0,015 & 0,027 \\
\hline cnf & 0,690 & 0,026 & 0,949 & 0,001 \\
\hline $\operatorname{csg} A$ & 0,655 & 0,251 & 0,936 & 0,039 \\
\hline pic & 0,034 & 0,059 & 0,001 & 0,543 \\
\hline ag43 & 0,620 & 0,104 & 0,170 & 0,001 \\
\hline pils & 0,855 & 0,076 & 0,313 & 0,000 \\
\hline aatA (pCVD) & 0,237 & 0,922 & 0,313 & 0,022 \\
\hline $\operatorname{agg} R$ & 0,237 & 0,922 & 0,313 & 0,022 \\
\hline
\end{tabular}

A análise para a identificação das associações estatísticas (teste exato de Fisher) (Tabela 10) demonstrou que cepas positivas para fyuA, chuA, vat e pic foram estatisticamente associadas $(p<0,05)$ às infecções atendidas no PS (infecções comunitárias). De uma forma geral, pensa-se que casos de ITU comunitárias são causados por cepas capazes de alcançar o trato geniturinário e ascender ativamente pela uretra explorando mecanismos de virulência e competindo com os demais integrantes da microbiota geniturinária. Em relação a maior frequência de isolamento de fyuA e chuA em cepas isoladas de infecção comunitária, modelos de infecção in vivo têm mostrado que, na ausência destes sistemas, cepas de UPEC são facilmente superadas por aquelas da microbiota normal (TORRES et al., 2001). A associação estatística de fyuA e chuA com as ITU comunitárias endossam a importância destes sistemas de captação de ferro para sobrevivência de cepas de $E$. coli durante os processos naturais de translocação para o sistema geniturinário.

A mucinase Pic possui um papel essencial no processo de adesão bacteriana a mucosa de bexiga, atuando na degradação do muco produzido pelas células 
epiteliais como resposta frente a tentativa de colonização por E. coli (NAVARROGARCIA et al., 2010).

O gene vat, que codifica a toxina autotransportadora vacuolizante, foi descrito inicialmente em cepas de E. coli patogênica aviária (APEC) e é reconhecido como um fator de virulência neste patotipo. Não obstante, cepas de APEC e UPEC frequentemente compartilham perfis de virulência semelhantes, incluindo a presença de vat (ZHAO et al., 2009; ZHU GE et al., 2014). A ocorrência de vat em cepas de UPEC recuperadas de infecções comunitárias revela a versatilidade da espécie $E$. coli em obter fatores de virulência associados a diferentes nichos que contribuam para uropatogênese humana.

Em um cenário oposto, infecções urinárias hospitalares estão geralmente associadas ao uso de dispositivos invasivos, como os cateteres. Estes dispositivos funcionam como carreadores de microrganismos, além disso a produção de fibrinogênio provocada pela inserção do catéter facilita a colonização do trato urinário por cepas menos especializadas no que tange a virulência (Figura 4) (FLORES-MIRELES et al., 2015; STAMM, 1991).

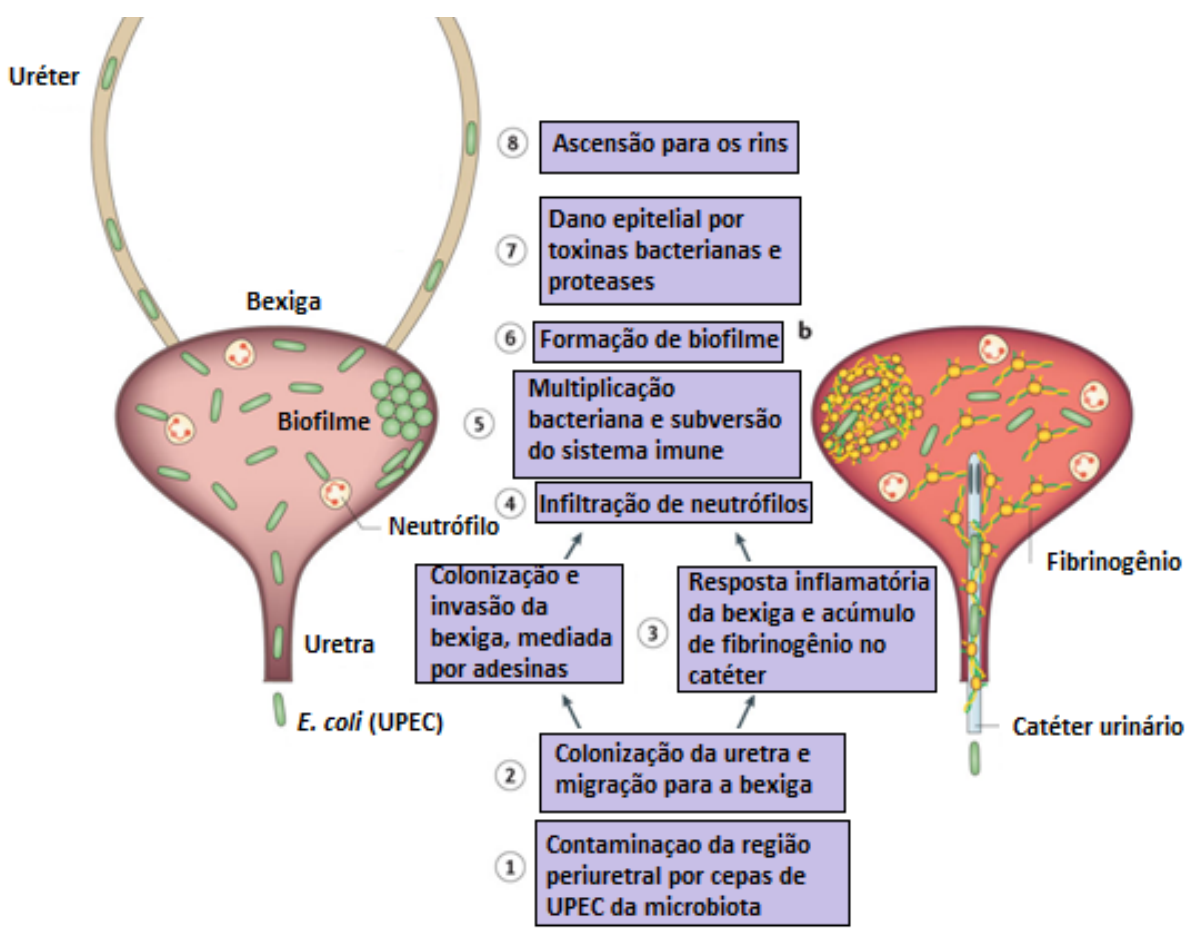

Figura 4 - Processos de colonização do trato urinário em infecções comunitárias e associadas a catéter urinário. Adaptado de Flores-Mireles et al., 2015. 
Em relação ao gênero dos pacientes, dois fatores de virulência (chuA e cnf) mostraram-se estatisticamente associados a um dos gêneros. O gene chuA foi detectado em $66,7 \%$ (80/120) das cepas isoladas de homens e em $84,4 \%(217 / 257)$ das cepas isoladas de mulheres, mostrando-se assim estatisticamente associado ao aos casos no gênero feminino ( $p=0,000$ ) (Tabela 10). A associação de chuA com infecções extraintestinais em mulheres envolvendo $E$. coli tem sido reportada em outros estudos. Um trabalho realizado em São Paulo com 74 cepas de E. coli isoladas de bacteremia também reportou o gene chuA como mais frequentemente detectado em pacientes do gênero feminino (24/31 - 77\%, feminino vs. $24 / 43-56 \%$ masculino) (SANTOS et al., 2013).

Em relação ao gênero masculino, nossos dados mostraram que cepas positivas para cnf foram estatisticamente associadas $(p=0,029)$ aos casos envolvendo homens (detecção em 27,5\% - 33/120 - vs. 17,5\% - 45/245 - em mulheres). Alguns trabalhos apresentam frequência de detecção do gene cnf em isolados de cistite em homens acima de $50 \%$. Este nível de positividade não é comumente encontrado em cepas isoladas de infecção extraintestinal em mulheres. Além disso, a relação de cnf com cepas isoladas de prostatite é fato recorrente na literatura (ANDREU et al., 1997; MILLS; MEYSICK; O'BRIEN, 2000; MITSUMORI et al., 1999). A anatomia do trato geniturinário masculino dificulta a colonização e ascensão de cepas de UPEC por via urinária. Diante deste fato, sugere-se que a ITU em homens, e a consequente prostatite, só possa ser conduzida por cepas de UPEC altamente especializadas apresentando alto fitness. Um trabalho recente, mostrou a contribuição de cnf para a melhoria do fitness de cepas de UPEC na infecção do trato urinário. Os dados demonstram que a produção de CNF confere maior sobrevivência às células bacterianas na presença de neutrófilos em virtude da diminuição da capacidade fagocítica das células de defesa (DAVIS; RASMUSSEN; O'BRIEN, 2005; SUBASHCHANDRABOSE; MOBLEY, 2015).

Tanto em homens quanto em mulheres, foram encontradas associações estatísticas entre fatores de virulência e faixas etárias específicas. Os genes fyuA, $y f c V$, chuA foram estatisticamente associados as faixas etárias $<50$ anos em homens $(p<0,05)$ (Tabela 10). O aumento da frequência dos fatores de virulência 
dos isolados de homens mais jovens ( $<50$ anos) pode estar associada a diferenças na patogênese da ITU em homens de diferentes faixas etárias. Em pacientes com idade acima dos 50 anos, as infecções do trato urinário estão geralmente associadas a coleção de resíduo urinário, gerada pela obstrução da uretra em consequência de hiperplasia benigna prostática. $O$ resíduo urinário favorece a proliferação de cepas menos especializadas em relação a virulência, visto que a permanência desses microrganismos no trato urinário não está necessariamente atrelada a mecanismos de virulência envolvidos na uropatogênese. Baseado nisso, é possível compreender porque boa parte dos fatores de virulência apresentaram uma queda na frequência em cepas isoladas de pacientes $>50$ anos. Em oposição a esta generalização, as cepas positivas para focA foram estatisticamente associadas a ITU em homens na faixa etária $>50$ anos. Neste grupo de pacientes, foc $A$ apresentou frequência 2 vezes maior (38,9\%) em comparação com as demais faixas etárias ( $0 \%$ - $\leq 2$ anos; $16,7 \%$ - 3 a 15 anos; $12,5 \%$ - 16 a 49 anos). A fímbria FC1 (focA) é reconhecida por mediar a formação de biofilme e colonização intestinal e a adesão bacteriana a células epiteliais do trato urinário de cepas comensais como a cepa de E. coli Nissle 1917 (LASARO et al., 2009). Este fato apenas reforça a ideia sobre a participação de cepas menos virulentas nas ITUs em homens maiores de 50 anos.

Embora em menor número e em faixas etárias diferentes, os fatores de virulência também foram estatisticamente associados a infecções em mulheres quando menores de 15 anos (Tabela 10). Os genes fyuA, chuA, pap e cnf foram estatisticamente associados a cepas isoladas de pacientes $\leq 15$ anos. A associação de vários fatores de virulência a esse grupo etário sugere que cepas isoladas de crianças e adolescente ( $\leq 15$ anos) são potencialmente mais virulentas, quando comparadas a mulheres jovens e adultas.

Quando analisado o grupo de mulheres, detectamos que pap foi estatisticamente mais frequente nas mulheres menores de 15 anos $(70,29 \%$ de positividade) quando comparadas com aquelas com idade superior $(30,37 \%$ de positividade). A fímbria Pap expressa por cepas de UPEC liga-se a receptores específicos em células epiteliais. Evidências confirmam que os glicolipídeos contendo o motivo dimérico Gal-Gal são receptores para a fímbria Pap, já que 
domínio é o principal determinante da ligação de Pap a receptores celulares (BERTIN et al., 2000; BRITO et al., 2004; JOHNSON, 1991). Uma possível explicação para estas associações pode estar relacionada à diferença de expressão de receptores celulares em adultos e crianças. Para a verotoxina de E. coli, um trabalho já definiu que receptores com motivo dimérico Gal-Gal (especificamente gala1-4 galß1-4 glicosilceramida) são expressos com maior intensidade em biópsias de túbulos renais de crianças ( $<2$ anos) quando comparadas com adultos (LINGWOOD, 1994). Este fato também já foi demonstrado para os receptores DAF (CD55) que tem nível de expressão diferenciado em decorrência da idade e são reconhecidos por adesinas Afa/Dr expressas por $E$. coli de adesão difusa (DAEC) (MANSAN-ALMEIDA; PEREIRA; GIUGLIANO, 2013; WAITUMBI et al., 2004). 
Tabela 10 - Análise de frequência (teste exato de Fisher) de fatores de virulência com distribuição desigual entre as categorias clínico-epidemiológicas analisadas

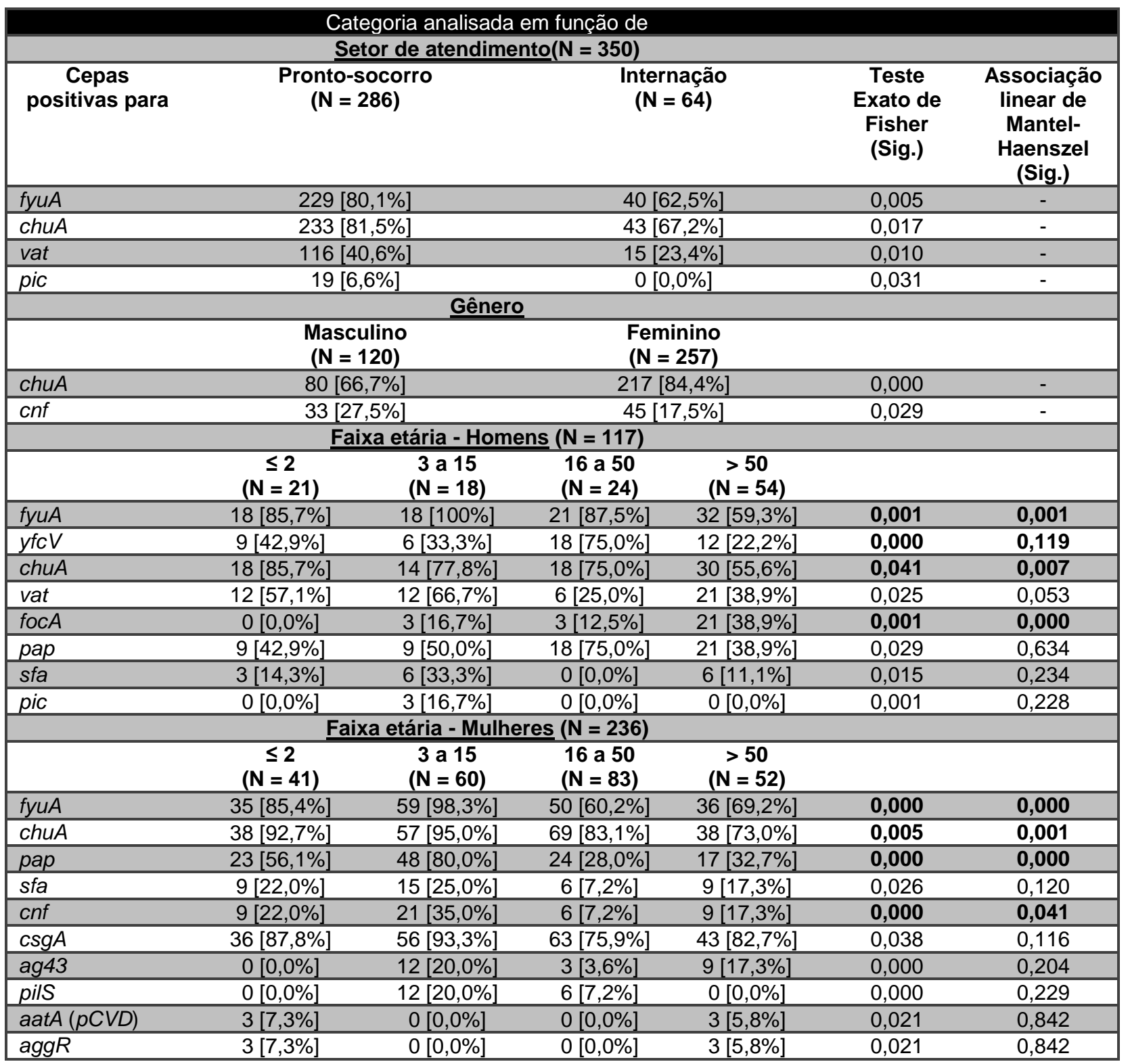

A frequência estatisticamente maior de fatores de virulência em cepas de UPEC isoladas de crianças do gênero feminino pode indicar uma característica epidemiológica associada a esse grupo etário: a ocorrência mais frequente de cepas com maior carga de virulência em grupos etários mais jovens do gênero feminino. Para cada cepa analisada foi definida a carga de virulência como a somatória dos marcadores genéticos detectados. Esta análise mostrou que a carga de virulência média nas cepas isoladas das menores de 15 anos era estatisticamente superior $(5,40)$ quando comparado ao restante das pacientes adultas $(3,97)$ ( $p=0,001)$ (Figura 5). Nas pacientes de 3 a 15 anos de idade as cepas isoladas atingiram uma 
média de carga de virulência de 5,80 genes/cepa, um valor estatisticamente superior às médias calculadas para os grupos etários de adultas $(3,86)(p=0,000)$ e maiores de $50(4,15)(p=0,000)$. $O$ fato de que cepas de patotipos de $E$. coli isoladas de crianças carregam uma carga de virulência maior quando comparadas as de adultos tem sido reportado por outros trabalhos. Em um estudo epidemiológico recente, também conduzido em Brasília, foi mostrado que cepas de E. coli diarreiogênicas isoladas de crianças apresentavam genes de virulência em frequência superior àquelas isoladas de adultos assintomáticos ou diarreicos (MANSAN-ALMEIDA; PEREIRA; GIUGLIANO, 2013).

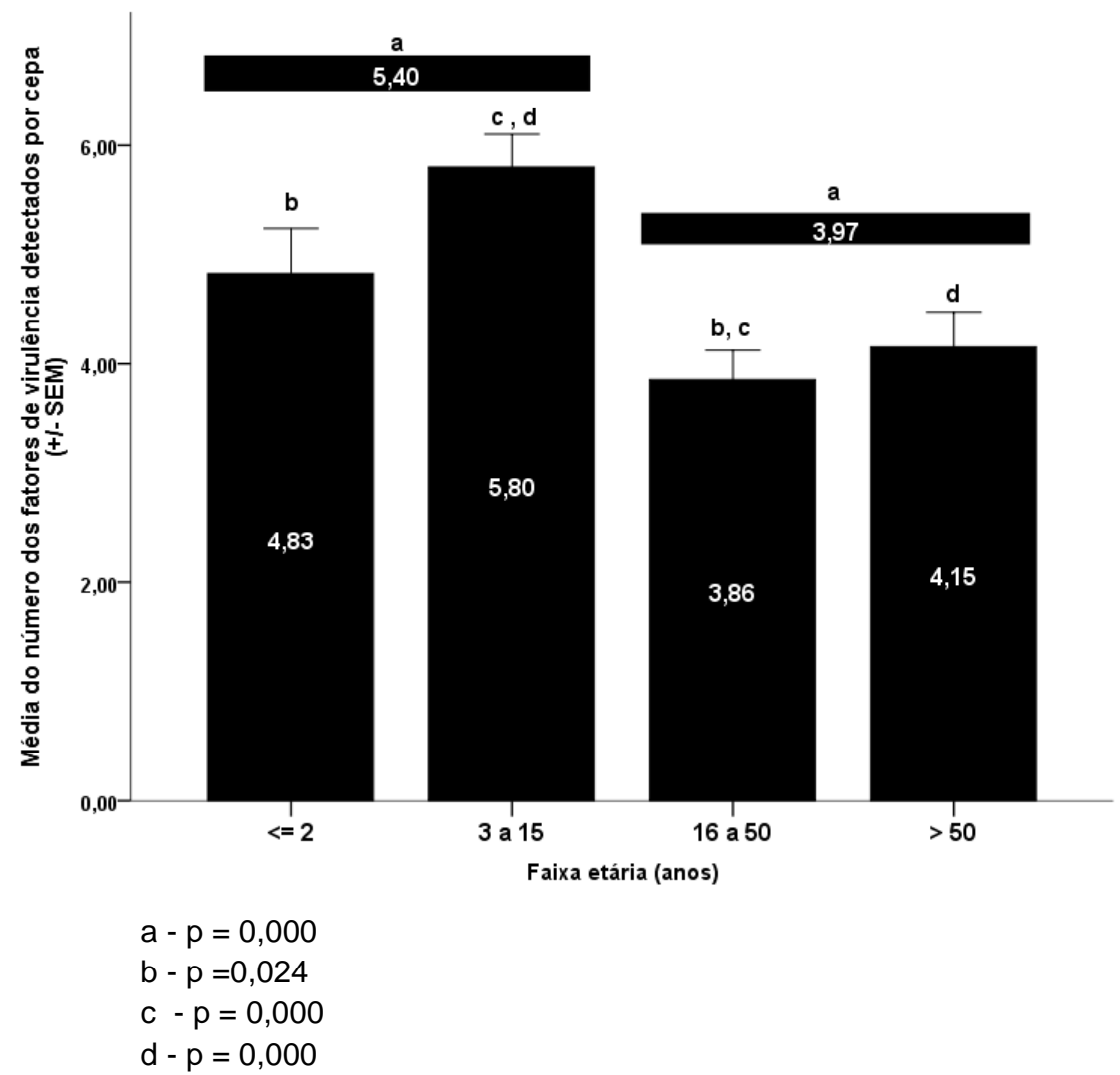

Figura 5 - Carga de virulência em cepas de $E$. coli isoladas de casos de infecções extraintestinais em mulheres

A mesma análise foi realizada nas faixas etárias do gênero masculino, no entanto não foi encontrada a mesma associação vista no gênero feminino (Figura 6). Apesar das cepas isoladas da faixa etária $<50$ anos apresentarem menor carga de virulência (4,15 genes/cepa), a análise não mostrou qualquer diferença significativa entre as faixas etárias. 
Apesar da maior dificuldade de colonização do trato urinário masculino sugerir a necessidade de cepas mais especializadas, a análise mostrou que a média de fatores de virulência em todas as faixas etárias masculinas (4,6 fatores/cepa) foi idêntico ao encontrado nas faixas etárias femininas (4,6 fatores/cepa) o que demonstra que não só o número de fatores de virulência contribui para a uropatogênese, mas sim a presença de combinações específicas que favoreçam o fitness dessas cepas.

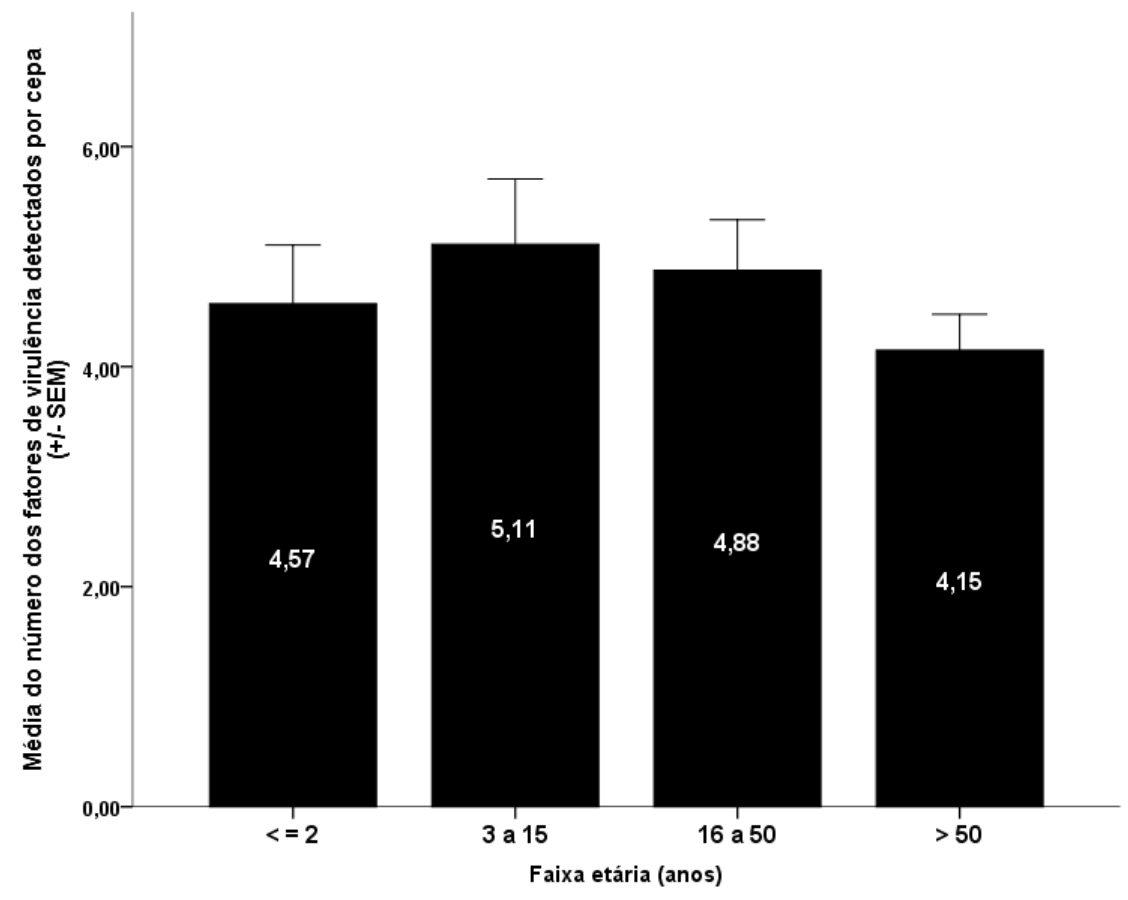

Figura 6 - Carga de virulência em cepas de E. coli isoladas de casos de infecções extraintestinais em homens

\subsubsection{PERFIS GENÉTICOS ASSOCIADOS A PADRÕES ANALÍTICOS FLAGRADOS NO EAS}

Para avaliar se alterações nos elementos figurados da urina associam-se ao perfil de virulência das cepas isoladas, a frequência dos genes foi analisada em função dos parâmetros avaliados nos ensaios de EAS (Tabela 11 e 12). Nessa análise foram consideradas as cepas isoladas de pacientes que haviam realizado 0 EAS concomitante a urocultura. A presença de muco estava ausente em alguns exames, o que explica a variação do número de cepas analisadas neste parâmetro. 
A análise mostrou que vários dos fatores de virulência testados se distribuem de forma diferente em relação presença de muco e ao número de piócitos por campo. A fímbria Pap, em especial, apresentou uma distribuição diferente para todos os parâmetros testados (Tabela 11 e 12).

Tabela 11 - Nível de significância (valor de p) calculado (teste de Kruskall-Wallis) para a distribuição dos fatores de virulência em função dos parâmetros analíticos testados para as amostras de urina

\begin{tabular}{|c|c|c|}
\hline \multicolumn{3}{|c|}{$\begin{array}{l}\text { Frequência dos genes é distribuída igualmente em função dos } \\
\text { resultados do EAS? }\end{array}$} \\
\hline Genes & $\begin{array}{l}\text { Piócitos/campo } \\
\text { (valor de p) }\end{array}$ & $\begin{array}{c}\text { Presença de muco } \\
\text { (valor de } p \text { ) }\end{array}$ \\
\hline fуиA & 0,002 & 0,237 \\
\hline$y f c V$ & 0,005 & 0,667 \\
\hline chuA & 0,003 & 0,849 \\
\hline vat & 0,520 & 0,523 \\
\hline focA & 0,048 & 0,006 \\
\hline pap & 0,000 & 0,002 \\
\hline sfa & 0,570 & 0,015 \\
\hline cnf & 0,142 & 0,012 \\
\hline $\operatorname{csg} A$ & 0,081 & 0,027 \\
\hline pic & 0,211 & 0,802 \\
\hline ag43 & 0,000 & 0,037 \\
\hline pils & 0,115 & 0,095 \\
\hline aatA $(p C V D)$ & 0,220 & 0,691 \\
\hline aggR & 0,220 & 0,691 \\
\hline
\end{tabular}

Em relação a contagem de piócitos, as análises estatísticas mostraram que apenas pap apresentou distribuição desigual de frequência (teste exato de Fisher com $p<0,05$ ) e relação linear (teste de Mantel-Haenszel com $p<0,05$ ) em função do aumento da quantidade de piócitos observados nas amostras de urina (Tabela 12). A fímbria Pap é considerada um dos fatores de virulência com maior potencial pró-inflamatório, seu mecanismo pode explicar a associação estatística de cepas positivas para pap com a presença aumentada de piócitos na urina (Tabela 12). Além disso, há uma correlação entre a presença de pap e a severidade dos casos de ITU (HOLDEN et al., 2007). 
As adesinas FocA, Pap, Sfa e CsgA, que atuam no processo de colonização das mucosas trato urinário, foram estatisticamente associadas a presença de muco nas amostras de urina analisadas (Tabela 12). Sobre a superfície das mucosas, a camada de muco age primariamente como barreira de proteção evitando que microrganismos contatem intimamente a superfície celular impedindo, assim, a interação dos fatores de adesão bacterianos com receptores nas células epiteliais (CORNISH; VANDERWEE; MILLER, 1987). É resposta comum às mucosas, o aumento na expressão de muco diante de processos de colonização por microrganismos patogênicos (CORNISH; VANDERWEE; MILLER, 1987).

Já os fatores de virulência ag43 e cnf foram estatisticamente associados a escassez de muco. Embora medeie a interação entre bactérias (agregação bacteriana) e a formação de biofilme, a adesina ag43 não reconhece receptores de células epiteliais de mamíferos, incluindo humanos (DE LUNA et al., 2008). Adicionalmente, a agregação bacteriana por ação de ag43 impede a expressão de adesinas fimbriais que promovem a secreção de muco por meio da interação com receptores celulares (HASMAN; CHAKRABORTY; KLEMM, 1999). Em relação a cnf não foram encontrados dados na literatura que elucidem pragmaticamente a associação entre ausência ou redução de muco e colonização por cepas portando cnf. No entanto, é conhecido o efeito inibitório de CNF sobre efetores de resposta pró-inflamatória em neutrófilos (proteína Rho) com a consequente redução na liberação de grânulos tóxicos, incluindo elastase (HOPKINS et al., 2003; SUBASHCHANDRABOSE; MOBLEY, 2015). A elastase é um indutor da produção de muco em células epiteliais de mucosa (LINDEN et al., 2008). 
Tabela 12 - Análise de frequência (teste exato de Fisher) de fatores de virulência com distribuição desigual entre os parâmetros analíticos observados no exame de urina (EAS)

\begin{tabular}{|c|c|c|c|c|c|}
\hline \multicolumn{6}{|c|}{ Categoria analisada em função de } \\
\hline \multicolumn{6}{|c|}{ Piócitos/campo (N = 209) } \\
\hline & $\begin{array}{l}\text { Até 10/campo } \\
(N=36)\end{array}$ & $\begin{array}{c}11 \mathrm{a} \\
30 / \mathrm{campo} \\
(\mathrm{N}=36)\end{array}$ & $\begin{array}{c}>30 / \text { campo } \\
(\mathrm{N}=137)\end{array}$ & $\begin{array}{l}\text { Teste Exato de } \\
\text { Fisher (Sig.) }\end{array}$ & $\begin{array}{l}\text { Associação } \\
\text { linear de Mantel- } \\
\text { Haenszel } \\
\text { (Sig.) }\end{array}$ \\
\hline fyuA & $27[75,0 \%]$ & $20[55,6 \%]$ & $114[83,2 \%]$ & 0,003 & 0,055 \\
\hline$y f c V$ & $15[41,7 \%]$ & $6[16,7 \%]$ & $64[46,7 \%]$ & 0,004 & 0,172 \\
\hline chuA & $30[83,3 \%]$ & $21[58,3 \%]$ & $115[83,9 \%]$ & 0,006 & 0,319 \\
\hline focA & $3[8,3 \%]$ & $3[8,3 \%]$ & $30[21,9 \%]$ & 0,051 & 0,023 \\
\hline pap & 9 [25,0\%] & $12[33,3 \%]$ & $92[67,2 \%]$ & 0,000 & 0,000 \\
\hline ag43 & $0[0,0 \%]$ & $12[33,3 \%]$ & $12[8,8 \%]$ & 0,000 & 1,000 \\
\hline \multicolumn{6}{|c|}{ Presenca de muco $(\mathrm{N}=194)$} \\
\hline & $\begin{array}{l}\text { Esca } \\
(n=\end{array}$ & & $\begin{array}{l}\text { Evide } \\
(\mathrm{N}=1\end{array}$ & $\mathrm{Te}$ & $\begin{array}{l}\text { Exato de Fisher } \\
\text { (Sig.) }\end{array}$ \\
\hline focA & $6[7,8$ & & $27[23$ & & 0,006 \\
\hline pap & $32[41$ & & $75[64$ & & 0,003 \\
\hline sfa & $3[3$, & & $15[12$ & & 0,043 \\
\hline cnf & $21[27$ & & $15[12$ & & 0,014 \\
\hline $\operatorname{csg} A$ & $62[80$ & & $107[91$ & & 0,030 \\
\hline ag43 & $15[19$ & & $9[7,7$ & & 0,024 \\
\hline
\end{tabular}

\subsubsection{PERFIL DE FILOGRUPOS EM CEPAS DE UPEC}

Nossos dados revelam que cepas de UPEC se distribuíram entre os 4 filogrupos pesquisados, incluindo filogrupos de linhagens intestinais comensais $A$ e B1 que responderam por $22,2 \%$ das ITU. Cepas de linhagens extraintestinais B2 e D responderam pela maior parte dos isolados de ITU (252/324 - 77,8\%), bem como pela totalidade dos casos de SU. Em relação ao filogrupo D, cepas desta linhagem foram estatisticamente associado a SU (68\% em SU vs. 32,1\% em ITU - p = 0,002), apresentando no grupo de SU frequência superior ao filogrupo B2 (68\% - 17/25 - vs. $32 \%-8 / 25)$.

O predomínio dos filogrupos $B 2$ e $D$ em relação aos filogrupos $A$ e $B 1$ em infecções extraintestinais é fato recorrente na literatura, não só no Brasil, mas também em outros países. No entanto, a participação dos filogrupos B2 e D em casos de sepse podem assumir proporções diferentes em função da região geográfica estudada. Apesar de escassos os estudos de filogenia de UPEC no 
Brasil, uma observação recorrente é que os filogrupos B2 e D possuem frequência semelhante nos casos de sepse. Essa proporção similar de B2 e D em casos de sepse não é observada em outros países (SANTOS et al., 2013). Estudos norteamericanos abordando cepas de $E$. coli isoladas de bacteremia mostram um predomínio de cepas B2 com frequência próxima a $65 \%$; enquanto que menos de $20 \%$ das cepas são do filogrupo D (MORENO et al., 2005; SANNES et al., 2004). Contraditoriamente aos estudos norte-americanos, mas consonante com nossos dados de predomínio do filogrupo $D$ em casos de sepse, um trabalho realizado na Espanha, mostrou que $52 \%$ das cepas de $E$. coli isoladas de sepse pertenciam ao filogrupo D; enquanto que cepas B2 perfaziam 18\% dos isolados (MARTíNEZ et al., 2006).

Tabela 13 - Distribuição dos filogropos em ITU e SU

\begin{tabular}{cccc}
\hline & $\begin{array}{c}\text { Infecção do trato } \\
\text { urinário } \\
(\mathbf{N}=\mathbf{3 2 4})\end{array}$ & $\begin{array}{c}\text { Sepse urinária } \\
\mathbf{( N = \mathbf { 2 5 } )}\end{array}$ & $\begin{array}{c}\text { Teste Exato de } \\
\text { Fisher (Sig.) }^{*}\end{array}$ \\
\hline Filogrupo A & $34[10,5 \%]$ & $0[0,0 \%]$ & 0,152 \\
Filogrupo B1 & $38[11,7 \%]$ & $0[0,0 \%]$ & 0,091 \\
\hline Filogrupo B2 & $148[45,7 \%]$ & $8[32,0 \%]$ & 0,214 \\
Filogrupo D & $104[32,1 \%]$ & $17[68,0 \%]$ & $\mathbf{0 , 0 0 2}$ \\
\hline
\end{tabular}

\subsubsection{DISTRIBUIÇÃO DE FATORES DE VIRULÊNCIA EM FILOGRUPOS DE E. COLI}

A análise da distribuição dos fatores de virulência entre os filogrupos revelou diferentes padrões em relação as linhagens comensais e extraintestinais (Tabela 14).

A maior parte dos fatores de virulência pesquisados (fyuA, pap, yfcV, cnf, sfa, pic e pilS) foi estatisticamente associado às cepas extraintestinais (B2+D) (Tabela 14). Especificamente sobre o filogrupo $B 2$, este grupo de cepas concentrou de forma estatisticamente significativa $(p=0,000)$ a ocorrência de 4 (yfcV, cnf, sfa e pic) dos 7 dos fatores associados às cepas extraintestinais. A concentração de marcadores de virulência de UPEC em filogrupos específicos é fato constantemente relatado na literatura e endossa a ideia de que cepas do filogrupo B2 são as mais 
potencialmente virulentas (LÓPEZ-BANDA et al., 2014). De forma diferente, o marcador focA foi estatisticamente associado a linhagens de cepas intestinais tendo sua ocorência concentrada no filogrupo $A(p=0,000)$.

Tabela 14 - Distribuição de fatores de virulência em filogrupos intestinais e extraintestinais de E. coli

\begin{tabular}{|c|c|c|c|c|c|c|c|}
\hline & \multicolumn{3}{|c|}{ Filogrupos Intestinais } & \multicolumn{3}{|c|}{ Filogrupos Extraintestinal } & \multirow{2}{*}{$\begin{array}{l}\text { Teste } \\
\text { Exato } \\
\text { de } \\
\text { Fisher } \\
\text { (Sig.) }\end{array}$} \\
\hline & $\begin{array}{c}A \\
(N=34)\end{array}$ & $\begin{array}{c}\mathrm{B} 1 \\
(\mathrm{~N}=38)\end{array}$ & $\begin{array}{c}A+B 1 \\
(N=72)\end{array}$ & $\begin{array}{c}\text { B2 } \\
(\mathrm{N}=156)\end{array}$ & $\begin{array}{c}D \\
(N=121)\end{array}$ & $\begin{array}{c}\mathrm{B} 2+\mathrm{D} \\
(\mathrm{N}=277)\end{array}$ & \\
\hline Gene & $\%$ & $\%$ & $\%$ & $\%$ & $\%$ & $\%$ & \\
\hline $\operatorname{csg} A$ & $91,2(31)$ & $81,6(31)$ & $86,1(62)$ & $82,1(128)$ & $95,0(115)$ & 87,7 (243) & 0,004 \\
\hline $\operatorname{chuA}$ & $0,0(0)$ & $0,0(0)$ & $0,0(0)$ & $100(156)$ & $100(121)$ & $100(277)$ & * \\
\hline fyuA & $38,2(13)$ & $13,2(5)$ & $25,0(18)$ & $92,9(145)$ & $81,8(99)$ & $88,0(244)$ & 0,000 \\
\hline pap & $17,6(6)$ & $7,9(3)$ & $12,5(9)$ & $54,5(85)$ & $60,3(73)$ & $57,0(158)$ & 0,000 \\
\hline$y f c V^{\mathbf{a}}$ & $8,8(3)$ & $0,0(0)$ & $4,1(3)$ & $69,9(109)$ & $24,0(29)$ & $49,8(138)$ & 0,000 \\
\hline vat & $55,9(19)$ & $7,9(3)$ & $30,5(22)$ & $64,1(100)$ & $12,4(15)$ & $41,5(115)$ & 0,000 \\
\hline$c n f^{a}$ & $0,0(0)$ & $0,0(0)$ & $0,0(0)$ & $44,9(70)$ & $2,5(3)$ & $26,3(73)$ & 0,000 \\
\hline foc $A^{\mathbf{b}}$ & $61,8(21)$ & $39,5(15)$ & $50,0(36)$ & $16,0(25)$ & $9,1(11)$ & $12,9(36)$ & 0,000 \\
\hline$s f a^{\mathbf{a}}$ & $0,0(0)$ & $0,0(0)$ & $0,0(0)$ & $30,8(48)$ & 2,5 (3) & $18,4(51)$ & 0,000 \\
\hline $\operatorname{ag} 43$ & $17,6(6)$ & $7,9(3)$ & 12,5 (9) & $9,6(15)$ & $14,9(18)$ & 11,9 (33) & 0,330 \\
\hline$p i c^{a}$ & $0,0(0)$ & $0,0(0)$ & $0,0(0)$ & $12,8(20)$ & $1,7(2)$ & $7,9(22)$ & 0,000 \\
\hline pils & $0,0(0)$ & $0,0(0)$ & $0,0(0)$ & $7,7(12)$ & $5,8(7)$ & $6,8(19)$ & 0,141 \\
\hline aat $A$ & $8,8(3)$ & $0,0(0)$ & $4,1(3)$ & $0,0(0)$ & $4,1(5)$ & $1,8(5)$ & 0,003 \\
\hline $\operatorname{agg} R$ & $8,8(3)$ & $0,0(0)$ & $4,1(3)$ & $0,0(0)$ & $4,1(5)$ & $1,8(5)$ & 0,003 \\
\hline
\end{tabular}

\subsubsection{GENÓTIPOS ASSOCIADOS A SEPSE URINÁRIA DE FILOGRUPOS VINCULADOS}

A análise de perfis moleculares realizada até agora mostrou dois achados aparentemente paradoxais. A associação estatística do filogrupo $D$ com casos de SU (Tabela 13), ao mesmo tempo que mostra cepas do filogrupo B2 apresentando o maior potencial de virulência ao concentrarem a maior quantidade de genes de virulência (Tabela 14). Dado estes resultados, analisamos em paralelo a distribuição de genótipos (compostos pela combinação de 3 genes) no grupo de ITU e SU 
juntamente com a distribuição em filogrupos (Tabela 15). Dos genótipos testados ( $\mathrm{n}$ =11), três foram estatisticamente associados aos casos de SU: fyuA-pap-csgA; pap$\operatorname{csg} A$-ag43 e fyuA-csgA-ag43. A análise mostrou que um destes genótipos era prevalente em cepas de filogrupo $D$ (fyuA-pap-csgA) e que outro era estatisticamente associado ao filogrupo $D$ (pap-csgA-ag43). Para o terceiro genótipo associado a casos de SU (fyuA-csgA-ag43), a análise mostrou distribuição equânime entre os filogrupos A, B1, B2 e D. Como contraponto, é importante notar que três genótipos foram estatisticamente associados ao filogrupo B2 mas sem demonstrar associação estatítica com casos de SU (Tabela 15). Como conclusão dessa análise, verificamos que a associação do filogrupo $D$ com casos de SU está vinculada a ocorrência de combinações genéticas específicas e não ao acúmulo de genes

virulência. 
Tabela 15 - Distribuição de genótipos em função da gravidade da infecção (ITU vs. SU) e dos filogrupos detectados

\begin{tabular}{|c|c|c|c|c|c|c|c|c|}
\hline \multirow[b]{2}{*}{ GENÓTIPOS b } & \multicolumn{2}{|c|}{ INFECCCÃO $^{a}$} & \multirow[b]{2}{*}{$\begin{array}{l}\text { Teste Exato } \\
\text { de Fisher } \\
\text { (Sig.) }\end{array}$} & \multirow[b]{2}{*}{$A(N=34)$} & \multicolumn{2}{|c|}{ FILOGRUPOS $^{a}$} & \multirow[b]{2}{*}{$D(N=121)$} & \multirow[b]{2}{*}{$\begin{array}{l}\text { Teste Exato } \\
\text { de Fisher } \\
\text { (Sig.) }\end{array}$} \\
\hline & ITU (N=324) & $S U(N=25)$ & & & $B 1(N=38)$ & $B 2(N=156)$ & & \\
\hline fyuA-pap-csgA & $39,2 \%$ (127) & $64,0 \%(16)$ & 0,020 & $8,8 \%(3)$ & $0 \%(0)$ & $44,9 \%(70)$ & $57,9 \%(70)$ & 0,000 \\
\hline pap-csgA-ag43 ${ }^{c}$ & $7,4 \%(24)$ & $36,0 \%(9)$ & 0,000 & $8,8 \%(3)$ & $0 \%(0)$ & $7,7 \%(12)$ & $14,9 \%(18)$ & 0,023 \\
\hline fyuA-csgA-ag43 & 10,2\% (33) & $36,0 \%(9)$ & 0.001 & $17,6 \%(6)$ & $7,9 \%(3)$ & $9,6 \%(15)$ & $14,9 \%(18)$ & 0,330 \\
\hline fyuA-pap-cnf & $16,7 \%(54)$ & $24,0(6)$ & 0,406 & $0 \%(0)$ & $0 \%(0)$ & $36,5 \%(57)$ & $2,5 \%(3)$ & 0,000 \\
\hline vat-focA-csgA & $12,3 \%(40)$ & $0 \%(0)$ & 0,095 & $44,1 \%(15)$ & $0 \%(0)$ & $14,1 \%(22)$ & $2,5 \%(3)$ & 0,000 \\
\hline fyuA-vat-focA & $10,5 \%(34)$ & $0 \%(0)$ & 0,152 & $17,6 \%(6)$ & $0 \%(0)$ & $16,0 \%(25)$ & $2,5 \%(3)$ & 0,000 \\
\hline vat-csgA-ag43 & $7,4 \%(24)$ & $0 \%(0)$ & 0,239 & $8,8 \%(3)$ & $0 \%(0)$ & $9,6 \%(15)$ & $5,0 \%(6)$ & 0,109 \\
\hline pap-vat-ag43 & $6,5 \%(21)$ & $0 \%(0)$ & 0,383 & $8,8 \%(3)$ & $0 \%(0)$ & $7,7 \%(12)$ & $5,0 \%(6)$ & 0,235 \\
\hline pap-csgA-vat & $21,3 \%(69)$ & $16,0 \%(4)$ & 0,370 & $8,8 \%(3)$ & $0 \%(0)$ & $39,7(62)$ & $6,6 \%(8)$ & 0,000 \\
\hline fyuA-cnf-csgA & $18,5 \%(60)$ & $24,0 \%(6)$ & 0,595 & $0 \%(0)$ & $0 \%(0)$ & $40,4 \%(63)$ & $2,5 \%(3)$ & 0,000 \\
\hline cnf-csgA-ag43 & $3,7 \%(12)$ & $12,0 \%(3)$ & 0,083 & $0 \%(0)$ & $0 \%(0)$ & $7,7 \%(12)$ & $2,5 \%(3)$ & 0,060 \\
\hline
\end{tabular}

a- Células com preenchimento sólido marcam frequências com distribuição desigual entre os tipos de infecção (ITU vs. SU) ou entre filogrupos ( $p<$ $0,05)$.

b-Genótipos em negrito foram estatisticamente associados a casos de sepse urinária (SU).

c- Genótipo estatisticamente associado a casos de SU e ao filogrupo D. 


\subsubsection{GENÓTIPOS DETECTADOS EM FILOGRUPOS INTESTINAIS E}

EXTRAINTESTINAIS

A distribuição de genótipos mostrou uma considerável diversidade de tipos com 66 diferentes genótipos detectados em 350 cepas analisadas. Em relação a distribuição de genótipos por filogrupos, cepas de filogrupos extraintestinais (B2 e D) apresentaram a maior diversidade de genótipos e concentraram 51 (77,2\%) genótipos diferentes.

Adicionalmente, genótipos híbridos EAEC/UPEC foram detectados em 9 cepas analisadas para filogrupo. Dois dos genótipos híbridos foram detectados em cepas do filogrupo D (fyuA-chuA-pap-csgA-ag43-aatA-aggR; fyuA-chuA-pap-csgA aatA-aggR) e o outro genótipo híbrido (fyuA-vat-focA-pap-csgA-ag43-aatA-aggR) em cepas do filogrupo A (Tabela 16). 
Tabela 16 - Perfil de genótipos detectados em 350 cepas de UPEC analisadas para filogrupo

\begin{tabular}{|c|c|c|c|c|}
\hline \multirow[t]{2}{*}{ Genótipos ( $N=66$ ) } & \multicolumn{2}{|c|}{$\begin{array}{l}\text { Filogrupos } \\
\text { intestinais }\end{array}$} & \multicolumn{2}{|c|}{$\begin{array}{c}\text { Filogrupos } \\
\text { extraintestinais }\end{array}$} \\
\hline & $A(N=34)$ & $\mathrm{B1}(\mathrm{N}=38)$ & $B 2(N=156)$ & $D(N=122)$ \\
\hline fyuA chuA csgA & $0,0 \%(0)$ & $0,0 \%(0)$ & $9,0 \%(14)$ & $16,5 \%(20)$ \\
\hline fуuA сhuA pap csgA & $0,0 \%(0)$ & $0,0 \%(0)$ & $1,3 \%(2)$ & $15,7 \%(19)$ \\
\hline fyuA yfcV chuA pap csgA & $0,0 \%(0)$ & $0,0 \%(0)$ & $0,0 \%(0)$ & $15,7 \%(19)$ \\
\hline $\operatorname{chu} A \operatorname{csg} A$ & $0,0 \%(0)$ & $0,0 \%(0)$ & $3,2 \%(5)$ & $8,3 \%(10)$ \\
\hline fyuA yfcV chuA vat pap csgA & $0,0 \%(0)$ & $0,0 \%(0)$ & $9,0 \%(14)$ & $0,0 \%(0)$ \\
\hline fyuA yfc $\vee \operatorname{chu} A \operatorname{csg} A$ & $0,0 \%(0)$ & $0,0 \%(0)$ & $5,8 \%(9)$ & $2,5 \%(3)$ \\
\hline fyuA yfcV chuA vat csgA & $0,0 \%(0)$ & $0,0 \%(0)$ & $7,1 \%(11)$ & $0,0 \%(0)$ \\
\hline fyuA yfc $V$ chuA vat pap sfa cnf csgA & $0,0 \%(0)$ & $0,0 \%(0)$ & $5,8 \%(9)$ & $0,0 \%(0)$ \\
\hline fyuA chuA focA pap csgA & $0,0 \%(0)$ & $0,0 \%(0)$ & $0,0 \%(0)$ & $5,0 \%(6)$ \\
\hline fyuA yfc $V$ chuA vat focA pap sfa cnf csgA & $0,0 \%(0)$ & $0,0 \%(0)$ & $4,5 \%(7)$ & $0,0 \%(0)$ \\
\hline fyuA chuA pap & $0,0 \%(0)$ & $0,0 \%(0)$ & $3,8 \%(6)$ & $0,0 \%(0)$ \\
\hline fуuA chuA pap cnf csgA & $0,0 \%(0)$ & $0,0 \%(0)$ & $3,8 \%(6)$ & $0,0 \%(0)$ \\
\hline fyu $A$ yfc $V$ chuA vat sfa cnf $\operatorname{csg} A$ & $0,0 \%(0)$ & $0,0 \%(0)$ & $3,8 \%(6)$ & $0,0 \%(0)$ \\
\hline fуuA chuA pap csgA ag43 pils & $0,0 \%(0)$ & $0,0 \%(0)$ & $0,0 \%(0)$ & $3,3 \%(4)$ \\
\hline fyuA yfc $V$ chuA vat pap cnf $\operatorname{csg} A$ & $0,0 \%(0)$ & $0,0 \%(0)$ & $3,2 \%(5)$ & $0,0 \%(0)$ \\
\hline fуuA chuA & $0,0 \%(0)$ & $0,0 \%(0)$ & $2,6 \%(4)$ & $0,0 \%(0)$ \\
\hline fyuA yfcV chuA pap cnf csgA & $0,0 \%(0)$ & $0,0 \%(0)$ & $2,6 \%(4)$ & $0,0 \%(0)$ \\
\hline chuA & $0,0 \%(0)$ & $0,0 \%(0)$ & $0,0 \%(0)$ & $2,5 \%(3)$ \\
\hline fuyA chuA vat focA $\operatorname{csg} A$ & $0,0 \%(0)$ & $0,0 \%(0)$ & $0,0 \%(0)$ & $2,5 \%(3)$ \\
\hline fyuA chuA pap csgA ag43 & $0,0 \%(0)$ & $0,0 \%(0)$ & $0,0 \%(0)$ & $2,5 \%(3)$ \\
\hline fyuA chuA pap csgA ag43 aatA aggR & $0,0 \%(0)$ & $0,0 \%(0)$ & $0,0 \%(0)$ & $2,5 \%(3)$ \\
\hline fyuA chuA pap csgA pils & $0,0 \%(0)$ & $0,0 \%(0)$ & $0,0 \%(0)$ & $2,5 \%(3)$ \\
\hline fyuA chuA pap sfa cnf csgA ag43 & $0,0 \%(0)$ & $0,0 \%(0)$ & $0,0 \%(0)$ & $2,5 \%(3)$ \\
\hline fyuA chuA vat $\operatorname{csg} A$ & $0,0 \%(0)$ & $0,0 \%(0)$ & $0,0 \%(0)$ & $2,5 \%(3)$ \\
\hline fyuA chuA vat pap csgA ag43 & $0,0 \%(0)$ & $0,0 \%(0)$ & $0,0 \%(0)$ & $2,5 \%(3)$ \\
\hline yuA yfcV chuA pap csgA ag43 & $0,0 \%(0)$ & $0,0 \%(0)$ & $0,0 \%(0)$ & $2,5 \%(3)$ \\
\hline$y f c V \operatorname{chu} A \operatorname{csg} A$ & $0,0 \%(0)$ & $0,0 \%(0)$ & $0,0 \%(0)$ & $2,5 \%(3)$ \\
\hline yfcV chuA pap csgA & $0,0 \%(0)$ & $0,0 \%(0)$ & $0,0 \%(0)$ & $2,5 \%(3)$ \\
\hline$y f c V \operatorname{chu} A$ vat $\operatorname{csg} A$ & $0,0 \%(0)$ & $0,0 \%(0)$ & $1,3 \%(2)$ & $0,8 \%(1)$ \\
\hline fyuA chuA vat & $0,0 \%(0)$ & $0,0 \%(0)$ & $1,9 \%(3)$ & $0,0 \%(0)$ \\
\hline fyuA chuA vat pap sfa cnf csgA & $0,0 \%(0)$ & $0,0 \%(0)$ & $1,9 \%(3)$ & $0,0 \%(0)$ \\
\hline fyuA yfc $V$ chuA & $0,0 \%(0)$ & $0,0 \%(0)$ & $1,9 \%(3)$ & $0,0 \%(0)$ \\
\hline fyuA yfc $V$ chuA vat $\operatorname{csg} A$ pic & $0,0 \%(0)$ & $0,0 \%(0)$ & $1,9 \%(3)$ & $0,0 \%(0)$ \\
\hline fyuA yfcV chuA vat focA pap csgA ag43 pils & $0,0 \%(0)$ & $0,0 \%(0)$ & $1,9 \%(3)$ & $0,0 \%(0)$ \\
\hline fyuA yfcV chuA vat focA pap sfa cnf csgA ag43 pilS & $0,0 \%(0)$ & $0,0 \%(0)$ & $1,9 \%(3)$ & $0,0 \%(0)$ \\
\hline fyuA yfc $V$ chuA vat focA pap sfa cnf csgA pic & $0,0 \%(0)$ & $0,0 \%(0)$ & $1,9 \%(3)$ & $0,0 \%(0)$ \\
\hline fyuA yfcV chuA vat focA pap sfa cnf csgA pic pilS & $0,0 \%(0)$ & $0,0 \%(0)$ & $1,9 \%(3)$ & $0,0 \%(0)$ \\
\hline fyuA yfcV chuA vat focA pap sfa cnf pic & $0,0 \%(0)$ & $0,0 \%(0)$ & $1,9 \%(3)$ & $0,0 \%(0)$ \\
\hline
\end{tabular}




\begin{tabular}{|l|l|l|l|l|}
\hline fyuA yfcV chuA vat focA sfa csgA pic & $0,0 \%(0)$ & $0,0 \%(0)$ & $1,9 \%(3)$ & $0,0 \%(0)$ \\
\hline fyuA yfcV chuA vat pap cnf csgA ag43 & $0,0 \%(0)$ & $0,0 \%(0)$ & $1,9 \%(3)$ & $0,0 \%(0)$ \\
\hline fyuA yfcV chuA vat pap cnf csgA ag43 pilS & $0,0 \%(0)$ & $0,0 \%(0)$ & $1,9 \%(3)$ & $0,0 \%(0)$ \\
\hline fyuA yfcV chuA vat sfa cnf csgA ag43 & $0,0 \%(0)$ & $0,0 \%(0)$ & $1,9 \%(3)$ & $0,0 \%(0)$ \\
\hline fyuA yfcV chuA vat sfa cnf csgA pic & $0,0 \%(0)$ & $0,0 \%(0)$ & $1,9 \%(3)$ & $0,0 \%(0)$ \\
\hline yfcV chuA vat pap csgA & $0,0 \%(0)$ & $0,0 \%(0)$ & $1,9 \%(3)$ & $0,0 \%(0)$ \\
\hline chuA focA csgA & $0,0 \%(0)$ & $0,0 \%(0)$ & $0,0 \%(0)$ & $1,7 \%(2)$ \\
\hline fyuA chuA pap csgA aatA aggR & $0,0 \%(0)$ & $0,0 \%(0)$ & $0,0 \%(0)$ & $2,5 \%(3)$ \\
\hline fyuA chuA vat pap csgA pic & $0,0 \%(0)$ & $0,0 \%(0)$ & $0,0 \%(0)$ & $1,7 \%(2)$ \\
\hline fyuA yfcV chuA vat pap cnf csgA pic & $0,0 \%(0)$ & $0,0 \%(0)$ & $1,3 \%(2)$ & $0,0 \%(0)$ \\
\hline fyuA yfcV chuA vat pap sfa csgA & $0,0 \%(0)$ & $0,0 \%(0)$ & $1,3 \%(2)$ & $0,0 \%(0)$ \\
\hline yfcV fyuA chuA & $0,0 \%(0)$ & $0,0 \%(0)$ & $1,3 \%(2)$ & $0,0 \%(0)$ \\
\hline yfcV chuA vat pap cnf & $0,0 \%(0)$ & $0,0 \%(0)$ & $0,6 \%(1)$ & $0,0 \%(0)$ \\
\hline csgA & $17,6 \%(6)$ & $31,6 \%(12)$ & $0,0 \%(0)$ & $0,0 \%(0)$ \\
\hline focA cgsA & $0,0 \%(0)$ & $23,7 \%(9)$ & $0,0 \%(0)$ & $0,0 \%(0)$ \\
\hline vat focA csgA & $17,6 \%(6)$ & $0,0 \%(0)$ & $0,0 \%(0)$ & $0,0 \%(0)$ \\
\hline focA & $8,8 \%(3)$ & $7,9 \%(3)$ & $0,0 \%(0)$ & $0,0 \%(0)$ \\
\hline pap csgA & $8,8 \%(3)$ & $7,9 \%(3)$ & $0,0 \%(0)$ & $0,0 \%(0)$ \\
\hline fyuA focA cnf csgA ag43 & $8,8 \%(3)$ & $0,0 \%(0)$ & $0,0 \%(0)$ & $0,0 \%(0)$ \\
\hline fyuA vat csgA & $8,8 \%(3)$ & $0,0 \%(0)$ & $0,0 \%(0)$ & $0,0 \%(0)$ \\
\hline fyuA vat focA csgA & $8,8 \%(3)$ & $0,0 \%(0)$ & $0,0 \%(0)$ & $0,0 \%(0)$ \\
\hline fyuA vat focA pap csgA ag43 aatA aggR & $8,8 \%(3)$ & $0,0 \%(0)$ & $0,0 \%(0)$ & $0,0 \%(0)$ \\
\hline yfcV vat focA csgA & $8,8 \%(3)$ & $0,0 \%(0)$ & $0,0 \%(0)$ & $0,0 \%(0)$ \\
\hline focA csgA & $0,0 \%(0)$ & $7,9 \%(3)$ & $0,0 \%(0)$ & $0,0 \%(0)$ \\
\hline fyuA csgA ag43 & $0,0 \%(0)$ & $7,9 \%(3)$ & $0,0 \%(0)$ & $0,0 \%(0)$ \\
\hline vat csgA & $0,0 \%(0)$ & $7,9 \%(3)$ & $0,0 \%(0)$ & $0,0 \%(0)$ \\
\hline fyuA csgA & $0,0 \%(0)$ & $5,3 \%(2)$ & $0,0 \%(0)$ & $0,0 \%(0)$ \\
\hline fyuA yfcV vat csgA & $2,9 \%(1)$ & $0,0 \%(0)$ & $0,0 \%(0)$ & $0,0 \%(0)$ \\
\hline
\end{tabular}

\subsection{CARACTERIZAÇÃO FILOGENÉTICA DE CEPAS PORTANDO GENÓTIPO HÍBRIDO EAEC/UPEC}

A fim de estudar a relação filogenética entre as cepas de genótipo híbrido e as demais cepas da nossa coleção, foi conduzido um estudo complementar. Para tanto, foram selecionadas 86 cepas da nossa coleção ( 3 de genótipos híbridos e 83 outros genótipos selecionados ao acaso) para retestar os marcadores de EAEC (aat $A$ e aggR). Nesta análise também incluímos o marcador aapA (dispersina).

As cepas com genótipo híbrido EAEC/UPEC foram recuperadas de dois casos de ITU (casos 63 e 85) e de um caso de sepse urinária (caso 17). Três cepas 
foram classificadas como filogrupo A (associadas ao caso ITU 63) e as seis cepas restantes foram classificadas como filogrupo D (associadas ao caso ITU 85 e ao caso SU 17) (Tabela 17). Os genes das fímbrias de EAEC também foram detectados nas estirpes EAEC/UPEC. Além desses dados, um fato interessante foi que em três cepas recuperadas de um caso de ITU (caso 55) foram positivas para o gene de dispersina (aapA), embora não tenham nenhum dos preditores EAEC (aatA e aggR).

EAEC é uma categoria heterogênea que tem sido reconhecida pela reunião de cepas versáteis desde o final da década de 1990, quando sua associação epidemiológica com diarréia envolvendo crianças, adultos, pacientes infectados com HIV e viajantes tornou-se cada vez mais evidente (HUANG et al., 2006). Além disso, as cepas de EAEC têm sido recentemente relatadas como um agente etiológico esporádico de infecções extraintestinais, principalmente em infecções do trato urinário (ITU). No Brasil, um estudo epidemiológico prévio sobre a ITU mostrou que $3,5 \%$ (8/225) das cepas foram classificadas como EAEC com base na presença do marcador de virulência aatA (ABE et al., 2008). Além de outros marcadores clássicos de UPEC, 5 de 8 cepas aatA positivas também carregavam pap (pilus associado a pielonefrite) e aggA (fímbria de adesão agregativa I - AAF/l) (ABE et al., 2008). Este cenário epidemiológico é semelhante ao encontrado em nosso estudo.

Tabela 17 - Cepas isoladas de infecções extraintestinais albergam marcadores de EAEC

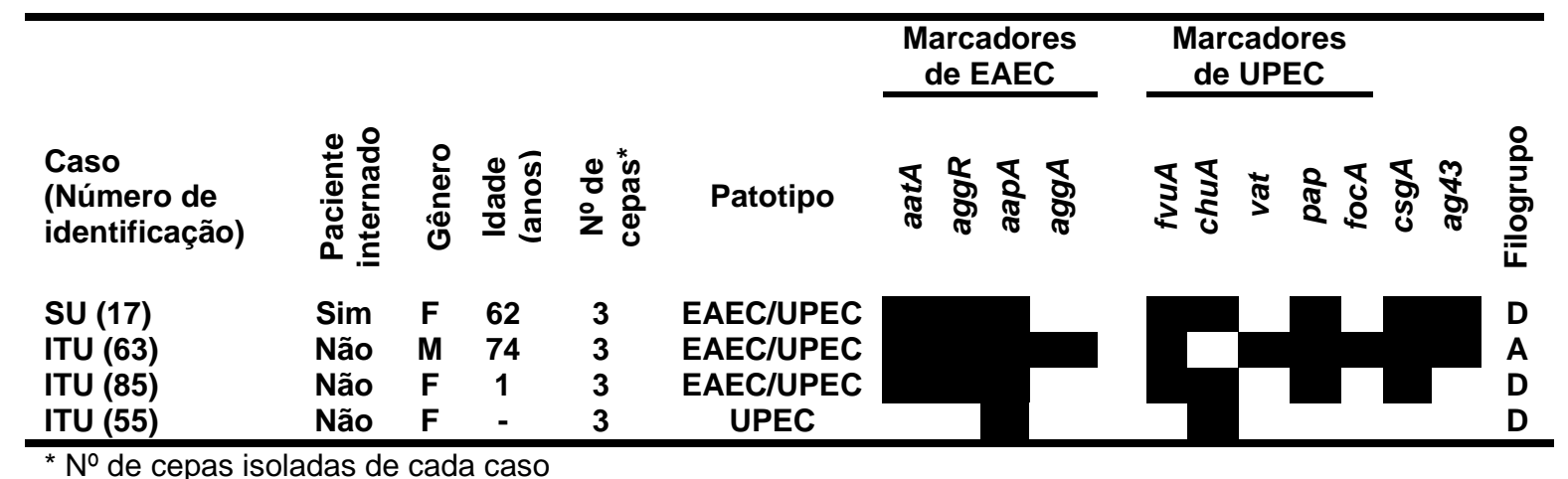

Três cepas híbridas de EAEC/UPEC (um isolado de cada caso) tiveram seus perfis alélicos e STs (protocolo Pasteur) determinados e comparados com os de outras 19 cepas de UPEC típicas (cada cepa de um caso diferente escolhido aleatoriamente) (Tabela 18). Os equivalente do ST de Warwick foram determinados seguindo a equivalência relatada em estudo (DENAMUR; CLERMONT; GORDON, 2015). Foram detectados 12 perfis alélicos entre as 22 cepas analisadas. O perfil 
alélico predominante correspondeu ao ST3 (Warwick ST69) $(n=8)$ e foi seguido pelo ST43 $(n=3)$ (Warwick ST 131). Cinco STs foram detectados uma única vez (ST8, ST34, ST44, ST478 e ST479); e dois STs eram variantes de um único locus do ST43 e ST4 (Warwick ST73) (Tabela 18). Em relação as cepas híbridas EAEC/UPEC, duas cepas (17.1 e 85.1) foram classificados como ST3 (Warwick ST69), enquanto que a cepa 63.1 classificada como ST478. Estes achados revelam a heterogeneidade de nossa coleção e mostram que um considerável subconjunto de cepas $(n=11)$ pertencem a linhagens genéticas reconhecidas pelo potencial epidêmico (ST3 e ST43), incluindo duas das cepas híbridas EAEC/UPEC.

A relação filogenética dos híbridos EAEC/UPEC com cepas típicas UPEC, com a cepa protótipo 042, e com sequências genômicas de referência foram visualizadas em um dendrograma construído com base no alinhamento de sequências genéticas concatenadas (dinB-icdA-pabB-polB-putP-trpA) (Figura 7). Genótipos, filogrupos e STs também foram inseridos no dendrograma no intuito de destacar características compartilhadas entre as cepas. Duas das três cepas EAEC/UPEC testadas compartilharam com cepas de UPEC um clado bem definido (valor de bootstrap igual a 94), que foi caracterizado por agrupar cepas portando preditores de UPEC (fyuA e chuA) e também da fimbria específica de UPEC Pap (Figura 7). Adicionalmente, as cepas neste clado foram classificadas como filogrupo D e ST3 (Warwick ST 69). Fora do clado D-ST3, as cepas mostraram uma positividade reduzida para pap $(40 \%$ - 6/15). Um posicionamento diferente foi demonstrado para a terceira cepa EAEC/UPEC (cepa 63.1), que foi alocada em um ramo diferente compartilhando um clado com a sequência genômica de referência da cepa comensal K12. O fato de que ambas as cepas pertencem ao filogrupo A endossa esse a proximidade filogenética (Figura 7).

Estudos sobre a distribuição de genes plasmidiais e cromossômicos de EAEC propuseram que algumas cepas não pertencentes a linhagens típicas de EAEC possam adquirir e manter o plasmídeo $p A A$, o principal elemento de virulência em cepas de EAEC (JENKINS et al., 2005). Assim, o grupo 2 de EAEC, definido por Jenkins et al., compreende um grupo mais heterogêneo de cepas de EAEC que emerge da aquisição de pAA por cepas que não retêm marcadores cromossomais de cepas típicas de EAEC (JENKINS et al., 2005). Para explicar o surgimento de 
cepas híbridas de EAEC/UPEC, alguns autores tem fomentado discussões similares (OLESEN et al., 2012). Neste estudo, nós mostramos que diferentes alternativas para emergência de cepas híbridas EAEC/UPEC isoladas de infeção humana podem existir. Baseado em análises filogenéticas realizadas com sequências cromossomais, foi definido que duas das cepas híbridas EAEC/UPEC compartilham a linhagem cromossômica de cepas de UPEC. Consequentemente, esta constatação sugere que os marcadores genéticos de EAEC posicionados no plasmídeo pAA (aatA, aggR e aapA) podem ser adquiridos por cepas de UPEC. No que se refere às cepas 17.1 e 85.1 de EAEC/UPEC (ambas classificadas como filogrupo D-ST3 [ST69]), nossos resultados estão em conflito com o paradigma estabelecido na literatura que sugere que os marcadores de virulência de patotipos diarreicos raramente são detectados em cepas de UPEC do grupo filogenético DST3 [ST69] (BLANCO et al., 2011). No entanto, um estudo de Wallace-Gadsden endossa nossos resultados, mostrando que o complexo ST69 tem propensão para adquirir genes de virulência de EAEC e, assim, pode ter evoluído como uma linhagem progenitora a partir da qual emergiram cepas de UPEC e EAEC pertencentes ao grupo ST69 (WALLACE-GADSDEN et al., 2007).

Por outro lado, linhagens de $E$. coli que frequentemente reúnem cepas comensais (filogrupos A e B1) também podem incluir cepas de UPEC altamente virulentas. A cepa híbrida EAEC/UPEC 63.1, caracterizada por possuir o conjunto mais completo de genes de virulência testados para EAEC (aat $A$, aggR, aapA e aggA) e UPEC (fyuA, vat, focA e pap), além de ser positiva para $\operatorname{csg} A$ e ag43, foi classificada como filogrupo A. Cepas de E. coli com arranjos genéticos semelhantes já foram associados com surtos de ITU. Em 1991, foi detectado em Copenhague um surto de ITU envolvendo uma cepa híbrida EAEC/UPEC (OLESEN et al., 2012). A caracterização molecular adicional mostrou que 18 das 19 cepas do surto foram positivas para os genes específicos de EAEC aatA, agg $R$, aagA e aapA juntamente com os genes de UPEC sat e fyuA. Posteriormente, análises filogenéticas mostraram que as cepas EAEC/UPEC do surto pertenciam ao filogrupo $A$, que é conhecido por reunir linhagens comensais (OLESEN et al., 2012).

Para avaliar se os genótipos híbridos possuem melhor capacidade de formar biofilmes, testou-se a aderência à superfície abiótica (em placas de cultura de 96 
poços) de cepas EAEC/UPEC e comparou-se com a aderência de 77 cepas UPEC (Figura 8). Em geral, a formação de biofilmes foi maior no DMEM (mediana $=0,536$ com terceiro quartil [Q3] $=0,853$ ) do que em urina humana (mediana $=0,391$ com T3 $=0,475)(p<0,001$ - teste de Kruskal-Wallis). As cepas híbridas EAEC/UPEC formaram biofilmes a níveis modestos, mas perceptíveis tanto no DMEM (mediana = 0,535 com Q3 = 0,731) quanto em urina (mediana =0,270 com Q3 =0,411). Apenas seis cepas demonstraram uma capacidade invariável para formar biofilme independente das condições testadas (DMEM ou urina humana), incluindo a cepa híbrida EAEC/UPEC 63.1 (média de 0,535 —0,76 em DMEM e 0,553 — 0,026 em urina) (Figura 8). Quando comparadas as cepas híbridas 17.1 (genótipo: aatA-aggR aapA-fyuA-chuA-pap-csgA-ag43) e 85.1 (genótipo: aatA-aggR-aapA-fyuA-chuA-pap$\operatorname{csg} A$ ), a cepa EAEC/UPEC 63.1 (genótipo: aatA-aggR-aggA-aapA-fyuA-vat-focA pap-csgA-ag43) distingue das outras por albergar a especificamente as fímbrias AAF/l $(\operatorname{agg} A)$ e FocA. Em comparação com as cepas protótipos 17-2 (também positivo para AAF/ I) e 042 (positivo para AAF/II), a estirpe 63.1 formou biofilmes em níveis semelhantes quando testados na urina humana (Figura 8).

A formação de biofilme é considerada um passo fundamental durante os processos de infecção bacteriana desenvolvidos nas mucosas humanas. As cepas de EAEC são conhecidas pela sua alta capacidade de formar biofilme, essa habilidade é geralmente mediada por fímbrias de adesão agregativa codificadas no plasmídeo pAA. Casos e surtos de ITU envolvendo cepas heteropatogênicas de EAEC/UPEC endossam suspeitas de que genes de virulência de EAEC possuam também propriedades uropatogênicas (OLESEN et al., 2012). No que diz respeito às cepas de EAEC/UPEC envolvidas no surto de ITU em Copenhague (genótipo: aatAaggR-aapA-aggA-fyuA-pic), foi mostrado que a expressão de AAF/l (aggA) permitiu um aumento significativo da aderência bacteriana às células epiteliais de bexiga humana. Além do mais, AAF/I permitiu a formação de biofilmes a níveis significativamente superiores quando comparadas as cepas protótipo da UPEC (BOLL et al., 2013). No nosso estudo, a cepa AAF/I positiva EAEC/UPEC 63.1 (genótipo: aatA-aggR-aggA-aapA-fyuA-vat-focA-pap-csgA-ag43; filogrupo A) mostrou capacidade de produzir biofilmes perceptíveis e invariavelmente em DMEM e urina humana. Embora os níveis de biofilme não tenham sido superiores aos produzidos pela cepa protótipo de EAEC 17-2 em DMEM, a cepa EAEC/UPEC 63.1 
quando testada em urina formou biofilmes em níveis mais elevados aos formados pela cepa EAEC 17-2 e em níveis semelhantes àqueles da cepa protótipo de UPEC FVL-2.

Se as cepas híbridas de EAEC/UPEC têm ou não potencial para causar diarréia é um problema a ser avaliado. No entanto, estudos baseados na extensa caracterização genética de cepas típicas de EAEC mostraram que padrões filogenéticos semelhantes aos detectados aqui também são encontrados em cepas de EAEC associadas à diarréia. Cepas de EAEC filogrupo $D$ e o genótipo aatAaggR-aapA-fyuA-chuA foram recuperadas da diarreia e incluindo a cepa protótipo 042 (CZECZULIN et al., 1999; OKEKE et al., 2010). Além disso, cepas EAEC filogrupo $\mathrm{A}$ e genótipo aatA-aggR-aapA-fyuA também foram recuperadas de casos de diarreia (CZECZULIN et al., 1999; OKEKE et al., 2010) incluindo a cepa C119292 recuperada de um caso de diarreia e ITU simultaneamente ocorrido em Copenhague em 1991 (OLESEN et al., 2012).

E. coli tem uma notável capacidade de adaptação que se baseia principalmente na sua plasticidade genômica (TOUCHON et al., 2009). Tendo um pan-genoma com cerca de 17.000 genes e em média 4.700 genes por genoma, uma única cepa de $E$. coli não pode ser considerada representante da espécie. Nesse cenário, a aplicação em estudos epidemiológicos de parâmetros genéticos que espelham arquétipos de $E$. coli tem se mostrado elusivo. Eventos envolvendo cepas híbridas ou heteropatogênicas de $E$. coli respaldam esta perspectiva e obscurecem a classificação de cepas de E. coli em patotipos clássicos. 
Tabela 18 - Perfil alélico, tipo de sequência (ST) e genótipo associados a cepas de UPEC

\begin{tabular}{|c|c|c|c|c|c|c|c|c|c|c|c|c|}
\hline \multirow{3}{*}{ Cepa } & \multirow{3}{*}{ Patotipo } & \multicolumn{10}{|c|}{ Perfil alélico - Instituto Pasteur } & \multirow{3}{*}{$\begin{array}{c}\begin{array}{c}\text { Equivalente } \\
\text { Warwick }^{\mathrm{a}}\end{array} \\
\text { ST }\end{array}$} \\
\hline & & Amostra & & & & & & & & & ST & \\
\hline & & & $\stackrel{\mathscr{D}}{\mathbf{s}}$ & ఫ্ర & $\begin{array}{l}\frac{1}{0} \\
\frac{1}{\pi} \\
2\end{array}$ & $\stackrel{\mathfrak{c}}{\mathrm{O}}$ & $\frac{Q}{5}$ & క & $\stackrel{\infty}{2}$ & $\frac{\pi}{3}$ & & \\
\hline 17.1 & EAEC/UPEC & Sangue & 3 & 8 & 5 & 11 & 8 & 3 & 5 & 3 & 3 & 69 \\
\hline 85.1 & EAEC/UPEC & Urina & 3 & 8 & 5 & 11 & 8 & 3 & 5 & 3 & 3 & 69 \\
\hline 9.1 & UPEC & Urina & 3 & 9 & 5 & 11 & 8 & 3 & 5 & 3 & 3 & 69 \\
\hline 16.1 & UPEC & Urina & 3 & 8 & 5 & 11 & 8 & 3 & 5 & 3 & 3 & 69 \\
\hline 19.1 & UPEC & Urina & 3 & 8 & 5 & 11 & 8 & 3 & 5 & 3 & 3 & 69 \\
\hline 28.1 & UPEC & Urina & 3 & 8 & 5 & 11 & 8 & 3 & 5 & 3 & 3 & 69 \\
\hline 38.1 & UPEC & Urina & 3 & 8 & 5 & 11 & 8 & 3 & 5 & 3 & 3 & 69 \\
\hline 76.1 & UPEC & Urina & 3 & 8 & 5 & 11 & 8 & 3 & 9 & $N^{b}$ & 3 & 69 \\
\hline 12.1 & UPEC & Urina & 9 & 1 & 15 & 7 & 4 & 9 & 6 & 9 & 43 & 131 \\
\hline 8.1 & UPEC & Urina & 9 & 1 & 15 & 7 & 4 & 9 & 145 & 9 & SLV $^{d} 43$ & 131 \\
\hline 21.1 & UPEC & Urina & 9 & 1 & 15 & 7 & 4 & 9 & 6 & 9 & 43 & 131 \\
\hline 58.1 & UPEC & Urina & 9 & 1 & 15 & 7 & 4 & 9 & 6 & 9 & 43 & 131 \\
\hline 81.1 & UPEC & Urina & 2 & 4 & 6 & 4 & 1 & 6 & 1 & 25 & SLVd4 & 73 \\
\hline 63.1 & EAEC/UPEC & Urina & 8 & 2 & 7 & 84 & 7 & 1 & $N D^{b}$ & 2 & 478 & - \\
\hline 23.1 & UPEC & Secreção & 12 & 45 & 24 & 19 & 13 & 24 & 8 & 29 & 34 & - \\
\hline 50.1 & UPEC & Urina & 23 & 9 & 8 & 12 & 8 & 11 & 7 & 13 & 8 & - \\
\hline 73.1 & UPEC & Urina & 17 & 9 & 28 & 12 & 9 & 13 & 5 & 11 & 44 & - \\
\hline 84.1 & UPEC & Urina & 9 & 37 & 4 & 146 & 78 & 8 & 2 & 30 & 479 & - \\
\hline 6.1 & UPEC & Urina & 30 & 45 & 33 & 37 & 27 & 34 & 24 & $N^{c}$ & - & - \\
\hline 11.1 & UPEC & Urina & 30 & 45 & 33 & 37 & 27 & 34 & 24 & $N^{c}$ & - & - \\
\hline 57.1 & UPEC & Urina & 30 & 45 & 33 & 37 & 27 & 34 & 24 & $N^{c}$ & - & - \\
\hline 27.1 & UPEC & Urina & 30 & 45 & 24 & 37 & 27 & 34 & 24 & $N^{c}$ & - & - \\
\hline
\end{tabular}

aDefinido de acordo com Clermont et al., 2015.

b Alelo não definido

${ }^{c}$ Alelo não amplificado

dSLV - Variante delocus único 


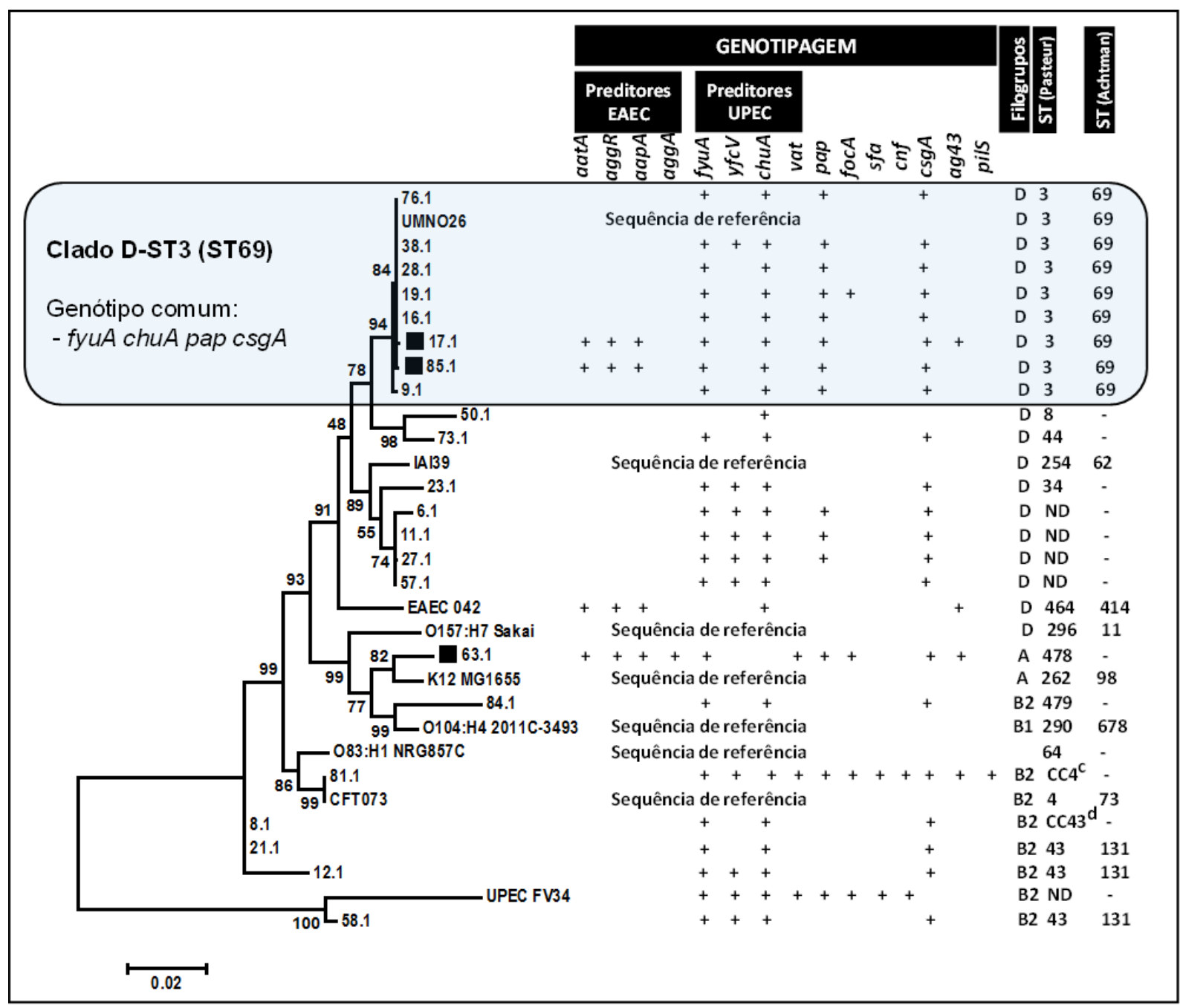

*A história evolucionária foi inferida pelo método de Máxima Verossimilhança (modelo Tamura-Nei) explorando a sequência concatenada $\operatorname{dinB}$-icdA-polB-putP-trpA (2.901 pares de base). As sequências concatenadas derivadas de genomas sequenciados de cepas protótipo foram adotadas para caracterizar os clados filogenéticos. $O$ percentual de vezes que determinado táxon foi agrupado ao longo de 1.500 replicações é mostrado junto aos nós de cada ramo. Cepas híbridas EAEC/UPEC estão sinalizadas com um quadrado sólido.

Figura 7 - Relação filogenética de cepas com genótipos clássicos de UPEC e com genótipos híbridos EAEC/UPEC 


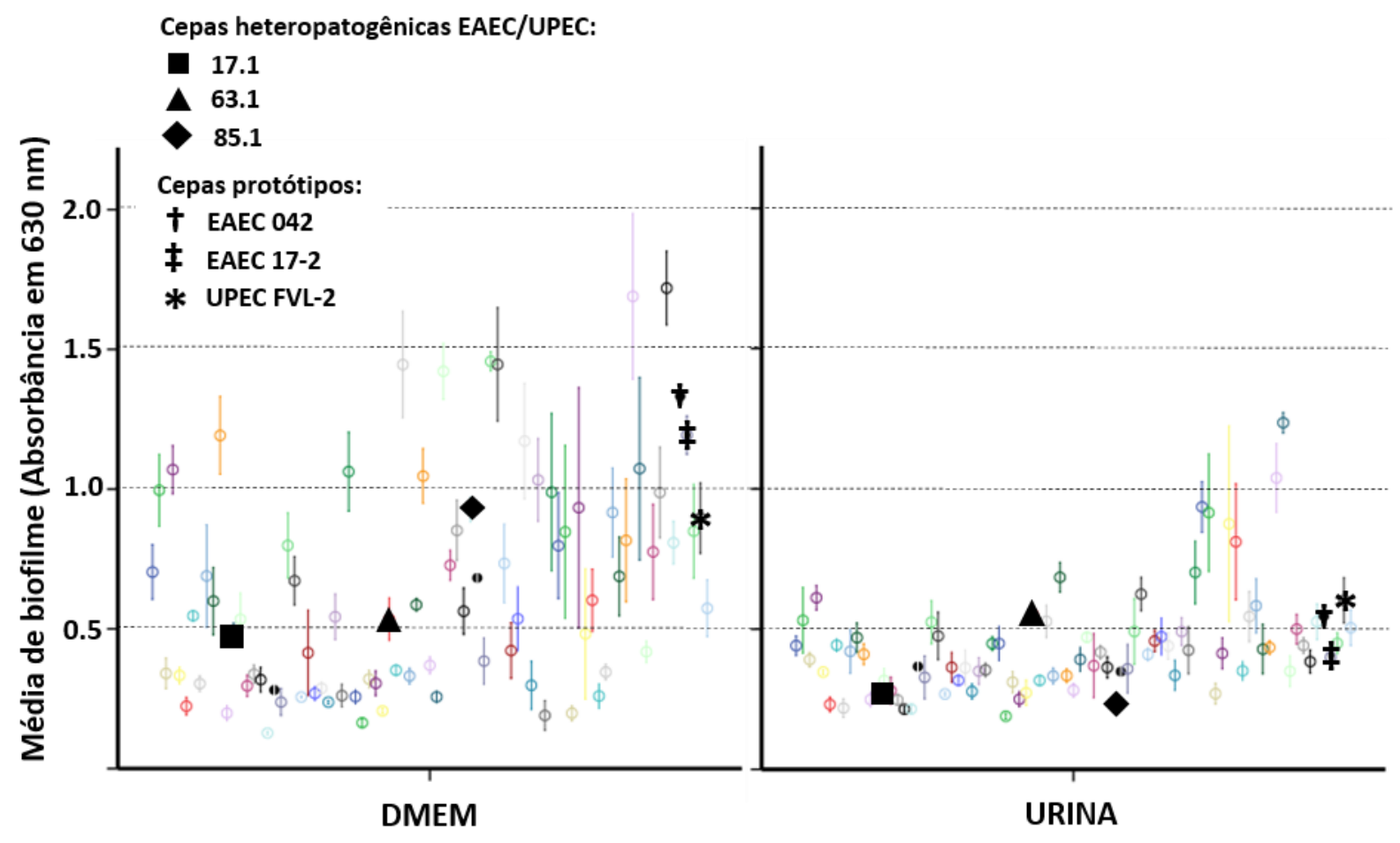

*Cepas híbridas EAEC/UPEC e cepas protótipos são indicadas por figuras geométricas pretas sólidas e símbolos em negrito (respectivamente). Cada ponto com diferentes cores indicam os diferentes isolados clínicos testados. Em geral, as cepas EAEC/UPEC formam biofilme em níveis modestos, exceto a cepa 63.1 que formou biofilme em nível similar ao fomado por cepas protópicos em urina

Figura 8 - Biofilme formado pos cepas de E. coli em DMEM e urina humana 


\section{CONCLUSÕES}

6.1. Fatores de virulência de UPEC são estatisticamente associados a diferentes aspectos clínicos, epidemiológicos e analíticos da uropatogênese:

- Cepas portando genes para sistemas sideróforos (chuA), para fatores de adesão envolvidos na colonização da região perianal $(\operatorname{csg} A)$, ou envolvidos na colonização persistente do trato urinário (ag43) foram associadas à sepse urinária;

- Infecções comunitárias são conduzidas por cepas mais virulentas e apresentaram associação estatística com cepas portando fyuA (sistema sideróforo), chuA (sistema sideróforo), vat (toxina vacuolizante) ou pic (mucinase);

- Cepas isoladas em mulheres menores de 15 anos apresentam carga de virulência significativamente superior quando comparadas com os demais grupos de pacientes analisados;

- Cepas portando pap (pilus associado a pielonefrite) foram estatisticamente associadas a alterações de caráter proinflamatório (aumento de leucócitos e muco) no exame do sedimentourinário.

6.2. Marcadores de urovirulência são diferentemente distribuídos entre filogrupos de E. coli, apresentando uma concentração significativa no filogrupo B2.

6.3. Cepas do filogrupo $D$ foram estatisticamente vinculados à sepse urinária, concentrando a distribuição de dois (fyuA-pap-csgA; pap-csgA-ag43) dos três genótipos associados a sepse urinária.

6.4. Diferentes linhages de $E$. coli (intestinais ou extraintestinais) podem sustentar a emergência de cepas híbridas EAEC/UPEC com potencial uropatogênico;

- Grupos clonais clássicos de cepas de UPEC (D-ST3/ST69) podem adquirir e manter fatores de virulência de categorias diarreiogênicas (EAEC). 


\section{PERSPECTIVAS}

- Melhor caracterizar o efeito de fatores de virulência de EAEC em fenótipos associados a urovirulência: determinar efeito sobre a invasão de células uroepiteliais e verificar níveis de expressão de fatores de virulência quando em amostras de urina humana;

- Realizar a caracterização de plasmídeos pAA em cepas uropatogênicas;

- Ampliar a coleção de cepas isoladas de pacientes assintomáticos, sobretudo crianças, afim de se verificar a hipótese de potenciais reservatórios de cepas hipervirulentas;

- Verificar a ocorrência de genes de urovirulência em uma coleção de cepas (EAEC) diarreiogênica e controles. 


\section{REFERÊNCIAS BIBLIOGRÁFICAS}

ABE, C. M. et al. Uropathogenic Escherichia coli (UPEC) strains may carry virulence properties of diarrhoeagenic E. coli. FEMS Immunology \& Medical Microbiology, v. 52, n. 3, p. 397-406, abr. 2008.

ADAMS-SAPPER, S. et al. Clonal composition and community clustering of drugsusceptible and -resistant Escherichia coli isolates from bloodstream infections. Antimicrobial agents and chemotherapy, v. 57, n. 1, p. 490-7, jan. 2013.

AL-BADR, A.; AL-SHAIKH, G. Recurrent Urinary Tract Infections Management in Women: A review. Sultan Qaboos University medical journal, v. 13, n. 3, p. 35967, ago. 2013.

ANDREU, A. et al. Urovirulence Determinants in Escherichia coli Strains Causing Prostatitis. The Journal of Infectious Diseases, v. 176, n. 2, p. 464-469, ago. 1997.

ANG, C. W. et al. Diarrhea, Urosepsis and Hemolytic Uremic Syndrome Caused by the Same Heteropathogenic Escherichia coli Strain. The Pediatric Infectious Disease Journal, v. 35, n. 9, p. 1045-1047, set. 2016.

BADGER, J. L. et al. Application of signature-tagged mutagenesis for identification of Escherichia coli K1 genes that contribute to invasion of human brain microvascular endothelial cells. Infection and immunity, v. 68, n. 9, p. 5056-61, set. 2000.

BARNHART, M. M.; CHAPMAN, M. R. Curli biogenesis and function. Annual review of microbiology, v. 60, p. 131-47, 2006.

BEKAL, S. et al. Rapid Identification of Escherichia coli Pathotypes by Virulence Gene Detection with DNA Microarrays. Journal of Clinical Microbiology, v. 41, n. 5, p. 2113-2125, 1 maio 2003.

BERNIER, C.; GOUNON, P.; LE BOUGUÉNEC, C. Identification of an aggregative adhesion fimbria (AAF) type III-encoding operon in enteroaggregative Escherichia coli as a sensitive probe for detecting the AAF-encoding operon family. Infection and immunity, v. 70, n. 8, p. 4302-11, ago. 2002.

BERTIN, Y. et al. Epidemiological study of pap genes among diarrheagenic or 
septicemic Escherichia coli strains producing CS31A and F17 adhesins and characterization of $\mathrm{Pap}(31 \mathrm{~A})$ fimbriae. Journal of clinical microbiology, v. 38, n. 4, p. 1502-9, abr. 2000.

BHAT, R. G.; KATY, T. A.; PLACE, F. C. Pediatric Urinary Tract Infections. Emergency Medicine Clinics of North America, v. 29, n. 3, p. 637-653, ago. 2011.

BIAN, Z. et al. Expression of and Cytokine Activation by Escherichia coli Curli Fibers in Human Sepsis. The Journal of Infectious Diseases, v. 181, n. 2, p. 602-612, fev. 2000.

BIELASZEWSKA, M. et al. Heteropathogenic virulence and phylogeny reveal phased pathogenic metamorphosis in Escherichia coli O2:H6. EMBO molecular medicine, v. 6 , n. 3, p. 347-57, mar. 2014.

BLANCO, J. et al. National survey of Escherichia coli causing extraintestinal infections reveals the spread of drug-resistant clonal groups O25b:H4-B2-ST131, O15:H1-D-ST393 and CGA-D-ST69 with high virulence gene content in Spain. Journal of Antimicrobial Chemotherapy, v. 66, n. 9, p. 2011-2021, 1 set. 2011.

BLANCO, M. et al. Detection of pap, sfa and afa adhesin-encoding operons in uropathogenic Escherichia coli strains: Relationship with expression of adhesins and production of toxins. Research in Microbiology, v. 148, n. 9, p. 745-755, dez. 1997.

BOLL, E. J. et al. Role of enteroaggregative Escherichia coli virulence factors in uropathogenesis. Infection and immunity, v. 81, n. 4, p. 1164-71, abr. 2013.

BRITO, B. G. DE et al. Fatores de virulência presentes em amostras de Escherichia coli uropatogênicas - UPEC para suínos. Ciência Rural, v. 34, n. 2, p. 645-652, abr. 2004.

BRZUSZKIEWICZ, E. et al. Genome sequence analyses of two isolates from the recent Escherichia coli outbreak in Germany reveal the emergence of a new pathotype: Entero-Aggregative-Haemorrhagic Escherichia coli (EAHEC). Archives of microbiology, v. 193, n. 12, p. 883-91, dez. 2011.

CHATTAWAY, M. A. et al. Evidence of evolving extraintestinal enteroaggregative Escherichia coli ST38 clone. Emerging infectious diseases, v. 20, n. 11, p. 1935-7, 
nov. 2014.

CLERMONT, O. et al. The Clermont Escherichia coli phylo-typing method revisited: improvement of specificity and detection of new phylo-groups. Environmental Microbiology Reports, v. 5, n. 1, p. 58-65, fev. 2013.

CLERMONT, O.; BONACORSI, S.; BINGEN, E. Rapid and simple determination of the Escherichia coli phylogenetic group. Applied and environmental microbiology, v. 66 , n. 10 , p. $4555-8$, out. 2000.

CZECZULIN, J. R. et al. Phylogenetic analysis of enteroaggregative and diffusely adherent Escherichia coli. Infection and immunity, v. 67, n. 6, p. 2692-9, jun. 1999.

DAIGLE, F. et al. Expression and detection of pap-, sfa-, and afa-encoded fimbrial adhesin systems among uropathogenic Escherichia coli. Canadian journal of microbiology, v. 40, n. 4, p. 286-91, abr. 1994.

DAVIS, J. M.; RASMUSSEN, S. B.; O'BRIEN, A. D. Cytotoxic Necrotizing Factor Type 1 Production by Uropathogenic Escherichia coli Modulates Polymorphonuclear Leukocyte Function. Infection and Immunity, v. 73, n. 9, p. 5301-5310, 1 set. 2005.

DE LUNA, M. DAS G. et al. The Escherichia coli biofilm-promoting protein Antigen 43 does not contribute to intestinal colonization. FEMS Microbiology Letters, v. 284, n. 2, p. 237-246, jul. 2008.

DE MUINCK, E. J. Deep characterization of Escherichia coli in a cohort of mothers and their infants. 2013.

DENAMUR, E.; CLERMONT, O.; GORDON, D. Guide to the various phylogenetic classification schemes for Escherichia coli and the correspondence among schemes. Microbiology, v. 161, n. 5, p. 980-988, 1 maio 2015.

DIAS, R. C. S.; MOREIRA, B. M.; RILEY, L. W. Use of fimH single-nucleotide polymorphisms for strain typing of clinical isolates of Escherichia coli for epidemiologic investigation. Journal of clinical microbiology, v. 48, n. 2, p. 483-8, fev. 2010.

DOUMITH, M. et al. Improved multiplex PCR strategy for rapid assignment of the four major Escherichia coli phylogenetic groups. Journal of clinical microbiology, v. 50, 
n. 9, p. 3108-10, set. 2012.

DUDLEY, E. G. et al. An Incl1 plasmid contributes to the adherence of the atypical enteroaggregative Escherichia coli strain C1096 to cultured cells and abiotic surfaces. Infection and immunity, v. 74, n. 4, p. 2102-14, abr. 2006.

EMODY, L. et al. Virulence factors of uropathogenic Escherichia coli. International journal of antimicrobial agents, v. 22 Suppl 2, p. 29-33, out. 2003.

FLORES-MIRELES, A. L. et al. Urinary tract infections: epidemiology, mechanisms of infection and treatment options. Nature Reviews Microbiology, v. 13, n. 5, p. 269284, 8 abr. 2015.

FOXMAN, B. Epidemiology of urinary tract infections: incidence, morbidity, and economic costs. The American journal of medicine, p. 5S-13S, 8 jul. 2002.

GUAY, D. R. P. Contemporary Management of Uncomplicated Urinary Tract Infections. Drugs, v. 68, n. 9, p. 1169-1205, 2008.

HACKER, J. et al. Pathogenicity islands of virulent bacteria: structure, function and impact on microbial evolution. Molecular microbiology, v. 23, n. 6, p. 1089-97, mar. 1997.

HASMAN, $\mathrm{H}_{\text {.; }}$ CHAKRABORTY, T.; KLEMM, P. Antigen-43-mediated autoaggregation of Escherichia coli is blocked by fimbriation. Journal of bacteriology, v. 181, n. 16, p. 4834-41, ago. 1999.

HEILBERG, I. P.; SCHOR, N. Abordagem diagnóstica e terapêutica na infecção do trato urinário: ITU. Revista da Associação Médica Brasileira, v. 49, n. 1, p. 109116, jan. 2003.

HENDERSON, I. R. et al. Involvement of the enteroaggregative Escherichia coli plasmid-encoded toxin in causing human intestinal damage. Infection and immunity, v. 67, n. 10, p. 5338-44, out. 1999.

HOLDEN, N. et al. Regulation of P-Fimbrial Phase Variation Frequencies in Escherichia coli CFT073. Infection and Immunity, v. 75, n. 7, p. 3325-3334, 1 jul. 2007. 
HOOTON, T. M.; STAMM, W. E. Diagnosis and treatment of uncomplicated urinary tract infection. Infectious disease clinics of North America, v. 11, n. 3, p. 551-81, set. 1997.

HOPKINS, A. M. et al. Constitutive activation of Rho proteins by CNF-1 influences tight junction structure and epithelial barrier function. Journal of cell science, v. 116, n. Pt 4, p. 725-42, 15 fev. 2003.

HUANG, D. B. et al. A review of an emerging enteric pathogen: enteroaggregative Escherichia coli. Journal of Medical Microbiology, v. 55, n. 10, p. 1303-1311, 1 out. 2006.

HUNG, C. et al. The Bacterial Amyloid Curli Is Associated with Urinary Source Bloodstream Infection. PLoS ONE, v. 9, n. 1, p. e86009, 20 jan. 2014.

JENKINS, C. et al. Use of a microarray to assess the distribution of plasmid and chromosomal virulence genes in strains of enteroaggregative Escherichia coli. FEMS Microbiology Letters.

JOHNSON, J. R. Virulence factors in Escherichia coli urinary tract infection. Clinical microbiology reviews, v. 4, n. 1, p. 80-128, jan. 1991.

JOHNSON, J. R.; RUSSO, T. A. Molecular epidemiology of extraintestinal pathogenic (uropathogenic) Escherichia coli. International Journal of Medical Microbiology, v. 295, n. 6, p. 383-404, 2005.

KAPER, J. B.; NATARO, J. P.; MOBLEY, H. L. Pathogenic Escherichia coli. Nature reviews. Microbiology, v. 2, n. 2, p. 123-40, fev. 2004.

KASS, E. H. Pyelonephritis and bacteriuria. A major problem in preventive medicine. Annals of internal medicine, v. 56, p. 46-53, jan. 1962.

$\mathrm{KIKUCHI}$, T. et al. Curli Fibers Are Required for Development of Biofilm Architecture in Escherichia coli K-12 and Enhance Bacterial Adherence to Human Uroepithelial Cells. Microbiology and Immunology, v. 49, n. 9, p. 875-884, set. 2005.

KOREA, C.-G. et al. Escherichia coli K-12 possesses multiple cryptic but functional chaperone-usher fimbriae with distinct surface specificities. Environmental Microbiology, v. 12, n. 7, p. 1957-1977, 23 mar. 2010. 
LASARO, M. A. et al. F1C fimbriae play an important role in biofilm formation and intestinal colonization by the Escherichia coli commensal strain Nissle 1917. Applied and environmental microbiology, v. 75, n. 1, p. 246-51, jan. 2009.

LICHTENBERGER, P.; HOOTON, T. M. Complicated urinary tract infections. Current infectious disease reports, v. 10, n. 6, p. 499-504, nov. 2008.

LINDEN, S. K. et al. Mucins in the mucosal barrier to infection. Mucosal Immunology, v. 1, n. 3, p. 183-197, 5 maio 2008.

LINGWOOD, C. A. Verotoxin-binding in human renal sections. Nephron, v. 66, n. 1, p. 21-8, 1994.

LÓPEZ-BANDA, D. A. et al. Identification of virulence factors genes in Escherichia coli isolates from women with urinary tract infection in Mexico. BioMed research international, v. 2014, p. 959206, 2014.

LÜTHJE, P.; BRAUNER, A. Ag43 promotes persistence of uropathogenic Escherichia coli isolates in the urinary tract. Journal of clinical microbiology, v. 48, n. 6, p. 2316-7, jun. 2010.

MANSAN-ALMEIDA, R.; PEREIRA, A. L.; GIUGLIANO, L. G. Diffusely adherent Escherichia coli strains isolated from children and adults constitute two different populations. BMC microbiology, v. 13, p. 22, 2013.

MARRE, R.; KREFT, B.; HACKER, J. Genetically engineered S and F1C fimbriae differ in their contribution to adherence of Escherichia coli to cultured renal tubular cells. Infection and immunity, v. 58, n. 10, p. 3434-7, out. 1990.

MARTÍNEZ, J. A. et al. Relationship of phylogenetic background, biofilm production, and time to detection of growth in blood culture vials with clinical variables and prognosis associated with Escherichia coli bacteremia. Journal of clinical microbiology, v. 44, n. 4, p. 1468-74, abr. 2006.

MILLS, M.; MEYSICK, K. C.; O'BRIEN, A. D. Cytotoxic necrotizing factor type 1 of uropathogenic Escherichia coli kills cultured human uroepithelial 5637 cells by an apoptotic mechanism. Infection and immunity, v. 68, n. 10, p. 5869-80, out. 2000.

MITSUMORI, K. et al. Virulence Characteristics of Escherichia coli in Acute Bacterial 
Prostatitis. The Journal of Infectious Diseases, v. 180, n. 4, p. 1378-1381, out. 1999.

MONTEIRO, B. T. et al. The dispersin-encoding gene (aap) is not restricted to enteroaggregative Escherichia coli. Diagnostic microbiology and infectious disease, v. 65 , n. 1 , p. $81-4$, set. 2009.

MORENO, E. et al. Comparative study of Escherichia coli virulence determinants in strains causing urinary tract bacteremia versus strains causing pyelonephritis and other sources of bacteremia. Diagnostic microbiology and infectious disease, $v$. 53 , n. 2, p. 93-9, out. 2005.

MORIN, N. et al. Characterization of the AggR regulon in enteroaggregative Escherichia coli. Infection and immunity, v. 81, n. 1, p. 122-32, jan. 2013.

NAGY, G. et al. Expression of hemin receptor molecule ChuA is influenced by RfaH in uropathogenic Escherichia coli strain 536. Infection and immunity, v. 69, n. 3, p. 1924-8, mar. 2001.

NATARO, J. P.; KAPER, J. B. Diarrheagenic Escherichia coli. Clinical microbiology reviews, v. 11, n. 1, p. 142-201, jan. 1998.

NAVARRO-GARCIA, F. et al. Pic, an autotransporter protein secreted by different pathogens in the Enterobacteriaceae family, is a potent mucus secretagogue. Infection and immunity, v. 78, n. 10, p. 4101-9, out. 2010.

OELSCHLAEGER, T. A. et al. Pathogenicity islands of uropathogenic E. coli and the evolution of virulence. International journal of antimicrobial agents, v. 19, n. 6, p. 517-21, jun. 2002.

OKEKE, I. N. et al. Multi-Locus Sequence Typing of Enteroaggregative Escherichia coli Isolates from Nigerian Children Uncovers Multiple Lineages. PLoS ONE, v. 5, n. 11, p. e14093, 23 nov. 2010.

OLESEN, B. et al. Enteroaggregative Escherichia coli O78:H10, the Cause of an Outbreak of Urinary Tract Infection. Journal of Clinical Microbiology, v. 50, n. 11, p. 3703-3711, 1 nov. 2012.

OTT, M. et al. Gene clusters for S fimbrial adhesin (sfa) and F1C fimbriae (foc) of 
Escherichia coli: comparative aspects of structure and function. Journal of bacteriology, v. 170, n. 9, p. 3983-90, set. 1988.

PARKKINEN, J. et al. Binding sites in the rat brain for Escherichia coli S fimbriae associated with neonatal meningitis. The Journal of clinical investigation, v. $81, \mathrm{n}$. 3, p. 860-5, mar. 1988.

PEREIRA, A. L. et al. Enteroaggregative Escherichia coli virulence markers: positive association with distinct clinical characteristics and segregation into 3 enteropathogenic E. coli serogroups. The Journal of infectious diseases, v. 195, n. 3, p. 366-74, 1 fev. 2007.

PEREIRA, A. L. et al. Diarrhea-associated biofilm formed by enteroaggregative Escherichia coli and aggregative Citrobacter freundii: a consortium mediated by putative F pili. BMC Microbiology, v. 10, n. 1, p. 57, 2010.

POURHOSEINGHOLI, M. A.; BAGHESTANI, A. R.; VAHEDI, M. How to control confounding effects by statistical analysis. Gastroenterology and hepatology from bed to bench, v. 5, n. 2, p. 79-83, 2012.

QUEIRÓS, M. I. et al. Urinary infections and use of indwelling bladder catheter in pediatric unit. Northeast Network Nursing Journal, v. 12, n. 2, 2011.

SANNES, M. R. et al. Virulence Factor Profiles and Phylogenetic Background of Escherichia coli Isolates from Veterans with Bacteremia and Uninfected Control Subjects. The Journal of Infectious Diseases, v. 190, n. 12, p. 2121-2128, 15 dez. 2004.

SANTOS, A. C. M. et al. Assessing the diversity of the virulence potential of Escherichia coli isolated from bacteremia in S\&amp;\#227;0 Paulo, Brazil. Brazilian Journal of Medical and Biological Research, v. 46, n. 11, p. 968-973, out. 2013.

SCHEMBRI, M. A. et al. Differential expression of the Escherichia coli autoaggregation factor antigen 43 . Journal of bacteriology, v. 185 , n. 7, p. 223642, abr. 2003.

SOTO, S. M. et al. Implication of biofilm formation in the persistence of urinary tract infection caused by uropathogenic Escherichia coli. Clinical Microbiology and 
Infection, v. 12, n. 10, p. 1034-1036, 2006.

SPURBECK, R. R. et al. Escherichia coli isolates that carry vat, fyuA, chuA, and yfcV efficiently colonize the urinary tract. Infection and immunity, v. 80 , n. 12, p. 411522, dez. 2012.

STAMM, W. E. Catheter-associated urinary tract infections: epidemiology, pathogenesis, and prevention. The American journal of medicine, v. 91, n. 3B, p. 65S-71S, 16 set. 1991.

STAPLETON, A. E. Urinary Tract Infection Pathogenesis: Host Factors. Infectious Disease Clinics of North America, v. 28, n. 1, p. 149-159, 2014.

SUBASHCHANDRABOSE, S.; MOBLEY, H. L. T. Virulence and Fitness Determinants of Uropathogenic Escherichia coli. Microbiology spectrum, v. 3, n. 4, ago. 2015.

TAKAHASHI, A. et al. Escherichia coli isolates associated with uncomplicated and complicated cystitis and asymptomatic bacteriuria possess similar phylogenies, virulence genes, and O-serogroup profiles. Journal of clinical microbiology, v. 44, n. 12, p. 4589-92, dez. 2006.

TENAILLON, O. et al. The population genetics of commensal Escherichia coli. Nature Reviews Microbiology, v. 8, n. 3, p. 207-217, mar. 2010.

TORRES, A. G. et al. TonB-dependent systems of uropathogenic Escherichia coli: aerobactin and heme transport and TonB are required for virulence in the mouse. Infection and immunity, v. 69, n. 10, p. 6179-85, out. 2001.

TOUCHON, M. et al. Organised Genome Dynamics in the Escherichia coli Species Results in Highly Diverse Adaptive Paths. PLoS Genetics, v. 5, n. 1, p. e1000344, 23 jan. 2009.

TOVAL, F. et al. Characterization of Escherichia coli isolates from hospital inpatients or outpatients with urinary tract infection. Journal of clinical microbiology, v. 52, n. 2, p. 407-18, fev. 2014.

TÜKEL, C. et al. Responses to amyloids of microbial and host origin are mediated through toll-like receptor 2. Cell host \& microbe, v. 6, n. 1, p. 45-53, 23 jul. 2009. 
ULETT, G. C. et al. Functional analysis of antigen 43 in uropathogenic Escherichia coli reveals a role in long-term persistence in the urinary tract. Infection and immunity, v. 75, n. 7, p. 3233-44, jul. 2007.

VALIQUETTE, L. Urinary tract infections in women. The Canadian journal of urology, v. 8 Suppl 1, p. 6-12, jun. 2001.

WAITUMBI, J. N. et al. Age-Related Changes in Red Blood Cell Complement Regulatory Proteins and Susceptibility to Severe Malaria. The Journal of Infectious Diseases, v. 190, n. 6, p. 1183-1191, 15 set. 2004.

WALLACE-GADSDEN, F. et al. Enteroaggregative Escherichia coli related to uropathogenic clonal group A. Emerging infectious diseases, v. 13, n. 5, p. 75760, maio 2007.

WESTERLUND, B.; KORHONEN, T. K. Bacterial proteins binding to the mammalian extracellular matrix. Molecular Microbiology, v. 9, n. 4, p. 687-694, ago. 1993.

ZHAO, L. et al. Comparison of virulence factors and expression of specific genes between uropathogenic Escherichia coli and avian pathogenic E. coli in a murine urinary tract infection model and a chicken challenge model. Microbiology, v. 155, n. 5, p. 1634-1644, 1 maio 2009.

ZHU GE, X. et al. Comparative Genomic Analysis Shows That Avian Pathogenic Escherichia coli Isolate IMT5155 (O2:K1:H5; ST Complex 95, ST140) Shares Close Relationship with ST95 APEC O1:K1 and Human ExPEC O18:K1 Strains. PLoS ONE, v. 9, n. 11, p. e112048, 14 nov. 2014. 


\section{ANEXO 1- ARTIGO PUBLICADO}

\section{FRONTIERS IN MICROBIOLOGY: INFECTIOUS DISEASES}

Fator de impacto: 4,165

Virulence Markers and Phylogenetic Analysis of Escherichia coli Strains with Hybrid EAEC/UPEC Genotypes Recovered from Sporadic Cases of Extraintestinal Infections 


\section{OPEN ACCESS}

Edited by: Jorge Blanco,

University of Santiago de Compostela

Spain

Reviewed by:

Roxane Piazza,

Instituto Butantan, Brazl

Tânia Aparecida Tardelli Gomes, Universidade Federal de São Paulo,

Brazi

Ulrich Dobrindt,

University of Münster, Germany

*Correspondence:

Alex L. Pereira

alexpereira@unb.br

Specialty section: This article was submitted to Infectious Diseases,

a section of the journal

Frontiers in Microbiology

Received: 09 November 2016 Accepted: 19 January 2017

Published: 03 February 2017

Citation:

Lara FBM, Nery DR, de Oliveira PM

Araujo ML, Carvalho FRQ,

Messias-Silva LCF, Ferreira LB,

Faria-Junior C and Pereira AL (2017) Virulence Markers and Phylogenetic

Analysis of Escherichia coli Strains with Hybrid EAEC/UPEC Genotypes Recovered from Sporadic Cases of

Extraintestinal Infections.

Front. Microbiol. 8:146.

doi: 10.3389/fmicb.2017.00146

\section{Virulence Markers and Phylogenetic Analysis of Escherichia coli Strains with Hybrid EAEC/UPEC Genotypes Recovered from Sporadic Cases of Extraintestinal Infections}

\author{
Flaviane B. M. Lara ${ }^{1}$, Danielly R. Nery ${ }^{2}$, Pâmela M. de Oliveira ${ }^{2}$, Mayana L. Araujo ${ }^{2}$, \\ Fabiana R. Q. Carvalho' ${ }^{2}$, Lorena C. F. Messias-Silva ${ }^{2}$, Leonardo B. Ferreira ${ }^{3}$, \\ Celio Faria-Junior ${ }^{4}$ and Alex L. Pereira ${ }^{1,2 *}$ \\ ${ }^{1}$ Graduate Program in Microbial Biology, Biology Institute, University of Brasilia, Brasilia, Brazil, ${ }^{2}$ Campus of Ceilândia, \\ University of Brasilia, Brasilia, Brazil, ${ }^{3}$ Ceilândia Regional Hospital, Secretary of State for Health, Brasilia, Brazil, ${ }^{4}$ Central \\ Laboratory for Public Health, Secretary of State for Health, Brasilia, Brazil
}

Virulence genes from different E. coli pathotypes are blended in hybrid strains. E. coli strains with hybrid enteroaggregative/uropathogenic (EAEC/UPEC) genotypes have sporadically emerged causing outbreaks of extraintestinal infections, however their association with routine infections is yet underappreciated. We assessed 258 isolates of E. coli recovered from 86 consecutive cases of extraintestinal infections seeking EAEC and hybrid genotype (EAEC/UPEC) strains. Extensive virulence genotyping was carried out to detect 21 virulence genes, including molecular predictors of EAEC and UPEC strains. Phylogenetic groups and sequence types (STs) were identified, as well as it was performed phylogenetic analyses in order to evaluate whether hybrid EAEC/UPEC strains belonged to intestinal or extraintestinal lineages of $E$. coli. Adhesion assays were performed to evaluate the biofilm formation by hybrid strains in human urine and cell culture medium (DMEM). Molecular predictors of UPEC were detected in more than $70 \%$ of the strains (chuA in $85 \%$ and fyuA in $78 \%$ ). Otherwise, molecular predictors of EAEC (aatA and aggR) were detected in only 3.4\% (9/258) of the strains and always along with the UPEC predictor fyuA. Additionally, the pyelonephritis-associated pilus (раp) gene was also detected in all of the hybrid EAEC/UPEC strains. EAEC/UPEC strains were recovered from two cases of community-onset urinary tract infections (UTI) and from a case of bacteremia. Analyses revealed that hybrid EAEC/UPEC strains were phylogenetically positioned in two different clades. Two representative strains, each recovered from UTI and bacteremia, were positioned into a characteristic UPEC clade marked by strains belonging to phylogenetic group D and ST3 (Warwick ST 69). Another hybrid EAEC/UPEC strain was classified as phylogroup A-ST478 and positioned in a 